Basic skills programmes in the

Probation Service: evaluation

of the Basic Skills Pathfinder

Gráinne McMahon

Andy Hall

Geoff Hayward

Caroline Hudson

Colin Roberts,

Rosa Fernández

Ros Burnett 


\section{Basic skills programmes in the Probation Service: evaluation of the Basic Skills Pathfinder}

Gráinne McMahon, Andy Hall, Geoff Hayward, Caroline Hudson, Colin Roberts, Rosa Fernández and Ros Burnett

Probation Studies Unit, Centre for Criminological Research, in collaboration with the

Department of Educational Studies and SKOPE

University of Oxford

Online Report 14/04 


\section{Contents}

$\begin{array}{ll}\text { Acknowledgements } & \text { vi }\end{array}$

Summary vii

1. Why does the Probation Service need a basic skills programme? 1

What are basic skills? 1

The basic skills problem in the UK 1

The prevalence of basic skills needs among offenders 2

The relevance of basic skills to offending 3

Do basic skills interventions help to reduce offending? $\quad 5$

Summary $\quad 6$

2. The Basic Skills Pathfinder: background, projects and evaluation 7

History and basic skills provision in the Probation Service $\quad 7$

$\begin{array}{ll}\text { The Basic Skills Pathfinder } & 10\end{array}$

$\begin{array}{lc}\text { 3. Identifying basic skills needs } & 13\end{array}$

$\begin{array}{ll}\text { Preliminary screening to identify basic skills needs } & 13\end{array}$

The initial assessment procedure for basic skills needs $\quad 16$

$\begin{array}{ll}\text { Conclusion } & 19\end{array}$

$\begin{array}{ll}\text { 4. Profile of offenders with basic skills needs } & \mathbf{2 0}\end{array}$

The scale of basic needs among the pathfinder samples $\quad 20$

The nature of offenders' basic skills needs $\quad 21$

Correlates and characteristics of offenders with basic skills 22

How are basic skills needs related to unemployment and other variables 31

$\begin{array}{ll}\text { Conclusion } & 33\end{array}$

5. The tuition and learning that took place 34

$\begin{array}{ll}\text { The tuition } & 34\end{array}$

$\begin{array}{ll}\text { The learning } & 39\end{array}$

$\begin{array}{ll}\text { Conclusion } & 43\end{array}$

6. Those who did not get there: the problem of attrition 44

$\begin{array}{ll}\text { The extent of the problem } & 44\end{array}$

Reasons and explanations for attrition $\quad 47$

$\begin{array}{ll}\text { Dropping-out from tuition } & 52\end{array}$

7. How much does basic skills intervention cost?

Choice of method for costing of the projects $\quad 55$

The analysis of costs for the pathfinder projects 56

$\begin{array}{ll}\text { Performance ranking of the pathfinder projects } & 60\end{array}$

$\begin{array}{ll}\text { Summary } & 63\end{array}$

8. Improving the process, increasing success $\quad 64$

$\begin{array}{ll}\text { Stage 1: Screening } & 64\end{array}$

Stage 2: The initial assessment procedure for basic skills needs 66

$\begin{array}{ll}\text { Stage 3: Tuition } & 66\end{array}$

$\begin{array}{ll}\text { Monitoring and evaluation } & 68\end{array}$

$\begin{array}{ll}\text { An effective referral system } & 69\end{array}$

$\begin{array}{ll}\text { Motivational work } & 69\end{array}$

$\begin{array}{ll}\text { Conclusion } & 71\end{array}$

$\begin{array}{ll}\text { References } & 72\end{array}$ 
Appendices

Appendix A The relationship of basic skills levels to other qualifications

Appendix B The Prison Service agenda for addressing basic skills needs

Appendix C Description of the projects in the Basic Skills Pathfinder evaluation

78

Appendix D Case studies of offenders who participated in basic skills tuition

85

Appendix E Reliability of the BSA Fast Track 20 Questions screening tool

94

Appendix $F$ Analysis of the total screening sample

99

Appendix G Logistic regression of variables associated with basic skills needs 


\section{List of tables}

Table 1.1: Basic skills levels $\quad 1$

$\begin{array}{ll}\text { Table 4.1: In-depth assessments received } & 20\end{array}$

Table 4.2: The BSA's initial Assessment tool results 22

Table 4.3: Scores on the FT 20 Q broken down by sequence type 23

Table 4.4: The FT 20 Q scores of men and women sentenced to a 23

or CPRO

Table 4.5: The association between age and probable basic skills needs 24

for all offenders in the sample

Table 4.6: The association between an offender's score on the FT $20 \mathrm{Q}$

and their accommodation status for those offenders sentenced to a CRO or a CPRO

Table 4.7: Alcohol and drug abuse of offenders in the in-depth assessment sample

Table 4.8: Health of offenders in the in-depth assessment sample

Table 4.9: Number of schools attended by the in-depth assessment sample $(n-202)$

Table 4.10: Factors which affected offenders' education

Table 4.11: Views of school experience

Table 4.12: Employment status of offenders in the screening sample broken down by pathfinder area

Table 4.13: Mean scores on CRIME PICS II ( $n=288)$

Table 6.1: Reference to basic skills in court reports

Table 6.2: $\quad$ Reference to basic skills in supervision plans 49

Table 6.3: Problems identified in PSRs $\quad 50$

Table 6.4: Risk of reconviction in the comparison group and the 50

Table 6.5: Objectives in the supervision plan $\quad 50$

Table 6.6: Association between basic skills level and attendance at the initial 51 assessment procedure for basic skills needs $(n=283)$

Table 6.7: Frequency of attendance $\quad 52$

Table 6.8: Appointments missed $\quad 53$

Table 6.9: Reasons for failure to attend basic skills sessions $(n=486)$

Table 7.1: Total set-up costs, in pounds $\quad 57$

Table 7.2: Quarterly on-going costs, in pounds $\quad 58$

Table 7.3: Quarterly cost of screening, in pounds $\quad 59$

Table 7.4: Quarterly cost of the initial assessment procedure for basic skills 60

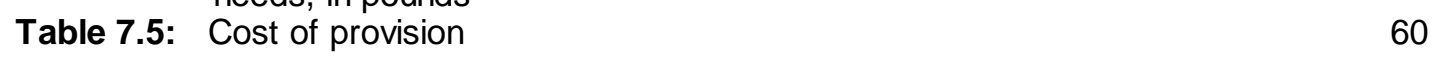

Table 7.6: $\quad$ General ranking $\quad 61$

Table F.1: Gender description by pathfinder area and sentence type 101

Table F.2: The FT 20 Q screening tool scores of men and women sentenced 101 to a CRO or CPRO

Table F.3: The age distribution of male and female offenders who were sentenced to a CRO or a CPRO aggregated across all pathfinder areas

Table F.4: The ethnic composition of the total sample

Table F.5: Accommodation status and sentence type of offenders 103

Table F.6: The type of accommodation being used by offenders who were 104 sentenced to a CRO or a CPRO, broken down by pathfinder area

Table F.7: $\quad$ PSR writer's judgement about substance abuse by an offender, broken down by sentence type

Table F.8: The highest level of qualification obtained by offenders, broken 105 down by sentence type

Table F.9: $\quad$ Offenders' school attendance, broken down by sentence type 105

Table F.10: Risk of reconviction, broken down by pathfinder area 106 
Table G.1: Results of a logistic regression for the probability of being unemployed for the complete screening sample $(n=4283$, $p<=0.05 ; p<=0.01$ )

Table G.2: Results of a logistic regression for the probability of being unemployed for those offenders sentenced to either a CRO or a CPRO $(n=1,492, p<=0.05 ; p<=0.01)$

Table G.3: Results of a logistic regression for the probability of having a probable basic skills need for the whole screening sample $(n=5873, p<=0.05 ; p<=0.01)$

Table G.4: Results of a logistic regression for the probability of having probable basic skills need for those sentenced to either a CRO or a CPRO $(n=2,028, p<=0.05 ; p<=0.01)$

\section{List of figures}

Figure 6.1: Attrition from PSR stage to initial assessment procedure

for basic skills needs

Figure 6.2: Attrition from screening to commencement of tuition

Figure 8.1: The process of addressing basic skills needs

Figure E.1: The FT 20 Q screening tool and literacy on the BSA's Initial

Figure E.2: The FT 20 Q screening tool and numeracy on the BSA's Initial

Figure E.3: Literacy on the BSA's BSA's Initial Assessment tool and Raven's

Figure E.4: Numeracy on the BSA's Initial Assessment tool and Raven's 


\section{Acknowledgements}

The evaluation team would like to thank all the staff in the Basic Skills Pathfinder areas. These were Cornwall, Cumbria, Dorset, Lincolnshire, Nottinghamshire, Sussex and Thames Valley Probation Areas. Without their patience and forbearance, this report would not have been possible.

We are indebted to staff in the Research, Development and Statistics Directorate within the Home Office, in particular, Sarah Pepper, Claire Flood-Page, Robin Elliott and Guy Eaton. We would like to thank the staff of the National Probation Directorate, in particular, Laura Fairweather and Chris Johnson.

We owe a special thank-you to our former colleague in the evaluation team, $\mathrm{Dr}$ Caroline Hudson, who is now the Basic Skills Advisor in the National Probation Directorate, and on whose work in the interim report, some parts of this report are based.

We are much indebted to $\mathrm{Dr}$ Ros Burnett, our colleague in the Centre for Criminological Research, for editing this report.

We are also grateful to Jenny Anderson, George Battle and Mark Ryan for data input and to Steve Ballinger and the administrative team in the Centre for Criminological Research for all their support.

Colin Roberts

Head of the Probation Studies Unit and Fellow of Green College. 


\section{Summary}

Previous research has shown that proportionally more offenders, when compared to the population as a whole, have low basic skills, poor school experience and are without vocational and academic qualifications. People with poor basic skills inevitably have restricted employment opportunities. Therefore, poor basic skills may be one factor underlying the overrepresentation of offenders and ex-prisoners in unemployment statistics. There is some evidence that interventions to improve basic skills and increase employment prospects are associated with reductions in reoffending. Projects to address the basic skills needs of offenders are therefore one way of potentially helping to reduce crime.

The Home Office Crime Reduction Programme funded a range of 'pathfinder' programmes aimed at developing evidence-based approaches to reducing crime. Pathfinder projects are exploratory, and are independently evaluated to learn more about 'what works'. The Basic Skills Pathfinder was one of these programmes and was intended to explore how best to help offenders in the community to improve their skills in literacy and numeracy.

Seven probation areas (nine before reorganisation of the National Probation Service) were selected to develop basic skills projects under central guidance from the National Probation Directorate. The Probation Studies Unit in the University of Oxford Centre for Criminological Research, together with the University's Department of Educational Studies and ESRC Research Centre on Skills, Knowledge and Organisational Performance, was commissioned to evaluate this pathfinder programme. The evaluation team collaborated with the project staff in the seven pathfinder areas in order to:

- make a baseline estimate of the prevalence of basic skills needs among offenders, by screening for basic skills needs all those offenders on whom pre-sentence reports had been prepared during the evaluation period;

- investigate the association between basic skills needs and other variables such as employment status, alcohol and drug abuse, school attendance and risk of reconviction;

- compare the different circumstances of those offenders who accessed basic skills provision (the experimental group) with those who did not (the comparison group);

- measure the progress of offenders who participated in basic skills provision within the seven pathfinder areas against intermediate outcomes such as improvements in basic skills, gaining and maintaining employment, and participation in further education and training. The time-span of the evaluation prevented the collection of reconviction data;

- undertake a cost-benefit analysis of the economic costs of implementing the basic skills projects, to compare these costs with positive results obtained through intermediate outcomes, and to estimate the resources needed to replicate the basic skills projects in other probation areas; and

- identify good practice and key challenges in the implementation of basic skills provision within community supervision.

'Basic skills needs' were defined as literacy and numeracy below Level 1, which, according to guidelines published by the Basic Skills Agency (BSA, 2000) is the minimum level of literacy and numeracy required for everyday functioning at work and in general. All of the seven projects developed their own model for tackling basic skills needs but were required to use the same screening and assessment tools, and to apply agreed procedures for data collection. The process of addressing basic skills needs involved three key stages:

- Screening for basic skills needs.

- Further, in-depth assessment of basic skills needs. 
- Basic skills provision.

Each of these stages was dependent on complementary work by staff to motivate participation, to organise referral, and to monitor and evaluate progress. Offenders' participation in tuition was generally voluntary, though co-operation with the further, in-depth assessment was often a requirement of their community supervision.

\section{The scale of basic skills needs among offenders}

It was found that a third of the sample of approximately 10,000 offenders probably had basic skills below Level 1 . This proportion is significantly higher than those with serious literacy difficulties (estimated at around 20\%) in the population as a whole, and reflects the proportion of individuals with serious numeracy difficulties (between $30 \%-50 \%$ ) in the general population.

\section{The characteristics of offenders with basic skills needs}

The offenders who were 'positively' screened (as probably having basic skills needs) were more likely to be unemployed and without qualifications than those who were 'negatively' screened. The overall unemployment rate of 51 per cent among offenders in the screening sample was very high compared with the total UK unemployment rate of five per cent in 2001.

There were important discrepancies between the characteristics of the whole sample who were 'positively' screened and the smaller sample of those who attended the next stage for the further, in-depth assessment. It was found that there was a significant association between alcohol or drug abuse and suspected basic skills need in the total screening sample but this was not the case for those who received the in-depth assessment of their basic skills needs. Likewise, there was a significant association between high risk of reconviction and being 'positively' screened, yet significantly more in-depth assessments were undertaken on 'low risk' offenders compared to 'high risk' offenders. Also, those with a history of irregular school attendance were significantly less likely to attend for the in-depth assessment of basic skills needs.

These discrepancies between characteristics of the sample screened and characteristics of the sample who were further assessed (and who attended basic skills tuition) are indicative of issues that 'got in the way' of planned interventions to meet basic skills needs, and that were reflected in high attrition.

\section{The problem of attrition}

There was a major problem with attrition (a lessening of numbers) at every stage of the Basic Skills Pathfinder evaluation process, which meant that only a small number of 'eligible' offenders received any basic skills tuition:

- Around a third of offenders were not screened at the PSR stage, although this had been required during the period of the evaluation.

- The highest rate of attrition occurred following screening for possible basic skills needs. Of the 1,003 who were screened as probably needing basic skills provision, only 194 (19\%) subsequently attended for assessment, and only 16 per cent received a more indepth assessment. The referral rate varied between areas (from 33\% to 10\% of those positively screened) and varied on a monthly basis within areas.

- Following through the progress of those who were first screened, then received the indepth assessment and were confirmed as having basic skills needs, only a small percentage went on to attend for tuition. 
- The majority of those who did receive help with their basic skills, did so for only a few hours and then 'dropped out'. The average number of sessions attended was six, while the most frequent number of sessions attended was only two.

Thus, the focus of the Basic Skills Pathfinder evaluation necessarily changed, from looking at both implementation issues and outcomes from basic skills provision, to focussing more on the reasons for attrition.

\section{Explaining attrition}

An analysis of why many of those who were 'eligible' did not access basic skills provision was undertaken, examining case material for the experimental group (145 offenders) and for a comparison group (311 offenders). The findings, together with interviews of probation staff, tutors and offenders, and statistical analysis of monitoring data (from five of the pathfinder projects), suggested the following explanations for the high attrition rate at each stage of the process:

- Problems other than basic skills needs were likely to be prioritised, for example, drugs rehabilitation, housing needs or attitudes to offending. A similar proportion of offenders in the comparison group could have benefited from basic skills help as in the experimental group, but the need to address the problem was less likely to be prioritised in the supervision plans for those in the comparison group.

- Offenders were often insufficiently motivated to attend the various stages of basic skills provision.

- Staff were inconsistent in applying the screening and referral criteria. Some offenders who were 'eligible' to be screened, and referred, were not, while others who had not been screened, or who were 'negatively' screened, were referred for the in-depth assessment and/ or basic skills provision.

\section{The tuition and support provided}

Basic skills tuition and other support was provided by qualified tutors or by mentors. Most of the tuition occurred on a one-to-one basis and generally took place in a probation office. Tutors were frequently based in probation offices, raising their profile among staff but potentially distancing them from their own professional development. Examples of good practice included: linking teaching material to the interests and needs of learners; applying a individual learning plan; providing transport for those who would otherwise be unable to attend; and ensuring that individuals have relevant information and encouragement to seek out support themselves over the long-term.

Quantitative data on outcomes for those who received basic skills provision was largely unavailable. Most of the small proportion who did progress to attending basic skills tuition only went on a small number of occasions. However, interviews with individuals who persevered in attending, and with their tutors, revealed encouraging 'success stories', indicating the major benefits that can be gained over even a short period of time. The most frequently mentioned motivation for attending was to improve their chances of gaining employment. Most thought that, by increasing their opportunities, and by changing their self-concept and quality of life, better basic skills would indirectly help them to avoid further offending.

\section{A cost-benefit analysis}

Staff costs were the main component in a cost-benefit analysis. On average, each screening and each in-depth assessment undertaken consumed staff time to the value of $£ 2.60$ and $£ 9.70$ respectively, excluding administrative costs. The average cost of one session (1.5 hours) of individualised teaching was $£ 15$. Frequent missed appointments therefore mount up to a considerable loss. Tackling the attrition rates would undoubtedly improve the economic performance of basic skills provision. Group provision was more expensive per hour; 
however, if attendance to group provision was guaranteed, then group provision would be cheaper than one to one.

\section{Learning points and recommendations}

Integration into case management systems

The evaluation revealed that basic skills work was generally given less attention than the extensiveness and impact of the problem merits. There should therefore be an explicit process for basic skills screening, assessment, referral and provision built into community sentences and promoted by staff on every level, with appropriate training and administrative support. While there is a need for consistency and regulation at each stage, the system should be flexible to allow for differences in individuals' readiness and motivation to address basic skills problems at different times. The quantity and quality of work undertaken at each stage of the process should be fully monitored and inspected.

Basic skills screening and the referral criteria

Experience gained in the pathfinder areas indicated that it was feasible and most appropriate for basic skills screening to be carried out by probation staff when they were interviewing an offender in order to prepare a court report. The BSA's 'Fast Track 20 Questions' was shown to be an adequate screening tool, despite some drawbacks. There was general agreement that prior training in use of the screening tool was required. For those screened as likely to have basic skills needs, it was found that rapid referral for the further, in-depth assessment was most likely to lead to 'take-up' of provision by the individual.

The further, in-depth assessment

It was feasible for the further investigation of basic skills to be carried out at the commencement of a community sentence, in order to inform the case manager's initial assessment and supervision plan. The majority of basic skills staff involved in carrying out the in-depth assessment thought that a shorter testing procedure, using fewer instruments than used during the evaluation period, would be more appropriate to avoid delays before tuition could be commenced. However, a common view was that the in-depth assessment should also include attention to speaking and listening skills.

Improving tuition

Planned tuition for basic skills should be integrated with other elements of a community sentence and included as an objective in the supervision plan and sentence. At the same time offenders should be helped to make contact with external providers of basis skills courses so that they are enabled to make improvements over the long-term.

More use should be made of information and communication technology (ICT) to facilitate learning and add to its appeal. Consideration should be given to the development of speaking and listening skills in accordance with the National Standards for Literacy and Numeracy (DfES, 2001) and the Adult Literacy Core Curriculum (BSA, 2001). More use could be made of group work to complement individualised teaching.

Outcome measures should include short-term, attitudinal changes to reflect increased selfefficacy and changed attitudes towards learning, employment prospects and desisting from crime. Positive outcomes can then be appropriately monitored over the short-term as well as long-term.

\section{Motivational work}

Much of the attrition was attributable to low motivation by offenders to address their basic skills needs. By implication, there is a clear need for motivational strategies to be utilised. A pre requisite to good motivational work by probation staff is that they themselves are committed to the value of basic skills interventions and that the relevance of such work to Probation Service goals is promoted by senior management and within training. 


\section{Why does the Probation Service need a basic skills programme?}

In order to appreciate why the Basic Skills Pathfinder was set up, it is necessary to be aware of the scale of basic skills need among offenders as well as the rest of the population, and the relevance of basic skills to offending and recidivism. This introductory section outlines the extent of the problem and national strategies to address it, and presents a brief literature review of research investigating the relationship between basic skills and other variables which have been found to be correlated with offending. Previous research investigating the effectiveness of educational interventions aimed at reducing offending is also discussed. A note of clarification about what was meant by 'basic skills needs' and the criterion applied during the pathfinder evaluation is first given.

\section{What are basic skills?}

The definition of 'basic skills' used by the Basic Skills Agency (BSA), and which has been applied for the Basic Skills Pathfinder evaluation, is:

The ability to read, write and speak in English or Welsh and use mathematics at a level necessary to function and progress at work and in society in general (BSA, 2000).

The emphasis is on everyday functioning rather than on developing skills for specific purposes that are separate from routine life. Functional literacy is defined in Skills for Life (Department for Education and Employment (DfEE), 2001) as the level that is expected of a competent 11/year/old. An example given of a serious difficulty with literacy is not being able to locate the page reference for plumbers in the Yellow Pages. An example of difficulty with numeracy, provided by the BSA, is working out the change from $£ 2$ after buying three items, one priced 68 pence, and two priced 45 pence. Functional numeracy is the equivalent to Entry and functional literacy is the equivalent to Level 1 in the hierarchy set out by the BSA.

Table 1.1 below shows the definitions of the basic skills levels following the adjustments made to the levels as part of the development of the National Standards for literacy and numeracy (Department for Education and Skills (DfES), 2001) as specified by the Qualifications and Curriculum Authority (see Appendix A also). In this report, however, the basic skills levels before adjustment will be used (see chapter 3 ).

Table 1.1: Basic skills levels

\begin{tabular}{|l|l|}
\hline Pre-Entry & Below National Curriculum Level 1. \\
\hline Entry 1 & National Curriculum Level 1. \\
\hline Entry 2 & $\begin{array}{l}\text { National Curriculum level 2. The level of a competent seven- } \\
\text { year-old. }\end{array}$ \\
\hline Entry 3 & National Curriculum level 3. \\
\hline Level 1 & $\begin{array}{l}\text { National Curriculum levels 4/5. The level of a competent 11- } \\
\text { year-old. }\end{array}$ \\
\hline Level 2 & GCSE $A^{*}$ to C. \\
\hline
\end{tabular}

For the purposes of the Basic Skills Pathfinder projects and throughout the evaluation, 'basic skills needs' was defined as literacy and numeracy skills below Level 1. From April 2002, the National Probation Directorate (NPD) has introduced 'below Level 2' as the criterion for assessing a person as having 'basic skills needs'.

\section{The basic skills problem in the UK}

A working group was appointed by the Secretary of State for Education in June 1998 to look at basic skills for adults over the age of 16 , and was chaired by Sir Claus Moser, Chairman of 
the BSA at that time. The product of this working group, A Fresh Start (DfEE, 1999), otherwise known as the Moser Report, has been crucial in drawing political attention to adult basic skills in England.

The report A Fresh Start suggested that one in five adults in England (approximately seven million) have serious difficulties with literacy and far more (30\%-50\%) have serious problems with numeracy. This is one of the worst levels of literacy and numeracy in Europe (Social Exclusion Unit, 2001). The report proposed far-reaching recommendations for developing adult basic skills practice and proposed a wide-ranging national strategy intended to 'halve the levels of functional illiteracy and innumeracy in about a decade' (DfEE, 1999).

In response to these recommendations, the Adult Basic Skills Strategy Unit (ABSSU) was set up in 2000, within the DfES. ABSSU is responsible for the implementation of Skills for Life (DfEE, 2001), and for ensuring that efforts to improve literacy, language and numeracy at national and local level are consistent and well co-ordinated. While poor basic skills in adults is by no means a new phenomenon, basic skills provision for adults has been very much a 'Cinderella' service (Brooks et al., 2001), but this situation is now being addressed. Funding for Skills for Life (DfEE, 2001) rose by $€ 150$ million between 2000 and 2003, taking spending overall on basic skills to around $£ 1.5$ billion by the year 2004. Skills for Life includes detailed recommendations and national targets aiming to reduce the number of adults with difficulties with literacy and numeracy (750,000 by 2004 and 1.5 million by 2007).

The numerous proposals put forward in Skills for Life to tackle basic skills problems include targeting resources on disadvantaged areas and groups at risk of sustained social exclusion. Four priority groups were identified: (1) unemployed people and other benefit claimants; (2) prisoners and offenders supervised in the community; (3) public sector employees; and (4) workers in low-skilled jobs (half of the seven million people with weak literacy and numeracy skills are in work). Research has revealed that literacy and numeracy problems are common for each of these groups.

\section{The prevalence of basic skills needs among offenders}

It has long been known from research into the characteristics of offenders that the average educational achievement of offenders is lower than that of the general population. They leave school at a younger age, have higher levels of truancy, suspension and permanent exclusion from school, and have fewer qualifications. What has not been recognised, until relatively recently, is how high the proportion of adult offenders is who, as a result, have not mastered basic literacy and numeracy skills. Recent attention to the issue of basic skills beyond the field of criminal justice has filtered down into criminological research and work with offenders. See Caddick and Webster (1998) for a helpful review of this literature.

Estimates of the prevalence of basic skills needs among the offending population have varied. Stewart and Stewart (1993) investigated a representative sample of 1,389 offenders aged between 17 and 23, drawn from seven probation services. Most were found to be early school leavers with no qualifications, who 'were ill-prepared for any possible employment opportunities'. A study during the 1970s found that 15 per cent of offenders in custody were semi-literate (Palfrey, 1974) while a more recent survey indicated that as many as one in two of all prisoners received into 16 prisons during one week had a low level of literacy (Adult Learning and Basic Skills Unit, 1994). In the report of the Social Exclusion Unit (2002), Reducing Reoffending by Ex-Prisoners, it is noted that:

- $\quad$ fifty-six per cent of prisoners are unemployed before sentencing;

- $\quad$ fifty per cent have poor reading skills;

- eighty per cent have poor writing skills; and

- sixty-seven per cent have poor numeracy skills.

Discrepancies in findings may reflect different assessment tools and alternative definitions of 'basic skills'. Some use 'basic skills' as an umbrella term covering both literacy and numeracy skills, and others focus more on literacy. 
Furthermore, definitions may or may not distinguish between basic skills needs that reflect lack of opportunities to learn and basic skills difficulties that are a result of learning disabilities, such as dyslexia. This distinction needs to be recognised because of the implications for differences in provision to tackle the underlying causes. Where to draw the line between basic literacy skills and dyslexia is a matter of some controversy. According to some research, dyslexia is over-represented in offender populations (Devlin, 1996), while others (e.g. Rice, 1999) have argued that the frequency of literacy difficulties found can more appropriately be attributed to other factors such as poor school experience and socio-economic status. Other research has suggested that the likely prevalence of dyslexia in the population depends upon the definition adopted (Snowling et al., 2000).

Regardless of where the boundaries are to be drawn in defining basic skills, what is at issue is not distinct skills for occasional or specialist use, but 'a set of tools for organising, planning and managing personal circumstances' (Davis et al., 1997) that are woven into the social processes of every day life.

\section{The relevance of basic skills to offending}

At first glance, having difficulties with, for example, filling in forms or subtraction of one sum of money from another, might seem remote from the more apparent causes of, and acknowledged motives for offending. While there is not a direct causal connection between difficulties with literacy and numeracy and committing crime, a lack of basic skills is related to several other variables that are known to be correlated with crime: unemployment, poor school experience, social exclusion and various psychological or cognitive factors linked to self-concept and attitudes to offending.

\section{Employment and basic skills}

Fairly obviously, for those who have poor basic skills, a large proportion of the employment market is closed to them, and therefore legitimate sources of sufficient income may be outside their reach. Apart from the financial implications of being without work, the long-term unemployed are also deprived of the potential psychological and interpersonal benefits of employment.

People with poor basic skills who do gain employment are less likely to secure 'a good job' in which they would happily remain. Those entering the job market are now increasingly expected to have qualifications and the jobs which require few or no academic achievements are diminishing (Bynner and Parsons, 1999; Felstead et al., 2002). At present, those without academic qualifications are far more likely to be unemployed than those with qualifications (Aronwitz and DiFazio, 1994; Joshi and Paci, 1999). Atkinson (1992) referred to more poorly skilled individuals 'swimming against a tide of increasing requirements' in the labour market, suggesting that those with poorer skills are in danger of being drowned.

The International Adult Literacy Survey (IALS), carried out in 1996, showed that gaining employment and the amount earned were linked to literacy levels (Carey et al., 1997). An analysis of the data from the 1970 British Cohort Study and the 1958 National Child Development Study carried out by Bynner et al. (2001) suggests that individuals who improve their basic skills also improve their chances in the labour market by moving up the occupational status scale and resisting unemployment. Bynner et al. also suggest that::

Level one or better numeracy skills produced a return to earnings on average of 26 per cent more than for adults with skills below this level and 16 per cent for literacy skills at this level.

Unemployment may be an indirect rather than a direct cause of crime (Tarling, 1982) which interacts with a variety of other social and demographic variables. In a study of offenders in six probation areas (with a sample of more than 7,000 offenders), May (1999) found that those who were recorded as unemployed were significantly more likely to be reconvicted than those who were employed. This confirms Farrington et al. (1986) findings when he followed 
up the Cambridge delinquency study. Research by Lipsey (1995) found that employment was the most significant factor in reducing offending rates.

\section{Offending and school experience}

Behaviour at school, academic performance and school attendance have been identified as relevant to offending (Graham and Bowling, 1995; Rutter et al.,1998; Berridge et al., 2001). Graham and Bowling (1995) based on a sample of over 2,000 young people, found the odds of offending for those who had truanted from school were more than three times than for those who had not truanted. Three-quarters of the males temporarily excluded from school were offenders. The Audit Commission (1996) found that 43 per cent of offenders of school age sentenced in the youth court had been expelled. Berridge and co-authors aimed to establish whether and to what extent permanent exclusion from school had an independent effect upon the offending careers of 343 young people. They concluded that school exclusion is mainly a male phenomenon with a ratio of four-to-one male to female exclusions, and that offenders are considerably over-represented in exclusion statistics. Of those who had been excluded from school, 65 per cent had been cautioned or convicted of a criminal offence at some point in their lives. A MORI survey carried out for the Youth Justice Board (Youth Justice Board, 2001) found that excluded children were significantly more likely to commit criminal offences than children in school (60\% compared to $25 \%)$.

Berridge et al. (2001) also found that most expelled students had experienced longstanding difficulties with education and were more likely to have special educational needs, usually related to emotional and behavioural difficulties. In some cases, under-achievement may arise as a result of a specific learning difficulty, such as dyslexia, rather than non-attendance or difficult behaviour (Hinshaw, 1992). Of course, such learning difficulties may themselves give rise to emotional and behavioural problems, and a reluctance to attend school, thereby compounding the problem.

\section{Social exclusion, education and offending}

A lack of basic skills may well play a large role in the gradual social exclusion of offenders from their communities and from society in general. The Social Exclusion Unit (2001) defines social exclusion as:

... a shorthand term for what can happen when people or areas suffer from a combination of linked problems such as unemployment, poor skills, low income, poor housing, high crime, bad health and family breakdown.

Based on an analysis of performance data from a reading test sat by individuals participating in the 1970 British Cohort Study at age 10, Bynner and Parsons (2002) concluded that 'poor reading is an important element of social exclusion, with early risk factors compounding the process'. Research conducted by MORI on behalf of the BSA (BSA, 2001), and using semistructured interviews with a representative sample of 2,089 adults throughout Great Britain showed links between poor basic skills, financial exclusion and social disadvantage. According to Bynner et al. (2001), increased levels of basic skills achievement would help to reintegrate those who are socially excluded, because of the resulting effect on levels of physical and mental health, achievement at school and opportunities to participate in various activities.

\section{Basic skills and self factors}

Another indirect association between poor basic skills and offending may be the psychological difficulties which can accrue. It has been suggested that restricted opportunities as a consequence of educational difficulties can contribute to negative self-concept and low selfefficacy. When legitimate opportunities are limited or blocked, the resulting frustration can contribute to anger and impulsive actions, including offending behaviour (Merton, 1968; Cloward et al., 1960; Agnew, 1992). Furthermore, individuals who lack educational 
achievement may be limited to socialising with others who are similarly disadvantaged, perhaps leading them into 'deviant' subcultures (Cohen, 1955).

\section{Do basic skills interventions help to reduce offending?}

Given the prevalence of basic skills deficiencies amongst the offending population, it is clear that interventions to improve basic skills are important. For this reason, there has been considerable interest in looking at whether educational intervention could reduce reoffending either on its own or in association with other programmes. Research into this question is fraught with difficulty because of numerous other variables that could impact on future offending either in combination with a basic skills intervention or unrelated to it. An additional barrier against carrying out a rigorous evaluation is that educational intervention tends to rely on self-selection of programme participants rather than random assignment to the intervention and controlled comparison groups, and therefore the true impact of the intervention cannot usually be evaluated adequately (MacKenzie, 1997; Cecil et al., 1997). Other problems with this kind of research include the adequacy of follow-up periods. However, research has been carried out in an effort to measure the effectiveness of educational intervention programmes on offending behaviour.

Perhaps the most promising findings, although obtained in a prison study in Canada, were from Porporino and Robinson (1992) who evaluated an initiative funded by the Correctional Service of Canada to provide adult basic education in prisons. A substantial reduction in reoffending among those who attended the basic literacy and numeracy courses was reported. While 30 per cent of the adult basic education completers were returned to prison during the follow-up period, 36 per cent of those who were released before completing the course, and 42 per cent who withdrew from it, returned to prison. Moreover, those who were assessed as 'higher risk' offenders appeared to benefit more than 'lower risk' offenders, thus ruling out the possibility that the completers were more successful in the community because of their risk status. Post-release interviews of those offenders who had completed the adult basic education course revealed that 79 per cent were employed full time. Over threequarters said that they felt more in control of their lives, and 30 per cent said their skills helped them with family matters. Porporino and Robinson conclude that:

The specific intellectual skills that are gained through Adult Basic Education training may equip offenders to deal more effectively with daily problems encountered in the community. Moreover, the sense of achievement and confidence that results from successfully completing a program may encourage some offenders to make further positive changes to their lives.

Another important study into the effects of educational intervention on offenders was carried out by Pearson and Lipton (1999) using a meta-analysis technique. They look specifically at educational programmes and vocational programmes. The authors cover research from 1968 to 1996, and they concluded that 'program participants recidivate at a lower rate than nonparticipants'. However, because of methodological weakness in the studies carried out, they were unable to categorically attribute this outcome solely to the programme.

In another US study, Cecil et al. (1997) examined the effectiveness of adult basic education and life skills programmes between 1980 and 1990 in reducing recidivism. They found that the majority of the research on educational intervention was methodologically weak, for example, because inadequate or no comparison groups had been used, or because statistical significance tests had not been applied. However, based on a few studies of sufficient methodological rigour, they stressed that, for reductions in recidivism to be obtained the crucial variable was, not simply programme participation, but the extent of involvement or programme completion. They concluded that adult basic education is a 'promising' method of reducing recidivism. 


\section{Summary}

Having inadequate basic skills is a surprisingly widespread problem among the adult population in the UK, but the proportion of those with poor basic skills is especially high among some subsections of the population. Prisoners plus people serving community sentences form one of those groups. Basic skills difficulties are linked to a variety of problems which are known to be correlated with offending: unemployment; poor school experience; social exclusion; and psychological factors. Therefore attention to basic skills needs should be included in interventions aimed at reducing crime. Research into the effects of basic skills interventions on recidivism rates is so far very limited but some promising outcomes have been obtained, suggesting that basic skills interventions should be further investigated. It is for this purpose that the Basic Skills Pathfinder, described in the next chapter, was introduced. 


\section{The Basic Skills Pathfinder: background, projects and evaluation}

The Basic Skills Pathfinder is part of the Crime Reduction Programme (including the What Works Strategy). This chapter briefly explains developments in the Probation Service leading up to the introduction of the Basic Skills Pathfinder. It should be noted that, following the reorganisation of probation services in April 2001 to form the National Probation Service (NPS) for England and Wales, the NPD has introduced an agenda for addressing poor basic skills. More recent events affecting basic skills provision since the commencement of the evaluation are therefore summarised. The chapter finishes with a description of the aims and stages of the Basic Skills Pathfinder and its evaluation.

\section{History of basic skills provision in the Probation Service}

Until recently, there was no systematic agenda within the service to address the basic skills needs of offenders. Davis et al. (1997) pointed to the previous low priority given to basic skills work within the Probation Service and, most importantly, a lack of direction at policy level in providing a framework in this area of community supervision practice. Although Davis et al. reported that literacy and education were sometimes addressed by probation areas, this was limited to:

Ad hoc or unsystematic provision... If and when an offender's poor level of literacy becomes apparent, the action taken depends more on the staff member's interest in the subject and knowledge of local sources of assistance than it does on servicewide policies and dedicated systems.

The absence of any reference to basic skills work in the first two editions of the National Standards for the Supervision of Offenders in the Community (Home Office, 1991; 1995) suggests that this was an accurate description of the prioritisation given to such educational work by probation areas. However, in the most recent publication of National Standards (Home Office, 2000) specific reference is made to identifying literacy and numeracy problems within the pre-sentence report (PSR).

\section{An emerging focus}

Probation Circular 40/1994 (Home Office, 1994) referred to the educational needs of offenders sentenced to community supervision prior to 1999. This was the original statutory basis for possible basic skills work. An emphasis was placed on work with offenders encompassing employment, training and education (ETE). The circular stated that: 'Research studies emphasise that offenders can more successfully be rehabilitated into the community and kept from further offending if they are helped into employment, education, or job related training' and concluded that the methods employed by probation areas should therefore have regard to these goals.

Some other Probation Service documents have been important in identifying the relevance of basic skills interventions to probation work. But it is Probation Circular 92/2000 National Probation Service Aims: The Home Secretary's Priorities and Action Plan 2001-02 and Performance Measures for the Service 2001-04 (Home Office, 2000a) that most strongly signalled the increasing importance of basic skills work in the NPS. This circular emphasised that local areas will participate in the delivery of Welfare to Work programmes, and will review and enhance strategies for generating employment, training and education opportunities for offenders, with particular emphasis on literacy and basic skills provision. 
The Home Office Crime Reduction Programme (Home Office, 1999) was a $£ 403$ million programme which ran for three years from April 1999. The intention of the Crime Reduction Programme was to obtain evidence on the most effective methods used by criminal justice services to tackle crime and its causes. Following rigorous evaluation and cost-benefit analysis, the best methods would be selected with a view to their development, accreditation and 'roll out' across services in England and Wales. Thus, a number of different 'pathfinders' were introduced, including offending behaviour programmes, employment projects and basic skills projects.

The Crime Reduction Programme dovetailed with the Home Office What Works policy, now taken up by both the Probation Service and the Prison Service (Home Office, http://www.crimereduction.gov.uk). These programmes combine to create an ambitious project to reduce crime in England and Wales. Between 1999 and 2002, £21million was earmarked for What Works from the Crime Reduction Programme investment, of which just over £13million was for NPS developments.

The Basic Skills Pathfinder evaluation consisted of seven projects in seven different probation areas (nine probation services before the reorganisation of the Probation Service), exploring how best to help offenders under supervision in the community to improve their skills in literacy and numeracy. Basic skills work has also become a more important part of HM Prison Service's aims in the past few years (see Appendix B). Features of the seven projects and the objectives of the evaluation are outlined later in this chapter.

\section{More recent developments following the Basic Skills Pathfinder evaluation}

Basic skills provision within the NPS has now reached a new milestone with the full implementation of basic skills from 1 April 2002. The NPS is drawing on the Skills for Life (DfEE, 2001) strategy and empirical findings from the Basic Skills Pathfinder evaluation to encourage good practice which has been shown to be feasible and effective in delivering basic skills work to offenders (Home Office, 1999a).

Probation areas were also allocated funds from the 2000 spending review for basic skills provision totalling £3.6million for 2002-03 and £7.9million for 2003-04. The Probation Service Delivery Agreement Measure, under Public Service Agreement 10 (Probation Circular 92/2000, Home Office, 2000a) has agreed to reduce the rate of reconvictions of all offenders punished by imprisonment or by community supervision by five per cent by 2004 compared to the predicted rate. The stated target is to increase the educational and vocational qualifications of offenders with 6,000 completions of Level 2 basic skills awards in the Probation Service in 2002-03 and 12,000 completions in 2003-04'. This target was considered by basic skills staff to be unrealistic because the hours taken to achieve such improvements were not available for those offenders sentenced to community supervision. The BSA states that, on average, 300 hours of tuition would be required to move an individual from below Entry Level to Level 1, and 200 hours to move an individual from Level 1 to Level 2, though the evidence base for this claim is not cited. Probation Circular 15/2002 Basic Skills - revised National/Local Targets and Implementation Arrangements (Home Office, 2002) changes these targets. The 2002-03 targets are for 6,000 basic skills programme starts and 1,000 basic skills qualifications at any level.

In the Consultation Paper: Improving the Basic Skills of Offenders on Community Supervision (Home Office, 2001) the NPD lays out its plans for basic skills work. As part of the challenge to improve the basic skills of offenders, it states that probation areas should endeavour to provide:

- screening and assessment for offenders sentenced to community supervision;

- continued learning opportunities for those offenders released on licence from prison;

- advice, guidance and referral to appropriate learning opportunities; 
- effective use of volunteers or mentors to support offenders participating on basic skills programmes;

- enough assistance for offenders to achieve qualifications; and

- sufficient provision to achieve Service Delivery Agreement targets.

It is expected that partnerships with educational providers in the community will be formed, and probation areas are recommended to access Learning and Skills Council (LSC) funding and provision for the majority of their offenders. A recent issue of What Works News (Issue 11. Dec 2002/Jan 2003, on the website for the NPS) has set out recommendations from the NPD for screening and assessment of basic skills.

\section{The Basic Skills Pathfinder}

The Crime Reduction Programme (Home Office, 1999; 1999a) provided funds for a Basic Skills Pathfinder to examine the extent to which systematic efforts to address poor basic skills within community sentences helped probation areas to reduce reoffending. The specific focus was on Community Rehabilitation Orders (CROs) and Community Punishment and Rehabilitation Orders (CPROs), but not Community Punishment Orders (CPOs).

\section{The seven Basic Skills Pathfinder projects}

Initially there were nine probation services involved in the pathfinder, but boundaries of some services changed following the formation of the NPS, resulting in seven projects. The Basic Skills Pathfinder areas were Cornwall, Cumbria, Dorset, Lincolnshire, Nottinghamshire, Sussex (formerly East and West Sussex) and Thames Valley (formerly Berkshire, and Oxfordshire and Buckinghamshire) Probation Areas. Each of these services had initiated some procedures and interventions to address basic skills needs before they became pathfinder projects. Apart from agreements made to use the same screening and assessment instruments during the period of the evaluation, and to follow agreed procedures for data collection, there was no single model of basic skills provision imposed and each area determined its own programme, strategy and methods of delivery. Each of the projects therefore had distinctive features and continued to evolve during the period of the pathfinder. Detailed descriptions of each project, plus their origins and 'exit strategies', are given in Appendix C.

\section{The evaluation}

The Probation Studies Unit in the University of Oxford Centre for Criminological Research, together with the University's Department of Educational Studies and ESRC Research Centre on Skills, Knowledge and Organisational Performance, was commissioned by the Home Office Research, Statistics and Development Directorate to evaluate this pathfinder programme. The evaluation commenced in October 2000, which was after most of the basic skills projects in the seven (then nine) probation areas had commenced. The evaluation was completed in March 2002.

Objectives and methods of the evaluation

The evaluation of the Basic Skills Pathfinder had six objectives. These were to:

- make a baseline estimate of the prevalence of basic skills needs among offenders, by screening for basic skills needs all those offenders on whom PSRs had been prepared during the evaluation period;

- investigate the association between basic skills needs and other variables such as employment status, alcohol and drug abuse, school attendance and risk of reconviction;

- compare the different circumstances of those offenders who accessed basic skills provision (the experimental group) with those who did not (the comparison group); 
- measure the progress of offenders who participated in basic skills provision within the seven pathfinder areas against intermediate outcomes such as improvements in basic skills, gaining and maintaining employment, and participation in further education and training. The time span of the evaluation prevented the collection of reconviction data;

- undertake a cost-benefit analysis of the economic costs of implementing the basic skills projects, to compare these costs with positive results obtained through intermediate outcomes, and to estimate the resources needed to replicate the basic skills projects in other probation areas; and

- Identify good practice and key challenges in the implementation of basic skills provision within community supervision.

The process of addressing basic skills needs involved three key stages, requiring the participation of the targeted offenders:

- Screening for basic skills needs.

- In-depth assessment ('initial assessment') of basic skills needs. ${ }^{1}$

- Provision of tuition.

Each of these stages was dependent on complementary work by staff to motivate participation, to organise referral, and to collect data for monitoring and evaluation of progress. A brief overview of each stage, and the data collected, is set out below, but the more detailed explanations, and methodological and practice issues involved at each of these stages is given in the appropriate section of this report.

Screening for basic skills needs (at the PSR stage)

It was the intention that all offenders on whom a PSR was prepared would be 'screened' to find out if they were likely to have to basic skills below Level 1. The BSA's Fast Track 20 Questions (FT 20 Q) and a background information form were used for this purpose (described in Chapter 3).

The Basic Skills Pathfinder evaluation staff were trained by the evaluation team in the use of these instruments. From the perspective of probation staff this stage is generally referred to as the 'PSR stage' although, in some situations a briefer report, the specific sentence report (SSR) is prepared instead. During the period of the evaluation, screening data was received on 10,252 cases.

The evaluation team also collected data on offenders' risk of reconviction status. The Offender Group Reconviction Score (OGRS2) was completed by all but one of the pathfinder areas. An alternative measure of the risk of reconviction was used in Sussex Probation Area: The Level of Service Inventory-Revised (LSI-R).

The initial assessment procedure for basic skills needs for those screened as likely to have basic skills needs (at the start of community supervision)

For those offenders who were positively screened as probably having basic skills below Level 1 and who were sentenced to either a CRO or CPRO, the pathfinder projects were asked to arrange an initial assessment procedure for basic skills needs. This would eliminate 'false positives' (those who were 'positively' screened as likely to have basic skills needs but who in fact did not have basic skills below Level 1) and help to determine more exactly the level and requirements of those who had been appropriately screened as probably having literacy and numeracy below Level 1. Five instruments (which will be described in Chapter 3) were provided by the evaluation team for use at this stage:

- The BSA's Initial Assessment.

- Raven's Progressive Matrices.

${ }^{1}$ During the Basic Skills Pathfinder evaluation, this stage was generally referred to as 'initial assessment' because its main component was the BSA's Initial Assessment and because it was timed to coincide with the Initial Assessment Stage which takes place with offenders at the start of communitysuperision in probation. This in-depth assessment 'stage' is commonly referred to as the 'initial assessment procedure for basic skills needs' in this report. 
- An additional background information form.

- Social Problem-Solving Inventory-Revised (SPSI-R) (short-form).

- CRIME-PICS II.

The evaluation team trained relevant project staff in the use of each of these instruments. All of these were to be completed during the Initial Assessment Stage of probation practice. If, at this stage, the use of these instruments confirmed that the offender did have basic skills below Level 1, then the individual was to be referred for tuition. For those who subsequently attended tuition, these tests served as pre-tests for later comparison with post-tests.

\section{Provision of tuition and courses}

The final and, of course, key stage for those who were screened and then assessed as having basic skills needs was attendance for tuition. Various items of data were essential to monitor their attendance and progress. Attendance records and relevant progress data were to be provided by tutors, plus any information about positive outcomes (such as gaining employment or acceptance on a college course). Post-tests were also to be provided by project staff. The post-tests involved completion of some of the same instruments (pre-tests) that had been used to assess the need for tuition:

- The BSA's Initial Assessment.

- SPSI-R (short-form).

- CRIME-PICS II.

It was suggested that these post-tests should be completed either at the end of offenders' basic skills provision, or at the eight-month point in offenders' basic skills provision. These post-tests provided a means of comparing the measures of basic skills level, problem solving ability and attitudes obtained before tuition commenced (pre-tests) with the same measures following tuition.

Data collection and analysis of outcomes

The evaluators aimed to monitor, on a monthly basis, the numbers of the following:

- Completed PSRs.

- Screenings completed.

- Referrals to the initial assessment procedure for basic skills needs.

- Attendances at the initial assessment procedure for basic skills needs.

- Completions of the in-depth assessments.

- Uptake of basic skills provision.

- Attendance on basic skills provision and attrition records.

- Progress and outcome measures.

Pathfinder areas were also asked to provide the evaluation team with information on date of sentence, offence type, court type, proposed outcome from the PSR, disposal (sentence) by the court, and disposal requirement data, on all offenders sentenced. The evaluation team requested copies of all of the above items.

Case material was also collected for a comparison between the 'experimental group' and a 'comparison group'. The experimental group consisted of all those offenders who had been screened as likely to have basic skills needs and who subsequently attended for tuition. The comparison group consisted of 50 per cent of offenders who were sentenced to a CRO or a CPRO, and whose FT 20 Q screening tool score indicated that they were likely to have a basic skills need, but who did not access basic skills provision. A content analysis of the records held for the offenders in the comparison and experimental groups (PSRs, supervision plans and quarterly reviews) was conducted. These data were used to compare the different circumstances of those offenders who accessed basic skills provision with those who did not. There were some major gaps in the data received by the evaluators, and not all areas applied the agreed procedures and eligibility criteria throughout the evaluation process. Much of the analysis was based on monthly monitoring information from five of the seven pathfinder 
areas. $^{2}$ One probation area only provided monitoring data for a three-month period and another did not provide any at all.

Interviews were carried out with 97 probation staff, ten project managers, 17 tutors (some of whom were mentors acting in a tutoring capacity), and 20 offenders who were attending for basic skills tuition. A total of 37 basic skills sessions were observed. In addition a set of six case studies were compiled (see Appendix D).

For the economic evaluation of the Basic Skills Pathfinder, a cost-benefit analysis was undertaken (described in Chapter 7).

The findings from the evaluation of the pathfinder projects are presented in Chapters 2 to 7 and the key implications and recommendations are given in Chapter 8.

${ }^{2}$ The reasons given for the lack of monitoring information in the other two pathfinders were that these data were not available, were difficult to collectorhad not been collected by the probation area. 


\section{Identifying basic skills needs}

In order to provide individuals with interventions to meet their basic skills needs, or to refer them to appropriate services, they must first be identified. Identification of basic skills needs in the pathfinder evaluation had two stages: screening, which was a relatively quick procedure to find out who is likely to have basic skills needs; and the initial assessment procedure for basic skills needs, which provided a more exact assessment of offenders' basic skills levels. This chapter describes the instruments and procedures that were involved in each of these two stages, and the views of project staff on their use.

\section{Preliminary screening to identify basic skills needs}

The evaluators collected data on all those offenders for whom a $\mathrm{PSR}^{3}$ was prepared during the period of between seven and 12 months (the exact period varied from one pathfinder area to another). The National Standards for the Supervision of Offenders in the Community (Home Office, 2000) stipulate that every PSR 'shall state the offender's status in relation to literacy and numeracy'. However, the sample of offenders for whom data were collected may not be fully representative of the larger population of offenders because courts are not always required to request PSRs. In 2000, for example, less than 20 per cent of all sentences passed followed a request for a report to be prepared (although oral representations and 'old' PSRs were likely to have been used in a proportion of these cases). In a minority of cases, the screenings were carried out during the preparation of SSRs rather than PSRs, and these were also included in the evaluation.

\section{Description of the screening tools}

Before the Basic Skills Pathfinder evaluation, probation areas were using a variety of tools for screening purposes. For the pathfinder evaluation, however, it was necessary for all areas to use the same screening procedures. Therefore two instruments (collectively referred to as 'screenings') were selected by the evaluation team for use by probation staff during the PSR interview: the FT 20 Q screening tool; and a background information form. The Basic Skills Pathfinder evaluation staff were trained by the evaluation team in the use of these instruments.

It was intended that these instruments would be completed by the PSR writer and based on self-report of the offender, with the exception of alcohol and drug abuse which was assessed from the perspective of the PSR writer. The evaluators subsequently learned, however, that both forms were not always completed in this way. Both of these two instruments were integral to the identification of basic skills needs and the subsequent process of meeting those needs.

\section{The BSA Fast Track 20 Questions screening tool}

The FT 20 Q screening tool has two questions about previous qualifications, 12 questions relating to everyday reading and writing practices, and six questions relating to everyday numeracy activities. The answers to these questions are scored using a simple system of ticks. Seven or more ticks on the FT 20 Q screening tool indicates that an individual is likely to have a literacy level below Level 1 and a numeracy level below Entry Level (BSA, 2000). These levels have since been adjusted, as part of the development of the National Standards for literacy and numeracy (DfES, 2001) (see Table 1.1 and Appendix A). For the purposes of the Basic Skills Pathfinder evaluation, however, both literacy and numeracy needs were taken to be below Level 1 and for the screening, the basic skills levels referred to in this report will be the levels before the adjustment: 'below Level 1' and 'at or above Level 1' .

Work by the BSA suggests that the correlation between the FT 20 Q screening tool scores and scores on the BSA's Initial Assessment tool was high (77\%) for the general population of

\footnotetext{
${ }^{3}$ Preparation of a PSR involves interviewing the offenders and relevant others, plus detailed checks, in order to make an assessment. The report is witten
} to assist the court in determining an appropriate sentence. 
adults on whom the FT 20 Q screening tool was piloted (BSA, 2000). This suggests that the FT 20 Q screening tool is fairly reliable for its purpose as a screening tool. Further reliability checks were run by the evaluation team using the data collected from the pathfinder (see Appendix E). A strong and significant association between scores on the FT 20 Q screening tool and the BSA's Initial Assessment tool was found. Although not standardised, the FT 20 Q screening tool was selected because it was piloted by the BSA before it was made available for general use (BSA, 2000). It was also selected because it has the following advantages:

- It is quick to administer (up to 10 minutes to go through the questions and mark).

- It can be administered by non-experts in basic skills.

- It is not a formal test.

- The question-and-answer format is appropriate for use during a PSR interview.

It should be stressed that the FT 20 Q screening tool was designed only to provide an indication of a likely basic skills need and was not designed to be a diagnosis of a definite basic skills need. This limitation is offset by the speed with which it can be administered and scored, an important consideration given the time constraints of the PSR interview. Also, use of a preliminary screening tool rather than going straight to a fuller assessment allows a quick check 'to make sure', whereas a longer assessment might seem heavy-handed and overbearing.

All screening forms were to be returned, including 'negative' screenings (fewer than seven ticks, plus forms for those whose qualifications exempted them). Once a person had been screened, strict criteria were applied for referral to the next stage. If the individual was 'positively' screened as likely to have basic skills below Level 1 (seven or more ticks on the FT 20 Q screening tool) and if s/he had been sentenced to a CRO or CPRO, then s/he should have been referred for further assessment of her/his basic skills levels. This should have taken place as soon as the CRO or CPRO commenced, when the case manager was undertaking the Initial Assessment of the offender (for all offender needs), although designated project staff were ordinarily responsible for the basic skills assessments.

\section{Screening for dyslexia?}

In the context of the Basic Skills Pathfinder evalution, no attempt was made to screen for dyslexia. Partly this was due to lack of suitable and valid screening instruments, partly due to cost and time considerations, and partly due to the fact that not all pathfinder areas had staff with sufficient expertise to assess dyslexia. However, the evaluation team were provided with information from Nottinghamshire Probation Area where offenders were screened for dyslexia using the Kaufmann Brief Intelligence Test and the Wide Ranging Abilities Test.

The background information form

This was a self-report questionnaire administered by the PSR writer which included questions on personal information (gender, age, race/ethnic classification, accommodation status and domestic circumstances); alcohol and drug abuse (reported from the perspective of the PSR writer); criminological data (criminal history, risk of reconviction, current offence, proposal and sentence); educational data (school attendance and highest level of qualification achieved); employment status; first language; and PNC/ ID numbers (for a reconviction study).

The screening was undertaken by the probation staff who were responsible for preparing the PSR. Training on the use of the screening tool was provided by the evaluation team.

\section{Use of the screening tools}

During the period of the evaluation, staff did not always complete the FT 20 Q screening tool, as requested, during the preparation of reports. Problems regarding non-usage of the tools for identifying basic skills needs were indicative of some issues underlying the attrition that occurred in referring people on to the various stages of addressing basic skills needs. The numbers involved and the reasons provided for not using the screening tool are discussed in Section 6 , which deals with the problem of attrition. Those who did undertake the screenings 
identified benefits and also a number of problems thrown-up by the process and the FT $20 \mathrm{Q}$ screening tool.

The staff interviewed were supportive, in principle, of screening for basic skills needs at the PSR stage, although some conceded that PSR writers may not have been the most appropriate people to do the screening because, in their view, basic skills work was not central to their role. One project manager also expressed doubts about the suitability of PSR writers to conduct screening, because of the host of other tasks and objectives to be achieved during the PSR interview in order to prepare a court report. Some staff thought it would be better for probation areas to create a new staff post dedicated to screening all offenders at the PSR stage. Evidence from Cumbria Probation Area, however, showed that such an arrangement for the screening of each offender in a back-to-back interview with the PSR interview had not, overall, been successful.

\section{The timing of the screening}

A small minority of PSR writers were categorical that screening for basic skills needs should not be conducted at the PSR stage, but the majority agreed, at least in principle, that it was important to screen offenders as early as possible - that is, as part of the pre-sentence assessment - so that sentencing and supervision plans, where applicable, could be appropriately informed. Quite apart from the need for poor basic skills to be addressed, literacy and numeracy problems could rule out the suitability of particular sentences and interventions, and could also affect the ability of the offender to co-operate.

However, despite this general recognition of the need for screening as part of assessment, many officers were against screening at the PSR stage because it added to their workload and was not seen as the highest priority. In particular, screening all offenders regardless of the expected court sentence, when only those sentenced to a CRO or CPRO would be 'eligible' for the basic skills project, was regarded as an ineffective use of time. Some voiced misgivings that screening would not be carried out with sufficient care because of time constraints, but would be treated as 'just another administrative task resulting from the target culture'. Another concern was that offenders might deliberately respond in ways that underestimated or overestimated their basic skills if they thought it could influence the probation officer's recommendation to the court. For the above reasons, many thought that screening would be better placed at the commencement of community supervision. Other advantages would be that it could be better addressed in the relative security of an established relationship between the officer and offender, and away from the pressure of a looming court sentence when the offender was more likely to focus on the issue. In the words of one PSR writer:

I doubt whether the PSR interview is the best environment in which to screen. The offender is more worried about whether they are going to go to prison and how much they are going to be fined, than answering questions [about basic skills].

\section{The strengths and weaknesses of the screening tool}

Overall, very few PSR writers reported that offenders refused or were reluctant to complete the FT 20 Q screening tool. On average, PSR writers completed two or three of the FT $20 \mathrm{Q}$ screening tools per week, at five to ten minutes per FT 20 Q screening tool. In general, it was seen as doing what it was intended to do: that is, serving as an indicator of basic skills needs. Its perceived advantages were that it is:

- nationally recognised;

- $\quad$ not just for offenders but used for a variety of population groups;

- in a standard question-and-answer format;

- $\quad$ quick and easy to use;

- non-confrontational; and

- easily fitted into the PSR interview. 
Other pluses mentioned were that it provided useful information for inclusion in the court report; was a good way of introducing educational history, literacy and numeracy skills into the PSR interview; and it provided a uniform and systematic measure of basic skills needs for all offenders at the PSR stage.

Not all staff supported the use of the FT 20 Q screening tool for future use, and a few were extremely critical, arguing that in order for the FT 20 Q screening tool to be used in the longterm, it should be refined to make it more appropriate for use with offenders. The most frequently made criticisms were that it is:

- unreliable, trading speed for accuracy;

- clumsy, repetitive, ambiguous;

- intrusive, patronising, too simplistic;

- middle class and irrelevant; and

- a distraction from writing the PSR.

Some probation staff felt that the FT 20 Q screening tool was 'embarrassing to administer' because of its unsuitability for the target group. It was thought that the answers to some items, and therefore the final score on the test, were open to misinterpretation. For example, answers of 'Never' to the questions 'How often do you read magazines?, 'How often do you read a newspaper?, and 'How often do you read for pleasure?' need not imply that a person has poor reading ability but would nevertheless score as three ticks towards a 'positive' screening, thus potentially indicating a basic skills need. Staff had different ways of handling these perceived problems, occasionally even completing the screening tool after the interview based on assumptions they made about the individual's basic skills during the course of the interview, although this was not advised. Thus, some suggested that answers to the FT $20 \mathrm{Q}$ screening tool were partly dependent on the way in which the tool was administered by the PSR writer, and that therefore an offender's score on the FT 20 Q screening tool could potentially alter from one use to the next (in successive PSRs) if $s /$ he answered the questions differently.

There are variations and anomalies in the way that the FT $20 Q$ screening tool is completed between probation officers and between teams of probation officers.

(project manager.)

Perhaps the most serious objection to the FT 20 Q screening tool was that it 'does not identify dyslexia', a problem believed to be very prevalent in the offending population by probation staff.

Despite these difficulties, most concluded that although the FT $20 \mathrm{Q}$ screening tool 'is not perfect', its faults would be likely to apply to any such screening tool or to be offset by other faults. For example, any screening tool would trade off accuracy of detail for the speed at which the tool could be completed.

\section{The initial assessment procedure for basic skills needs}

The pathfinder projects were asked to arrange a more detailed assessment and testing for all those offenders who were positively screened as likely to have basic skills needs and also who were sentenced to either a CRO or CPRO. This involved the use of several tests usually administered by designated project staff. During the Basic Skills Pathfinder evaluation, this stage coincided with the Initial Assessment Stage of probation practice.

The main purpose of the initial assessment procedure for basic skills needs was to determine the level and requirements of those who had been screened as probably having literacy and numeracy difficulties, and to gain a set of data to serve as 'pre-test' measures which could be compared with 'post-test' measures, using the same tests after a period of tuition had taken place. A secondary aim of the initial assessment procedure for basic skills needs was to eliminate 'false positives' (those with seven or more ticks on the screening test but who, nevertheless, did not have basic skills below Level 1). 


\section{Description of the assessment tools}

Five assessment tools were chosen for use in the Basic Skills Pathfinder evaluation at the commencement of community supervision in probation practice. These were as follows.

The BSA's Initial Assessment

This tool was selected for the pathfinder evaluation because, although it was not standardised, it was a nationally recognised tool which was used in a wide variety of contexts. It involved administering one of three parallel versions of a literacy and numeracy assessment. The BSA's Initial Assessment provided a more detailed assessment of basic skills than the FT 20 Q screening tool in that it identified a specific basic skills level. It was not, however, a full diagnostic assessment. There were four sections in the BSA's Initial Assessment: reading, spelling, and punctuation (all to assess literacy), and numeracy. The BSA's Initial Assessment was administered as a timed instrument, with offenders given a maximum of 35 minutes to complete it. The tool was scored so that individuals were placed in a basic skills level: below Entry Level, at Entry Level, at Level 1 and above Level 1. It should be noted that the BSA's Initial Assessment is now out of date, because the basic skills levels have been adjusted as part of the Skills for Life (DfEE, 2001) strategy (see Table 1.1 and Appendix A). However, the basic skills levels measured by the BSA's Initial Assessment will be the levels used before the adjustment as above.

\section{Raven's Progressive Matrices}

This is available as both Standard Progressive Matrices and Coloured Progressive Matrices. Raven's Progressive Matrices measures the eductive component of general intelligence (otherwise known as Spearman's $\boldsymbol{g}$ ) as defined in Spearman's theory of cognitive ability:

Eductive ability is the ability to forge new insights, the ability to discern meaning in confusion, the ability to perceive, and the ability to identify relationships. Since perception is primarily a conceptual process, the essential feature of eductive ability is the ability to generate new, largely non-verbal concepts which make it possible to think clearly

(Raven et al., 2000).

Raven's Progressive Matrices are administered untimed, but usually took from 25 to 45 minutes to complete during the Basic Skills Pathfinder evaluation. Raven's Progressive Matrices are scored and individuals are placed in a percentile which can be converted to a grade, using the categories developed by Raven et al. for the general population: 'intellectually superior', 'definitely above average', 'average', 'definitely below average' and 'intellectually impaired'. Raven's Coloured Progressive Matrices are a simpler form of Raven's Progressive Matrices than Raven's Standard Progressive Matrices. These were used when offenders failed to complete correctly the first five questions in Raven's Standard Progressive Matrices.

The additional background information form

This provided more detailed information on alcohol and drug abuse, health status, educational history and motivational variables. Depending on the amount of detail emerging from the discussion of topic areas, this form took approximately 15 to 45 minutes to complete.

\section{Social Problem Solving Inventory-Revised (short-form)}

Social problem solving is a cognitive and behavioural thought process by which an individual tries to identify, discover or invent effective solutions for problematic situations in everyday life. SPSI-R (short-form) is a multi-dimensional self-report measure of social problem-solving ability. It is a 25-item instrument scored according to the five sub-scales of social problem solving: Positive Problem Orientation; Negative Problem Orientation; Rational Problem Solving; Impulsivity/Carelessness Style; and Avoidance Style. It was found that the SPSI-R (short-form) took approximately ten minutes to complete. The SPSI-R (short-form) was read out to the offender and completed by the administrator according to the offender's responses. The SPSI-R (short-form) is currently used to assess offenders before their commencement on accredited offending behaviour programmes, and is then used to assess change in attitudes following the completion of a programme. 


\section{CRIME PICS II}

This is a 35-item instrument which provides a numerical and scaled score of: general attitude to offending; expectation of reoffending; measure of denial of victim hurt; evaluation of crime as worthwhile; and perception of current life problems. CRIME PICS II took approximately ten minutes to complete during the Basic Skills Pathfinder evaluation. It was read out to the offender and completed by the administrator according to the offender's responses. CRIME PICS II is currently used to assess offenders before their commencement on accredited offending behaviour programmes, and is then used to assess change in attitudes following the completion of a programme.

\section{The Offender Group Reconviction Score 2}

OGRS2 was used in six of the pathfinder areas to measure risk of reconviction. This instrument measures the probability that a convicted offender will be reconvicted at least once within two years of their release from custody or from the start of their community sentence for any type of offence. The LSI-R was used in Sussex instead of OGRS2. This enables a quantitative assessment of the attributes of offenders and their situations. One of its functions is to provide predictive information on the likelihood of recidivism.

\section{Views on using the tools in the initial assessment procedure for basic skills needs}

All seven of the pathfinder projects made use of the assessment instruments but two of them (Cornwall and Nottinghamshire) also used assessment tools that they had used prior to the evaluation, alongside the pathfinder assessment tools. The individuals responsible for administering assessment instruments varied across the pathfinder areas, and included basic skills tutors, ETE staff, National Association for the Care and Resettlement of Offenders (NACRO) staff and, in a minority of cases, probation service officers. Interviews with some of these staff were useful in providing feedback about the initial assessment procedure for basic skills needs overall, and about the use of specific instruments.

The initial assessment procedure for basic skills needs

The majority of those administering the materials thought that there had been too many assessment tools during the period of the pathfinder evaluation. The prospect of using these instruments as both pre-tests and again, at a later stage, as post-tests to assess progress was seen as unrealistic for the target group. The number of instruments and the time required of prospective learners at each stage was seen as too demanding for those who have had negative experiences at school and are likely to have basic skills below Level 1 . Some felt that the large number of tests was detracting from what they saw as the main aims of identifying people below Level 1 and motivating them to take up tuition, and having to complete five different assessment tools was seen as counterproductive to engaging offenders in learning.

Use of the BSA's Initial Assessment

All those involved in administering the assessment instruments thought that it was essential to have an assessment of basic skills needs which provided tutors with offenders' basic skills levels. However, there were criticisms of the BSA's Initial Assessment. In particular, tutors were disappointed that it identified literacy and numeracy needs but nothing more. Some suggested that speaking and listening skills should be included as part of the assessment, thus identifying the importance and relevance of communication skills. On the positive side, tutors found that the breakdown of literacy into reading, spelling and punctuation was helpful.

The BSA's Initial Assessment consisted of two-stage assessments, the second more difficult than the first. Most tutors commented that it was off-putting for an individual with very low skills to complete two assessments for each skill. Some thought the second assessment was too difficult for most people with basic skills needs and that timing individuals as they completed the assessment put them under too much pressure with the result that their responses were potentially misleading. Many also thought that the BSA's Initial Assessment would be likely to remind offenders of school. 
Use of the additional background information form

The basic tutors generally thought the additional background information form was useful in at least some aspects, particularly because it provided a focus around which a discussion with a potential learner could take place. Such discussion was useful at the time that the additional background information form was being completed because it became the basis for an ongoing conversation with the learner. The interview for the completion of the additional background information form also offered the opportunity to reassure a potential learner about the nature of the basic skills provision being offered and even to provide 'a taster' of basic skills tuition.

Use of the other tools in the basic skills procedure for basic skills needs

Three of the instruments used at the initial assessment procedure for basic skills, Raven's Progressive Matrices, SPSI-R (short-form) and CRIME PICS II, were used to evaluate other outcomes in addition to basic skills progress. Comments about their use illustrate the challenges of introducing new assessment tools. For example, those who administered the Raven's Progressive Matrices commented that offenders responded positively to them because 'it was like a puzzle'; 'no writing was involved'; and 'it was fun'. Comments about SPSI-R (short-form) and CRIME PICS II were essentially negative. Both instruments were seen as time-consuming and as providing little valuable information to basic skills tutors about educational needs. Furthermore, some tutors commented that in some cases, offenders had been unable to complete SPSI-R (short-form), and that, even in cases where offenders had completed SPSI-R (short-form), it was believed that it was unlikely to be an accurate assessment of offenders' social problem-solving skills, as the extent to which they had understood the content was questionable.

\section{Conclusion}

Screening for basic skills needs is a delicate business. People who do not believe that they have basic skills needs may well resent any such suggestion, whilst others may have additional problems that seem of greater concern. Equally, more detailed assessment of basic skills needs involving the use of various instruments may seem daunting or over-bearing. To offset such difficulties the instruments for identifying basic skills needs should be as problem free as possible. The experiences of those in the pathfinder revealed advantages and disadvantages of those tools that were selected.

In addition to providing a shared procedure across each of the pathfinder projects, the screening and assessment tools provided data for the evaluation. These tools were used to provide a baseline of the potential level of basic skills need among offenders who went through the PSR process, and a profile of their demographic characteristics and criminological, educational and employment histories. The analysis of the data obtained from the screening and assessment tools together with other data collected is discussed in the next chapter. 


\section{Profile of offenders with basic skills needs}

This chapter in the report summarises the findings from the analysis of quantitative data collected during both the screening stage and the initial assessment procedure for basic skills needs of the Basic Skills Pathfinder evaluation. These data were analysed, primarily, in order to learn more about the scale of basic skills needs among offenders, the nature of their basic skills needs and other characteristics of offenders with basic skills needs. Altogether, 10,252 cases were analysed.

\section{The scale of basic skills needs among the pathfinder samples}

A description of the samples from which data were drawn provides a breakdown of the analysis and an indication of the proportion of offenders who have, or probably have, basic skills below Level 1 .

\section{The total screening sample}

Baseline data on the offender population in the seven pathfinder areas were drawn from analysis of the FT 20 Qs received $(n=9,061)$. There were 8,138 cases for which both the screening tool and sentence information was received, including both those who were 'positively' screened as likely to have basic skills needs and those who were 'negatively' screened as not likely to have basic skills needs. In the following analysis, this sample is referred to as the total screening sample. Findings from an analysis of this total screening sample are presented in Appendix $\mathrm{F}$.

The 'positively' screened sample

From the total screening sample, 2,570 (32\%) scored more than seven ticks on the FT $20 \mathrm{Q}$ screening tool, indicating that this group were likely to have basic skills below Level 1 . In other words and to use shorthand terminology, they were 'positively' screened, while those who scored seven ticks or less were 'negatively' screened.

\section{The in-depth assessment sample}

More in-depth basic skills data and offender information were collected at the initial assessment procedure for basic skills needs, including the additional background information form $(n=321)$, the BSA's Initial Assessment tool $(n=434)$, Raven's Progressive Matrices $(n=418)$, the SPSI-R (short-form) $(n=345)$, and CRIME PICS II $(n=288)$. Although a smaller number of completed in-depth assessments were received than expected, a sufficient number of each instrument was completed and returned to undertake some analysis (see Table 4.1).

Table 4.1: In-depth assessments received ${ }^{\star}$

\begin{tabular}{|l|l|l|l|l|l|c|}
\hline Pathfinder area & $\begin{array}{l}\text { The BSA's } \\
\text { Initial } \\
\text { Assessment } \\
\text { tool }\end{array}$ & $\begin{array}{l}\text { Raven's } \\
\text { Progressive } \\
\text { Matrices }\end{array}$ & $\begin{array}{l}\text { Additional } \\
\text { background } \\
\text { information } \\
\text { form }\end{array}$ & $\begin{array}{l}\text { SPSI-R } \\
\text { (short- } \\
\text { form) }\end{array}$ & $\begin{array}{l}\text { CRIME } \\
\text { PICS II }\end{array}$ & $\begin{array}{l}\text { Full sets of in- } \\
\text { depth } \\
\text { assessments }\end{array}$ \\
\hline Cornwall & 22 & 22 & 22 & 13 & 12 & 11 \\
\hline Cumbria & 23 & 17 & 17 & 20 & 20 & 8 \\
\hline Dorset & 58 & 59 & 53 & 59 & 59 & 51 \\
\hline Lincolnshire & 115 & 98 & 50 & 84 & 18 & 0 \\
\hline Nottinghamshire & 98 & 119 & 72 & 66 & 70 & 37 \\
\hline Sussex & 17 & 18 & 18 & 18 & 16 & 16 \\
\hline Thames Valley & 101 & 85 & 89 & 85 & 93 & 74 \\
\hline Total & 434 & 418 & 321 & 345 & 288 & 197 \\
\hline
\end{tabular}

* These figures were from records kept by the evaluation team, which may have differed from those submitted by pathfinder areas. 


\section{Two caveats}

It is important to note that the samples (both those who were screened and those who attended the initial assessment procedure for basic skills needs) were not entirely representative of the offending population as a whole. The screened sample was limited to those for whom a court report (either a PSR or a SSR) had been prepared, and it is possible that such offenders are more likely to be sentenced for a more serious offence than those for whom a court report is not completed. PSRs and SSRs are only used when a court requires guidance as to a suitable sentence for the offender, and it is unlikely that in less serious offences (usually summary offences) a court would require a report if it intends to impose a fine or a discharge. Thus, a discrepancy in offence type and sentence for the Basic Skills Pathfinder evaluation screening sample compared to Criminal Statistics - England and Wales 2000 (Home Office, 2000b) could possibly be attributed to the sampling method used for the Basic Skills Pathfinder evaluation, i.e. collecting data on offenders for whom a PSR was written.

Another caveat to be borne in mind when interpreting these findings is that not all those who were 'positively' screened and who got a CRO/CPRO were referred for - or arrived for - the more in-depth testing of basic skills needs at the initial assessment procedure for basic skills needs. In theory, all of these individuals $(n=1,003)$ should have been referred to the initial assessment procedure for basic skills needs. However, only $194(19 \%)$ partial or full sets of in-depth assessment instruments were received by the evaluation team for this group, i.e. the target group for the Basic Skills Pathfinder projects. As part of these 194 in-depth assessments, the evaluation team received 156 completed BSA's Initial Assessment tools, i.e. of the 1,003 cases assessed as having a probable basic skills need at the PSR stage and who were sentenced to a CRO or a CPRO, there is evidence of only 156 (16\%) subsequently having a more in-depth assessment of their basic skills needs. The extent and possible causes of this attrition are discussed in Chapter 6.

\section{The nature of offenders' basic skills needs}

Of the 8,138 offenders for whom the FT 20 Q screening tool was received, 2,570 (32\%) scored more than seven ticks on the FT $20 \mathrm{Q}$ screening tool, indicating that this group had probable basic skills below Level 1 . This figure is larger than the estimated 20 per cent of the adult population in the UK who are thought to have serious difficulties with literacy, and in keeping with the higher percentage (from 30\%-50\%) believed to have serious difficulties with numeracy in the general population (DfEE, 1999). An analysis was carried out to test the reliability of the FT 20 Q screening tool (see Appendix E) and the results gave a degree of confidence in the estimates of the prevalence of basic skills needs amongst offenders screened at PSR stage using the FT 20 Q screening tool. ${ }^{4}$

There were 434 individuals assessed by the BSA Initial Assessment Tool (though not all of these had been previously screened - see Chapter 6). For the purposes of analysis, scores from below Entry Level to at Entry Level were combined to 'below Level 1' and scores from Level 1 to above Level 1 were combined to 'at or above Level 1'. The results are summarised in Table 4.2 below.

\footnotetext{
${ }^{4}$ The analysis showed that only nine per cent of the offenders who were screened 'positive' with the FT 20 Q screening tool were 'false positives'.
} 
Table 4.2: The BSA's Initial Assessment tool results*

\begin{tabular}{|l|l|l|}
\hline Section of the BSA's Initial Assessment tool & Below Level 1 ** & At or above Level 1 \\
\hline Reading $(n=507)$ & $211(42 \%)$ & $296(58 \%)$ \\
\hline Spelling $(n=507)$ & $332(67 \%)$ & $175(33 \%)$ \\
\hline Punctuation $(n=507)$ & $342(68 \%)$ & $165(32 \%)$ \\
\hline Literacy $(\text { combined } n=297)^{\star \star \star}$ & $190(64 \%)$ & $107(36 \%)$ \\
\hline Numeracy $(n=510)$ & $225(44 \%)$ & $285(56 \%)$ \\
\hline
\end{tabular}

*Dorset Probation Area provided the evaluation team with a number of copies of the BSA's Initial Assessment tool which had been completed with offenders on a CPO, but who were not strictly Basic Skills Pathfinder evaluation offenders. These BSA Initial Assessment tools were also included in the database for analysis.

$\star \star T h e$ percentage values in this column are the percentage of cases within each section.

*** The number of offenders for whom a combined literacy score was available was lower than that for a combined numeracy score. This is because literacy, on the BSA's Initial Assessment tool, is broken into three sections: reading, spelling and punctuation. Therefore, when combining the scores on these sections for a combined literacy score, offenders' scores were included only if they scored the same level on all three sections.

When the scores for the literacy sections (reading, spelling and punctuation) on the BSA's Initial Assessment tool were combined to provide an overall literacy level for each offender, 64 per cent of the sample scored below Level 1 and 36 per cent scored at or above Level 1 in literacy. For the numeracy section of the BSA's Initial Assessment tool, 44 per cent scored below Level 1 and 56 per cent at or above Level 1. Therefore, the evidence suggests that, in the sample of offenders who attended the initial assessment procedure for basic skills needs, more offenders had problems with literacy than numeracy. Furthermore, when the scores on the numeracy section were dichotomised for below and above Entry Level (Entry is regarded as functional numeracy), only eight per cent scored below Entry Level. ${ }^{5}$

As part of initial assessment procedure for basic skills needs, offenders were asked to complete one of two forms of Raven's Progressive Matrices. A total of 391 completed Raven's Progressive Matrices were received and scored from the seven pathfinder areas. The scores were then used to classify offenders using the procedures set out in the manual (Raven et al., 2000). Of the 391 cases for which there were data, four (1\%) were classified as 'above average', 59 (15\%) were classified as 'intellectually average', $163(42 \%)$ were classified as 'definitely below intellectually average' and $165(42 \%)$ were classified as 'intellectually impaired'. Of the 208 cases who were sentenced to a CRO or a CPRO and for whom there was a Raven's score, $32(16 \%)$ were classified as 'intellectually average' and above, 98 (47\%) 'definitely below intellectually average' and 76 (37\%) were classified as 'intellectually impaired'. Overall, the scores derived from Raven's Progressive Matrices suggest that, of those offenders assessed at initial assessment procedure for basic skills needs, 84 per cent were 'below intellectually average' (including $42 \%$ 'definitely below intellectually average' and $42 \%$ 'intellectually impaired') while a few were 'intellectually average' $(15 \%)$ or above $(1 \%)$.

\section{Correlates and characteristics of offenders with basic skills needs}

Comparison of the 'positively screened sample' against the 'total screening sample' provided useful information on the correlates and characteristics of offenders with such basic skills needs. (More detailed description of the analysis of the 'total screening sample' is given in Appendix F.)

\section{Distribution of probable basic skills need by sentence}

Table 4.3 shows the numbers and proportion of offenders who were 'positively' and 'negatively' screened, broken down by sentence. A significantly higher proportion of those who were sentenced to a CRO or a CPRO (36\%), custody (35\%) and other types of sentence (32\%) screened 'positively', compared to those who were sentenced to CPOs (23\%). Indeed, given sampling error, the prevalence of basic skills needs in the CPO population, based on

\footnotetext{
${ }^{5}$ The FT 20 Q screening tool was designed to provide an indication of literacy needs below Level 1 and numeracy needs below Entry Level although the levels measured by the FT $20 \mathrm{Q}$ screening tool were in use before the adjustments to the basic skills levels were made.
} 
this screening data, does not appear to be significantly different from the estimates for the adult population of the UK. Given that a higher proportion of the CPO population are employed or more educated (Rex et al., 2002), this lends further credibility to the FT 20 Q screening tool as a suitable screening tool. Furthermore, the levels of probable basic skills needs amongst offenders who were sentenced to either a custodial sentence, a CRO, or a CPRO, were of the same order of magnitude as reported in studies cited in Chapter 1 . The conclusion seems clear: there are very likely to be increased levels of basic skills needs amongst offenders sentenced to a CRO or a CPRO, the target group for the Basic Skills Pathfinder evaluation, compared to the general population.

Table 4.3: Scores on the FT 20 Q broken down by sentence type

\begin{tabular}{|l|l|c|}
\hline \multirow{2}{*}{ Sentence type } & \multicolumn{2}{|l|}{ The FT 20 Q Screening tool scores } \\
\cline { 2 - 3 } & At or above Level 1 & Below Level 1 \\
\hline Custody & $1,480(65 \%)$ * & $782(35 \%)$ \\
\hline CRO/CPRO & $1,799(64 \%)$ & $1,003(36 \%)$ \\
\hline CPO & $1,591(77 \%)$ & $481(23 \%)$ \\
\hline Other & $698(70 \%)$ & $304(30 \%)$ \\
\hline Total & $5,568(68 \%)$ & $2,570(32 \%)$ \\
\hline
\end{tabular}

*The percentage values in parentheses are the percentage of cases within each sentence type.

\section{Gender}

Table 4.4 shows the gender composition of those who were sentenced to a CRO or a CPRO and who screened 'positively'. The vast majority of the cases (83\%) were male, and significantly more males (36\%) than females (31\%) screened 'positively'.

Table 4.4: The FT 20 Q scores of men and women sentenced to a CRO or CPRO

\begin{tabular}{|l|c|c|}
\hline \multirow{2}{*}{ Gender } & \multicolumn{2}{|l|}{ The FT 20 Q screening tool scores } \\
\cline { 2 - 3 } & Below Level 1 (\%)* & Total \\
\hline Female & $149(31 \%)$ & $477(17 \%)$ \\
\hline Male & $851(36 \%)$ & $2,314(83 \%)$ \\
\hline Total & $1,000(36 \%)$ & 2,791 \\
\hline
\end{tabular}

*The percentage values in this column are the percentage of cases within each gender.

A comparison of the rate of attendance of men and women referred to the initial assessment procedure for basic skills needs, who were sentenced to a CRO or a CPRO, and who had also been screened 'positively', was made based upon the in-depth assessment data received from the pathfinder areas. These data provided some weak evidence that women were more likely to attend the initial assessment procedure for basic skills needs than men were, but the result was not statistically significant. ${ }^{6}$ Men and women were equally likely to complete the BSA's Initial Assessment tool. Thus, gender does not seem to play any major role in determining whether an offender will attend the initial assessment procedure for basic skills needs and complete the instruments. Rather, men and women appeared to have an equally poor chance of receiving any further assessment for basic skills needs that were indicated by the results of the FT $20 \mathrm{Q}$ screening tool at the PSR stage.

\section{Age distribution}

The association between age and probable basic skills needs, as assessed by the FT $20 \mathrm{Q}$ screening tool, is shown in Table 4.5 for all offenders in the screening sample. Clearly, the proportion of those with probable basic skills below Level 1 declined significantly ${ }^{7}$ with age in this cross-sectional sample. Indeed, those aged between 18 and 25 were more likely to have a basic skills need than those aged over 25 were, with the younger, 18-to 20-year-old age

\footnotetext{
${ }^{6}$ Chi-square $=3.34$, d.f. $=1, p=0.69$.

Chi-square $=186.9$, d.f. $=5, p<0.001$.
} 
group, having the greatest likelihood of having a basic skills need. However, the interpretation of this result is not that standards of literacy and numeracy teaching and learning have declined in recent years; rather, it is more likely to be due to the changing nature and composition of the offenders in different age groups.

Table 4.5: The association between age and probable basic skills needs for all offenders in the sample

\begin{tabular}{|l|c|l|}
\hline \multirow{2}{*}{ Age group (years) } & FT 20 Q Score & Age group (years) \\
\cline { 2 - 3 } & Below Level 1* & Total \\
\hline $18-20$ & $706(44 \%)$ & $1,603(19 \%)$ \\
\hline $21-25$ & $733(33 \%)$ & $2,193(26 \%)$ \\
\hline $26-30$ & $446(28 \%)$ & $1,615(19 \%)$ \\
\hline $31-40$ & $552(27 \%)$ & $2,078(24 \%)$ \\
\hline $41-50$ & $200(25 \%)$ & $799(9 \%)$ \\
\hline $51+$ & $68(21 \%)$ & $321(4 \%)$ \\
\hline Total & $2,705(31 \%)$ & 8,609 \\
\hline
\end{tabular}

*The percentage values in this column are the percentage of cases within each age group.

In the screening sample, there were data on 959 offenders who were sentenced to a CRO or a CPRO and who scored below Level 1 on the FT 20 Q screening tool, i.e. were eligible for referral to the initial assessment procedure for basic skills needs, and for whom data were also available on their ages. Of these 959 cases, 238 (25\%) were aged 18 to 20 years. In total, 184 offenders out of the eligible 959 attended the initial assessment procedure for basic skills needs. However, 18-to 20-year-olds constituted 33 per cent of the cases (60 out of 184) for which the pathfinder areas produced data from this procedure. Based on these data, offenders in the youngest age group were significantly ${ }^{8}$ more likely to attend the initial assessment procedure for basic skills needs than older offenders were. This suggests that the age of offenders cannot be used as an explanation for the low rate of referral to the initial assessment procedure for basic skills needs of those with probable basic skills needs. Why more young people attended the initial assessment procedure for basic skills needs than was expected based on the data remains unexplained, but could be due to extra guidance from probation staff or better motivation on the part of the young.

\section{Ethnicity}

There is some evidence to suggest that those who were assessed as being Indian during the screening stage were also less likely to score below Level 1 on the FT 20 Q screening tool at the PSR stage, but there were no other significant differences between the other ethnic groups. There were no significant differences between the proportions of different ethnic groups for whom the pathfinder areas provided data from the initial assessment procedure for basic skills needs: members of different ethnic groups were equally as likely not to attend the initial assessment procedure for basic skills needs.

\section{Accommodation}

The potential importance of the relationships between accommodation status, sentence and the pathfinder area an offender was supervised in lies in the significant association ${ }^{9}$ between the scores on the FT 20 Q screening tool and the type of accommodation being inhabited by an offender who was sentenced to a CRO or a CPRO, as shown in Table 4.6. Owner occupiers were significantly less likely to score below Level 1 on the FT 20 Q screening tool than other groups. However, those offenders who were living with family, friends or others, proportionately the second largest group of offenders sentenced to a CRO or a CPRO (see Table 4.6), were significantly more likely to score below Level 1 on the FT 20 Q screening tool.

\footnotetext{
${ }^{8}$ Chi-square $=12.6$, d.f. $=5, p=0.03$. The adjusted residual for the 18 - to 20 -year-olds attending the initial assessment procedure for basic skills needs is ${ }^{2}$ Chi-square $=28.5$, d.f. $=5, p<0.001$.
} 
Table 4.6: The association between an offender's score on the FT 20 and their accommodation status for those offenders sentenced to a CRO or a CPRO

\begin{tabular}{|l|l|c|}
\hline The FT 20 Q screening tool score & Below Level 1 * & Total \\
\hline Owner Occupied & $37(4 \%)$ & $198(8 \%)$ \\
\hline Tenant & $393(43 \%)$ & $1,091(42 \%)$ \\
\hline B\&B, lodging or hotel & $17(2 \%)$ & $48(2 \%)$ \\
\hline Unit or hostel & $29(3 \%)$ & $70(3 \%)$ \\
\hline Family, friends or others & $393(43 \%)$ & $1,033(40 \%)$ \\
\hline Other & $55(6 \%)$ & $156(6 \%)$ \\
\hline Total & 924 & 2,596 \\
\hline
\end{tabular}

*The percentage values in this column are the percentage of cases within accommodation type.

\section{Domestic circumstances}

There were no significant associations between domestic circumstances and probable basic skills needs or attendance at the initial assessment procedure for basic skills needs. ${ }^{10}$

\section{Alcohol and drug abuse}

There was a significant association between alcohol and drug abuse and probable basic skills need in the overall screening sample, ${ }^{11}$ but not amongst those subsequently sentenced to a CRO or a CPRO. ${ }^{12}$ There was, however, a significant association between attendance at the initial assessment procedure for basic skills needs and alcohol and drug abuse, for those both sentenced to a CRO or a CPRO who screened 'positively'. ${ }^{13}$ Those who were judged to have neither an alcohol nor drug abuse problem were significantly more likely to have received a further, in-depth assessment of their basic skills needs, when compared to those who were considered to be abusing either drugs, or both alcohol and drugs. However, there was no association between those judged to be abusing alcohol and attendance at the initial assessment procedure for basic skills needs. Whether this association was the product of a less stable lifestyle amongst drug users, or because drug users were more likely to be referred to drug treatment programmes, rather than the basic skills programmes, cannot be ascertained from this data set.

More detailed information was collected on alcohol and drug abuse on the additional background information form (see Table 4.7). More offenders reported that they were abusing alcohol than drugs at the initial assessment procedure for basic skills needs. ${ }^{14}$

\section{Table 4.7: Alcohol and drug abuse of offenders in the in-depth assessment sample}

\begin{tabular}{|l|l|l|l|}
\hline Substance & No (\%) & Occasionally ${ }^{\star *}$ & Regularly \\
\hline Cocaine & $285(95)$ & $12(4)$ & $4(1)$ \\
\hline Ecstasy & $269(89)$ & $30(10)$ & $3(1)$ \\
\hline Hallucinogens & $295(97)$ & $7(2)$ & $1(1)$ \\
\hline Opiates/ heroin & $276(92)$ & $11(4)$ & $12(4)$ \\
\hline Amphetamines & $282(93)$ & $13(4)$ & $7(3)$ \\
\hline Barbiturates & $294(98)$ & $3(1)$ & $2(1)$ \\
\hline Cannabis & $203(68)$ & $49(17)$ & $44(15)$ \\
\hline Benzodiazepines & $296(98)$ & $4(1)$ & $2(1)$ \\
\hline Steroids & $299(99)$ & $2(1)$ & $1(-)$ \\
\hline Solvents & $298(99)$ & $2(1)$ & $1(-)$ \\
\hline Alcohol & $139(46)$ & $97(30)$ & $72(24)$ \\
\hline
\end{tabular}

*The percentage values in parentheses are the percentage of cases within each substance.

${ }^{\star *}$ Classified as less than once a month.

\footnotetext{
${ }^{10}$ Chi-square $=5$, d.f. $=6, p=0.5 ;$ Chi-square $=3.9$, d.f. $=6, p=0.69$ respectively.

${ }_{11}^{11}$ Chi-square $=45$, d.f. $=3, p<0.001$.

Chi-square $=6.3$, d.f. $=3, p=0.097$

Chi-square $=22.5$, d.f. $=3, p<0.001$

${ }^{14}$ For a recent survey of offenders and drug use (arrestees in custody suites), see the NEW-ADAM Project (Bennett, 2000). For assessment of drugs and alcohol issues at PSR stage, see Emerging ACE Data (Merrington, 2001).
} 
Health

Offenders were also asked about health issues at the initial assessment procedure for basic skills needs. As Table 4.8 indicates, the proportion of offenders in this sample who had health problems was, for the most part, small. This was with the exception of emotional difficulties (25\% had emotional difficulties previously, and $20 \%$ had current emotional difficulties), and hearing and sight problems (10\% and 13\% respectively previously, and $10 \%$ and $16 \%$ respectively currently). It may be possible that hearing and sight problems affected an offender's ability to learn previously, or would continue to do so currently. Interestingly, 25 per cent of offenders in the in-depth assessment sample had previous head injuries which, according to basic skills tutors, may also have had an impact on these offenders' ability to learn. Twelve per cent of the offenders who attended the initial assessment procedure for basic skills needs reported that they had suffered from a chronic or serious illness at some point in their lives. In addition, 25 per cent reported that they needed to wear spectacles, while only 15 per cent reported that they actually did wear spectacles.

Table 4.8: Health of offenders in the in-depth assessment sample

\begin{tabular}{|l|l|l|}
\hline Health issue & Previously & Currently \\
\hline Head injuries $(\mathrm{n}=299)$ & $74(25 \%)$ & $11(4 \%)$ \\
\hline Epilepsy $(\mathrm{n}=296)$ & $17(6 \%)$ & $10(4 \%)$ \\
\hline Emotional difficulties $(\mathrm{n}=296)$ & $73(25 \%)$ & $60(20 \%)$ \\
\hline Mental health (diagnosed) $(\mathrm{n}=293)$ & $24(8 \%)$ & $21(7 \%)$ \\
\hline Speech problems $(\mathrm{n}=301)$ & $26(9 \%)$ & $14(5 \%)$ \\
\hline Hearing problems $(\mathrm{n}=300)$ & $31(10 \%)$ & $29(10 \%)$ \\
\hline Sight problems $(\mathrm{n}=298)$ & $40(13 \%)$ & $49(16 \%)$ \\
\hline
\end{tabular}

*The percentage values in parentheses are the percentage of cases within each health issue.

\section{Schooling and qualifications}

There were also strong associations between an offender's probable basic skills needs, the qualifications they held, and their pattern of school attendance. ${ }^{15}$ For example, half of the 1,314 individuals with no qualifications had a probable basic skills need, compared to just ten per cent of those with Level 2 qualifications. Of the 1,175 offenders who were classified as attending school regularly, 295 (25\%) screened 'positively'. By contrast, of the 1,075 offenders who were classified as attending school irregularly, 514 (48\%) screened 'positively'.

There was also a significant association between an offender's pathfinder area and the level of qualifications s/he held. ${ }^{16}$ For example, offenders in Cumbria and Nottinghamshire Probation Areas $^{17}$ were significantly more likely to have no qualifications compared with offenders in other areas, whilst those in Dorset, Sussex and Thames Valley Probation Areas were significantly less likely to have no qualifications compared with offenders in other areas. ${ }^{18} \mathrm{~A}$ possible reason for this might have been that the pattern of school attendance varied between the pathfinder areas, but there was no significant association between pathfinder areas and school attendance for those sentenced to a CRO or a CPRO. ${ }^{19}$

Finally, there was an association between school attendance and the receipt of data from the initial assessment procedure for basic skills needs; irregular school attendees were significantly less likely to have completed this procedure, when compared to regular school attendees. ${ }^{20}$ If a history of poor school attendance is accepted as evidence of poor motivation towards formal learning, then this could provide at least part of the explanation of why so few of those assessed as having a probable basic skills need during screening then received the

\footnotetext{
${ }^{15}$ Chi-square $=305$, d.f. $=3, p<0.001 ;$ Chi-square $=126$, d.f. $=1, p<0.001$ respectively.

${ }_{16}^{16}$ Chi-square $=95.2$, d.f. $=18, p<0.001$.

${ }_{17}^{17}$ Adjusted residuals 6 and 3.4 respectively.

${ }_{11}^{18}$ Adjusted residuals $-3.2,-2.1$ and -4.1 respectively.

${ }^{19}$ Chi-square $=11.4$, d.f. $=6, p=0.075$.

${ }^{20}$ Chi-square $=5.7$, d.f. $=1, p=0.02$.
} 
in-depth assessment. If so, then this suggests that offender motivation to learn will need to be addressed if referral to basic skills provision is to be more successful.

The data collected on the additional background information form provide a more detailed and valuable insight into the educational experiences, health status and motivation of the offenders who were referred to the initial assessment procedure for basic skills needs. The data collected on the additional background information form also confirm that these offenders had, for the most part, interrupted school experiences. ${ }^{21}$ The majority of this sample attended between two and five schools throughout their school years (see Table 4.9), and over one-quarter left school before age 16. When asked about types of school attended, the majority of offenders $(262,85 \%)$ reported that they attended mainstream school. Within mainstream education, approximately 19 per cent attended special classes, six per cent received Special Educational Needs support, and eight per cent received learning support in a mainstream school.

Table 4.9: Number of schools attended by the in-depth assessment sample ( $n=202)$

\begin{tabular}{|l|l|}
\hline Number of schools attended & Number of offenders \\
\hline One & $2(1 \%)$ \\
\hline Two & $62(31 \%)$ \\
\hline Three & $79(39 \%)$ \\
\hline Four & $33(16 \%)$ \\
\hline Five & $14(7 \%)$ \\
\hline Six or more & $12(6 \%)$ \\
\hline
\end{tabular}

Twelve per cent of offenders reported that they had received a statement of Special Educational Needs while at school. ${ }^{22}$ In the majority of cases, this was for learning difficulties, rather than emotional and behavioural difficulties or physical difficulties. Table 4.10 shows offenders' responses at the initial assessment procedure for basic skills needs to a question asking what, in their perception, affected their education. However, in the absence of objective assessment data, perceptions on learning difficulties and emotional and behavioural difficulties may not be considered to reflect accurately the impact of such factors on these offenders' education.

Table 4.10: Factors which affected offenders' education

\begin{tabular}{|l|c|}
\hline Factor & Number of offenders \\
\hline Learning difficulties & $121(40 \%)$ \\
\hline Emotional and behavioural difficulties & $95(32 \%)$ \\
\hline Family disruption (e.g. parental separation) & $89(30 \%)$ \\
\hline Other factors (e.g. bullying) & $67(22 \%)$ \\
\hline Sight problems & $21(7 \%)$ \\
\hline Speech problems & $12(4 \%)$ \\
\hline Hearing problems & $20(7 \%)$ \\
\hline
\end{tabular}

Table 4.11 compares offenders' ratings of the academic and social experience of school. Unsurprisingly, this indicates that offenders who underwent the in-depth assessment rated their social school experience as having been more positive than their academic school experience. $^{23}$

\footnotetext{
${ }_{21}^{21}$ See chapter 1 for comparison with similar research evidence.

${ }^{22}$ From the interviews with staff, it was found that those who conducted the initial assessment procedure for basic skills needs felt that offenders mightnot always remember whether they had been statemented on the Special Educational Needs register. Therefore, this figure of 12 per cent may possibly have been higher and should therefore be treated with caution.

${ }^{23}$ See section 1.4.2. above for comparison with similar research evidence.
} 
Table 4.11: Views of school experience

\begin{tabular}{|l|l|l|}
\hline View & Academic experience $(n=302)$ & Social experience $(n=300)$ \\
\hline Very positive & $14(4 \%)$ & $69(23 \%$ \\
\hline Positive & $42(14 \%)$ & $86(29 \%)$ \\
\hline Okay & $105(35 \%)$ & $93(31 \%)$ \\
\hline Negative & $69(23 \%)$ & $28(9 \%)$ \\
\hline Very negative & $72(24 \%)$ & $24(8 \%)$ \\
\hline
\end{tabular}

Although many offenders reported that they had difficulties with reading and writing while at school, but were motivated to improve reading and writing while at school, fewer reported that they had someone to help them with this. Those who had help reported that teachers, Special Educational Needs support, parents, friends and tutors were instrumental in helping them to improve their literacy skills. Similarly, although many had problems with numeracy in school and wanted to improve their numeracy skills, fewer had someone to help them. Since leaving school, many offenders reported that they had continued to have problems with literacy and numeracy and had wanted to improve these skills. However, once again, many had not received any help with this.

\section{Risk of reconviction}

Risk of reconviction amongst offenders sentenced to a CRO or a CPRO was also significantly associated with probable basic skills need as assessed by the FT 20 Q screening tool. Offenders sentenced to a CRO or a CPRO were significantly more likely to score below Level 1 on the FT 20 Q screening tool if they were in a 'high' risk compared to a 'low' risk group. ${ }^{24}$ 'High' risk offenders were also significantly more likely to have no qualifications and to have had poorer school attendance compared to offenders in the 'low' risk category, ${ }^{25}$ and to be judged as abusing drugs or both drugs and alcohol. Examining the data for those offenders who were sentenced to a CRO or a CPRO and screened 'positively' shows that offenders in the 'high' risk group were significantly more likely to be unemployed than those in the 'low' risk group. But, significantly more in-depth assessments were received on 'low' risk offenders compared to 'high' risk offenders. ${ }^{26}$

\section{Employment}

Table 4.12. shows the employment status of offenders broken down by pathfinder area for the whole of the screening sample. The overall unemployment rate of 38 per cent among offenders in the screening sample was very high compared with the total United Kingdom International Labour Organisation unemployment rate of 4.9 per cent recorded by the Labour Force Survey in 2001 (DfES, 2001a). There were also significant variations in unemployment rates between the pathfinder areas. ${ }^{27}$ For example, offenders were significantly more likely to be unemployed in Lincolnshire and Nottinghamshire Probation Areas than in other pathfinder areas, ${ }^{28}$ but significantly more likely to be employed in Dorset, Sussex and Thames Valley Probation Areas. ${ }^{29}$ This can be explained partly by the difference in labour markets between the pathfinder areas, and the continuing decline in the number of manual jobs in areas such as agriculture, mining and manufacturing.

\footnotetext{
${ }^{4}$ Adjusted residuals 4.5 and -5.2 respectively.

${ }^{25}$ Chi-square $=80.9$, d.f. $=6, p<0.001 ;$ Chi-square $=20.4$, d.f. $=2, p<0.001$

${ }^{26}$ Chi-square $=12$, d.f. $=2, p=0.003$.

${ }^{27}$ Chi-square $=127.1$, d.f. $=6, p<0.001$

${ }^{28}$ Adjusted residuals 3.9 and 8.1 respectively.

${ }^{29}$ Adjusted residuals $4.3,3.5$ and 7 respectively.
} 
Table 4.12: Employment status of offenders in the screening sample, broken down by pathfinder area

\begin{tabular}{|c|c|c|c|c|c|c|}
\hline Pathfinder area & Employed & Unemployed & $\begin{array}{l}\text { Education } \\
\text { and } \\
\text { training }\end{array}$ & $\begin{array}{l}\text { Incapacity } \\
\text { Benefit }\end{array}$ & Other & Total \\
\hline Cornwall & $68(27 \%)$ & $88(35 \%)$ & $8(3 \%)$ & $39(16 \%)$ & $47(19 \%)$ & 250 \\
\hline Cumbria & $230(36 \%)$ & $253(40 \%)$ & $12(2 \%)$ & $107(17 \%)$ & $31(5 \%)$ & 633 \\
\hline Dorset & $478(37 \%)$ & $380(30 \%)$ & $25(2 \%)$ & $266(21 \%)$ & $136(11 \%)$ & 1,285 \\
\hline Lincolnshire & $442(33 \%)$ & $581(43 \%)$ & $22(2 \%)$ & $116(9 \%)$ & $191(14 \%)$ & 1,352 \\
\hline Nottinghamshire & $832(33 \%)$ & $1,184(47 \%)$ & $53(2 \%)$ & $246(10 \%)$ & $198(8 \%)$ & 2,513 \\
\hline Sussex & $529(35 \%)$ & $450(30 \%)$ & $26(2 \%)$ & $212(14 \%)$ & $288(19 \%)$ & 1,505 \\
\hline Thames Valley & $823(42 \%)$ & $619(32 \%)$ & $28(1 \%)$ & $163(8 \%)$ & $320(16 \%)$ & 1,953 \\
\hline Total & $3,402(36 \%)$ & $3,555(38 \%)$ & $174(2 \%)$ & $1,149(12 \%)$ & $1,211(13 \%)$ & 9,491 \\
\hline
\end{tabular}

*The percentage values in parentheses are the percentage of cases within each area.

When the unemployment rate for those sentenced to a CRO or a CPRO was examined, a slightly different picture emerged. Offenders with this sentence were still more likely to be unemployed in Lincolnshire and Nottinghamshire Probation Areas, but offenders in Cornwall Probation Area who were sentenced to a CRO or a CPRO were also more likely to be unemployed compared to offenders in other pathfinder areas. ${ }^{30}$ Offenders sentenced to a CRO or a CPRO in Dorset, Sussex and Thames Valley Probation Areas were still all more likely to be employed compared to offenders in other pathfinder areas. ${ }^{31}$

Employment status for those on a CRO or a CPRO was also significantly associated with probable basic skills needs, holding a qualification, school attendance, alcohol and drug abuse, and risk of reconviction. ${ }^{32}$ Those who were screened 'positively', those with no qualifications or Level 1 qualifications, and offenders judged to be abusing drugs or both drugs and alcohol, were all significantly more likely to be unemployed as were those who had the highest risk of reconviction. ${ }^{33}$

Men were more likely to be employed than women amongst those sentenced to a CRO or a CPRO. ${ }^{34}$ The data on ethnicity were too sparse to come to any definite conclusions about an association with employment. Collapsing distinctions between black offenders and offenders of Indian, Pakistani and Bangladeshi origin would not be justified as it may obscure important cultural and social differences between groups. The indications are that for those sentenced to a CRO or a CPRO, there is some evidence that those described as Black Other were more likely to be unemployed than other groups, but there were no important differences between the likelihood of unemployment and ethnicity for other groups. An analysis using the complete screening sample provided no evidence of any association between ethnicity and employment status.

There was also a significant association between the age of an offender sentenced to a CRO or a CPRO and their employment status. ${ }^{35}$ Thus, those aged 26 to 30 years were more likely to be unemployed than other age groups of offenders, ${ }^{36}$ while those aged over 40 were more likely to be employed. As was indicated earlier, being judged to be a drug abuser was negatively associated with employment. Interestingly, offenders aged between 26 and 30 , i.e. those who were more likely to be unemployed, were also more likely to be judged as abusing drugs than other offenders, whilst those aged above 40 were the least likely to be judged as abusing drugs, or both drugs and alcohol.

The data received on employment on the additional background information form make it difficult to estimate how many offenders were employed at the time of their in-depth assessment. However, the data on employment status from the PSR stage for these offenders show that approximately 38 per cent (of 168) of offenders, for whom the additional

\footnotetext{
${ }^{30}$ Adjusted residuals $4.3,3$ and 2.5 respectively.

${ }^{31}$ Adjusted residual $3.5,3.2$ and 4.1 respectively.

${ }^{32}$ Chi-square $=25.2$, d.f. $=1, p<0.001 ;$ Chi-square $=34.7$, d.f. $=3, p<0.001 ;$ Chi-square $=33.1$, d.f. $=1, p<0.001 ;$ Chi-square $=203.6$, d.f. $=3, p<0.001 ;$

Chi-square $=115.1$, d.f. $=2, p<0.001$ respectively.

${ }_{33}$ Adjusted residuals $5,5.6,11.5,5.1$ and 8.8 respectively.

${ }^{34}$ Chi-square $=16.5$, d.f. $=1, \mathrm{p}<0.001$.

${ }^{35}$ Chi-square $=16.7$, d.f. $=5, \mathrm{p}=0.005$.

${ }^{36}$ Adjusted residual 2.
} 
background information form was received, reported that they were employed at the PSR stage. Caution is urged with this estimate for two reasons: employment status may have altered for offenders between the PSR and the initial assessment procedure for basic skills needs, and employment status on the background information form (i.e. at the PSR stage) was not available for all offenders for whom an additional background information form was received. On the additional background information form, the majority of offenders reported that they had or had had manual, largely unskilled jobs, for example labouring, cleaning, factory work, driving, gardening, catering, caring, retail, packing, or painting and decorating. Interestingly, over half of the sample who completed the additional background information form reported that they had never been dismissed from any employment and those who had been dismissed, had been so very few times. Many offenders also reported that they possessed useful job related skills, for example, labouring, mechanics, carpentry, electrics, hairdressing, painting and decorating, or plumbing. ${ }^{37}$

Seventy-two per cent of offenders who were unemployed (172) at the initial assessment procedure for basic skills needs expressed a wish to find a job, ${ }^{38}$ and 45 per cent of offenders who were employed (99) expressed a wish to find a better a job. ${ }^{39}$ In addition, although few offenders reported that they wished to help others with literacy and numeracy, many recognised that they needed to improve their own basic skills and expressed a wish to do so.

\section{Problem-solving}

An analysis was carried out of the data collected via completion of SPSI-R (short-form). The SPSI-R (short-form) consists of five subscales:

Positive Problem Orientation (PPO)

A constructive problem-solving cognitive set that involves the belief that problems can be solved with time, effort, commitment and persistence.

Negative Problem Orientation (NPO)

A dysfunctional cognitive-emotional set which involves the belief that problems are unsolvable, threatening and frustrating.

Rational Problem Solving (RPS)

A constructive dimension defined as the rational, systematic and efficient application of effective problem-solving skills.

Impulsivity/ Carelessness Style (ICS)

A dysfunctional dimension characterised by impulsive, careless and haphazard attempts to apply problem-solving strategies.

Avoidance Style (AS)

A dysfunctional dimension characterised by procrastination, passivity and dependence on others to solve problems. (Maydeu-Olivares et al., 1996)

The scores on the subscales of SPSI-R (short-form) are combined into a total score for analysis ranging from zero to 20. Higher scores on SPSI-R (short-form) indicate 'good' social problem-solving skills while lower scores indicate 'poor' social problem-solving skills. The mean score for offenders on SPSI-R (short-form) suggests that the majority of offenders in the Basic Skills Pathfinder evaluation had intermediate level social problem-solving skills.

\section{Attitudes to crime}

An analysis was carried out of the returned CRIME PICS II questionnaires in order to construct a profile of attitudes to crime held by those who participated in the initial assessment. CRIME PICS II consists of five subscales:

Scale G: measures offenders' general attitude to offending where a low score indicates a belief that offending is not an acceptable way of life.

\footnotetext{
${ }^{37}$ See chapter 1 for comparison with similar research evidence.
${ }_{33}(15 \%)$ reported that they did not want to find a job, and $18(8 \%)$ reported that they were indifferent.

${ }^{39}$ To this, 38 (38\%) of offenders said they did not want a better job, and $16(17 \%)$ were indifferent.
} 
Scale A: measures offenders' anticipation of reoffending where a low score indicates a resolve not to reoffend.

Scale V: measures offenders' denial of victim hurt where a low score indicates an acceptance that offending does have an adverse effect on the victim.

Scale E: measures offenders' evaluation of crime as worthwhile where a low score indicates an acceptance that the costs of crime outweigh the benefits.

Scale P: measures offenders' perception of current life problems where a lower score suggests that there are less problem areas identified by the offender (Frude et al., 1994).

Scores on each scale of CRIME PICS II range from zero to nine. The higher the scores on CRIME PICS II, the higher are the levels of attitudes and beliefs believed to be favourable to offending. In addition, a high score on the $\mathrm{P}$ scale indicates that an offender identified a high level of problems potentially associated with offending (Raynor and Vanstone, 1997). The results from CRIME PICS II indicated that, as the scores on the five scales were low, these offenders did not hold particularly severe attitudes to offending and had fewer current life problems associated with offending.

Table 4.13: Mean scores on CRIME PICS II ( $n=288)$

\begin{tabular}{|l|l|l|}
\hline CRIME PICS II scale & Mean scores & Standard deviation (SD) \\
\hline General attitude to offending (G) & 2.58 & 2.80 \\
\hline Anticipation of reoffending (A) & 3.68 & 2.83 \\
\hline Victim hurt denial (V) & 3.71 & 2.82 \\
\hline Evaluation of crime as worthwhile (E) & 3.33 & 2.66 \\
\hline Perception of current life problems (P) & 5.03 & 2.65 \\
\hline
\end{tabular}

\section{How are basic skills needs related to unemployment and other variables?}

Given the potential complexity of the interactions between all of the variables investigated above, a multivariate approach, employing logistic regression, was adopted to further analyse patterns of association between key explanatory variables such as gender, substance abuse and educational attainment, and two key response variables: employment status and 'positive' screening for basic skills needs.

Logistic regression allows for the examination of the association between one explanatory variable such as gender or school attendance, and the outcome variable of interest, whilst controlling for the effects of all the other variables. The strength of the association between different explanatory variables and the response variable of interest can then be assessed. While this does not imply causation, e.g. that poor school attendance causes unemployment, it does allow a more detailed examination of the patterns of associations between explanatory and response variables to be made. The strength of any association is indicated by the size of the odds ratio and these are detailed in Appendix $\mathrm{H}$. Each analysis was run twice: first, for the total screening sample and secondly, for only those sentenced to a CRO or a CPRO.

\section{Strength of association between employment status and other variables}

The following explanatory variables were used: age, gender, the FT 20 Q screening tool score, school attendance, highest level of qualification achieved, alcohol and drug abuse, and risk of reconviction. On their own, all of these variables had significant associations with employment status for the total screening sample.

Controlling for the effects of all the other variables, the probability of being unemployed was positively associated with:

- Basic skills needs 
There was a significant and positive association between the probability of being unemployed and being screened as likely to have basic skills need and being unemployed.

- Risk of reconviction

The probability of being unemployed was significantly higher for those in a 'medium' risk category compared with those in a 'low' risk category, and much higher for those in a 'high' risk category compared to those in the 'low' risk category.

In contrast, the probability of being unemployed was negatively associated with:

- Level of qualification achieved

The probability of being unemployed, all other things being equal, decreased as the level of qualification held increased with those having no qualifications being much more likely to be unemployed than those who held Level 2 and Level 3 qualifications.

- School attendance

Those who attended school irregularly were significantly more likely to be unemployed, all other things being equal, compared with those who attended regularly.

The pattern of association between unemployment and some variables was more complicated. Thus, the probability of being unemployed was ambiguously associated with:

- Substance abuse

The pattern of association here is complicated. Compared with offenders who were judged to abuse neither alcohol nor drugs, those judged to abuse alcohol were not significantly more likely to be unemployed. However, those judged to abuse drugs only or to be abusing both alcohol and drugs were significantly more likely to be unemployed, especially those judged to be abusing drugs.

- Age

Again, the pattern of association is complex. Compared to those aged 51 and over, the probability of being unemployed was significantly lower than for those aged 18 to 25 and 31 to 40 . The 26-to 30 -year-olds were also judged to be the most likely to be abusing drugs.

- Gender

Women were significantly more likely to be unemployed than men in the screening sample.

\section{Strength of association between basic skills needs and other variables}

The following explanatory variables were used: age, gender, school attendance, highest level of qualification achieved, alcohol and drug abuse and risk of reconviction. The initial logistic regression analysis using the whole screening sample included all of these explanatory variables and shows that neither gender nor alcohol and drug abuse were significantly associated with the FT 20 Q screening tool scores. These two variables were removed and the logistic regression analysis was rerun. The remaining four variables all had significant associations with the FT 20 Q screening tool scores.

Controlling for the effects of all the other variables, the probability of scoring below Level 1 on the FT 20 Q screening tool was positively associated with:

- Risk of reconviction

All other things being equal the probability of scoring below Level 1 on the FT 20 Q screening tool for those in a 'medium' and 'high' risk group was significantly higher compared to the 'low' risk group.

The probability of scoring below Level 1 on the FT 20 Q screening tool was negatively associated with:

- $\quad$ The highest qualification achieved

Unsurprisingly the probability of scoring below Level 1 on the FT 20 Q screening tool decreased as the level of qualification achieved by an offender increased.

- Regularity of school attendance 
The odds of scoring below Level 1 on the FT 20 Q screening tool were significantly higher for those who attended school irregularly compared to those who attended regularly.

- Age

The youngest age group was the most likely to score below Level 1 on the FT 20 Q screening tool. The likelihood of scoring below Level 1 on the FT 20 Q screening tool decreased with age.

\section{Conclusion}

The analysis of the total screening sample highlighted the following. Thirty-six per cent of offenders who were sentenced to a CRO or a CPRO were screened as being likely to have a basic skills need. In addition, offenders who attended school irregularly were more likely to have basic skills needs, to have lower levels of qualification, to be unemployed, and to be at greater risk of reconviction. There were strong statistical associations between being unemployed and an offender's gender, their patterns of drug and alcohol abuse, their risk of reconviction status and their geographical locations. Whilst it is difficult to ascertain the causes of offender unemployment, the analysis supplied strong evidence of an association between poor basic skills and an increased risk of being unemployed in the offending population. 


\section{The tuition and learning that took place}

This chapter, first, describes the arrangements made to extend learning opportunities once offenders had been identified as having basic skills below Level 1 and as willing to take up provision. Secondly, the progress and outcomes for those who attended for tuition are reviewed. Information about teaching resources and methods was collected during direct observations of teaching and learning, and in-depth interviews with basic skills staff. Given the small number of offenders who attended for basic skills tuition, the progress and outcome data during the period of evaluation were minimal. Therefore interviews with 20 offenders and with tutors were drawn on to assess the impact of the projects for those who accessed basic skills provision during the period of the pathfinder evaluation.

\section{The tuition}

The pathfinder projects targeted, primarily, those offenders whose basic skills were below Level 1 (see Table 1.1). Two of the pathfinder areas (Cornwall and Nottinghamshire Probation Areas) included provision for dyslexia as well as for basic skills. Six of the probation areas used basic skills tutors to teach offenders. Basic skills tutors were employed both within probation and by organisations outside the Probation Service. Thames Valley used mentor volunteers to tutor offenders. The tuition usually took place within probation offices and was principally on a one-to-one basis, though in two pathfinder areas individualised learning took place in a group situation.

\section{Who provided the tuition?}

As part of the Skills for Life (DfEE, 2001) strategy, there is a new qualifications infrastructure for staff involved in basic skills. Prior to this development, the Home Office (Home Office, 2001) suggested that basic skills tutors working within community supervision should be qualified to a minimum of City and Guilds (C\&G) 9281 . Tutors in the pathfinder areas met these minimum requirements. Other qualifications held by tutors included C\&G 9284, C\&G 9285, D 32 and 33 (the Royal Society of Arts' assessors' awards), Bachelor of Education and Post Graduate Certificate in Education. A small minority of tutors either had or were working towards a master's degree.

An important choice that pathfinder areas faced was whether to employ qualified staff to provide tuition or whether tuition should be provided through partnership arrangements. A partnership arrangement was perceived as offering the additional advantage of ready access to basic skills assessment and opportunities for the continuing professional development of tutors. However, disadvantages of delivering basic skills tuition through external partnership were raised by both sides. These centred on communication and relationship issues. As one project manager said, 'There are too many links in the chain. You have to look for decisionmaking from two or three sources and it takes time, paperwork and effort'. Some of the tutors felt that probation staff saw them as outsiders and that this blocked the development of effective working relationships - which, in turn, restricted their efforts to link the basic skills work with other elements of community supervision. Sharing of information about offenders presented some problems. Tutors did not always have ready access to information they needed about their learners, and, in other instances, were required to spend some of their limited time inputting information back into the IT system.

In some cases, partnership arrangements opened up possibilities for much more extended periods of learning: for example, an offender attending a Link into Learning centre in Cornwall Probation Area could, in theory, attend for an open ended number of hours. The development of literacy and numeracy skills is likely to be a long-term task for many individuals, extending beyond the period of community supervision. Probation staff interviewed for the evaluation were conscious of the need to ensure continuity between basic skills provision as part of a community sentence and more long-term provision. The importance of links with external providers to 'bridge the gap' between community supervision and mainstream provision was therefore recognised. One practical way in which tutors attempted to meet this need was by 
accompanying learners to college buildings for the first time. In some areas, volunteers rather than the tutors took on this role.

\section{Suitability, accessibility and quality of learning venues}

All of the pathfinder areas provided tuition on probation premises, though in one area (Cornwall) there were, in principle, arrangements for learners to be referred as soon as appropriate to a Link into Learning Centre. For the tutor, use of probation premises during the day or on reporting evenings facilitated an arrangement which met 'health and safety' requirements. The main argument put forward for using probation premises, though, was that individuals with low basic skills have often had negative experiences of school and would therefore be averse to an educational venue. It was thought, therefore, that they would be more likely to access provision if it took place on probation premises and was seen as part of their community supervision. For many, the probation office would already be a familiar place and offenders would therefore not be deterred by the prospect of finding their way to an unknown, perhaps intimidating venue. Another advantage was the potential integration of basic skills work with other elements of the supervision plan. Tutors could, in principle, readily liaise with the offender's case manager to discuss ways of embedding basic skills work into the community supervision. A small minority thought that probation offices, because of associations with rules and punishment, did not provide a positive learning environment.

In six of the pathfinder areas, the venue for tuition was generally within easy reach for those concerned because teaching took place in their local office. In the seventh area, Dorset, the basic skills provision was limited to Poole, but the area developed video conferencing so that offenders based in rural geographical areas had the opportunity to work either in a group or on a one-to-one basis with a tutor through a video link. In Sussex, the basic skills tuition provided in four offices was supplemented by the NACRO bus. Such initiatives underline the importance of thinking about how to target offenders who cannot readily access tuition in probation offices if probation areas are to provide some in-house basic skills tuition and if tuition is only provided in a limited number of probation offices.

The quality of accommodation for teaching varied across and within the pathfinder areas. Several tutors reported experiencing protracted negotiations with probation areas in attempting to obtain appropriate rooms to run group sessions. The best venues consisted of spacious rooms that could accommodate groups, and were designated teaching rooms where resources could be stored and basic skills materials could be displayed on the walls. Second best were rooms which were always accessible, if not exclusively used, for that purpose, so that learners could associate basic skills work with a specific place. Appropriate furniture also facilitated the process of teaching and learning. One project manager bought foldaway tables and chairs for use in a room she shared. By doing so, she had appropriate furniture for teaching sessions, but the furniture was not obtrusive for other users of the room. Other make-shift arrangements were far less feasible: one tutor reported having to teach in a kitchen, and another taught in the room where probation staff ate their lunch.

\section{One-to-one or group tuition?}

Most of the teaching in the pathfinder areas was one-to-one, the exceptions being in Dorset, where all of the tuition took place in a group context, and some sessions in Nottinghamshire. In Cornwall Probation Area, the tutors from Link into Learning attempted, where appropriate, to move learners from one-to-one provision in probation offices into a group context in one of Link into Learning's centres.

A number of tutors argued, particularly in the early stages of the Basic Skills Pathfinder evaluation, that only one-to-one teaching would be appropriate for the individuals targeted. It was thought that offenders with skills below Level 1 would be unlikely to participate in a group context because they would associate it with negative experiences of school, and would wish to avoid exposing their difficulties to others. On the other hand, some tutors who taught in a group context argued that learners with poor basic skills find reassurance in a group context because they discover they are not alone in having such difficulties. Other advantages put forward are that people feel less pressured than in a one-to-one situation, and they can 
improve their social skills through interacting with each other. One tutor highlighted that he found it easier to generate a 'buzz' when teaching in a group. This arrangement also meant that there was a better chance of his time being used productively because a few of the learners could not be relied on to attend.

\section{Use of ICT resources}

The use of information communication technology (ICT) is perhaps particularly appropriate for teaching adults with basic skills needs. Most tutors involved in the pathfinder projects regarded ICT, including use of computers and digital television, as a powerful motivational resource by which to engage adults in addressing their basic skills needs. In some of the pathfinder areas tutors had access to ICT learning materials and to computers, but there was variation in how much use they made of these, as opposed to relying solely on paper-based resources.

Some tutors found it difficult to keep up to date with new developments and resources. Either they had to spend much of their time seeking out appropriate material, or they were unaware of material that they might have used. One area (Thames Valley) set up a website for mentors who were acting as tutors. This enabled them to share each others' materials, to work more as a team, and to access information about basic skills teaching and about the Probation Service.

\section{Duration and intensity of tuition}

In the pathfinder areas, offenders had access to basic skills provision once a week, for between one and two hours. Exceptions were Nottinghamshire (where up to six hours a week was possible in some places) and Cornwall (where an open-ended number of hours was possible through access to a Link into Learning centre).

The duration and intensity of provision is a potentially important variable in the effectiveness of basic skills intervention with adult offenders (Cecil et al., 1997). Organisations could not gain the BSA Quality Mark (BSA, 1999), available until 2003, unless they provided at least four hours direct teaching a week. The number of learning hours recommended by the BSA (these may include direct instruction, supervised study, accreditation procedures, assessment of achievement and support) for learners to achieve competence in a level are on average: below Entry Level - 330 to 450 hours; Entry Level - 210 to 329 hours; and Level $1-120$ to 209 hours (BSA, 2000a), though the evidence-base for these claims is not cited.

\section{Teaching material}

Skills for Life (DfEE, 2001) emphasised that many basic skills tutors have to search for teaching materials from disparate sources and that this leads to inefficient use of time and inconsistency in standards. As part of Skills for Life, suites of learning materials have therefore been developed. Across the pathfinder areas, there was evidence of individual tutors, first, spending a considerable amount of time looking for resources, and second, not always being aware of the most appropriate materials for use with their client group. Some tutors found it difficult keeping up to date with new developments and resources. Although the majority of tutors did not experience this, most agreed that it would be very helpful to have mechanisms in place to enable tutors to exchange resources and ideas for teaching with one another. The Thames Valley Probation Area's website was a good example of this kind of support.

\section{Content of basic skills sessions}

From the direct observations of basic skills sessions, it was clear that a wide range of material was covered in basic skills sessions across the pathfinder areas including:

- learning how to disclose convictions;

- $\quad$ projects on issues relevant to learners' lives, such as finding accommodation; 
- materials linked to learners' interests (e.g. football; cookery; astrology; driving);

- formal letter writing, e.g. complaint letters;

- employment-related activities (e.g. CVs and job applications); and

- creative writing.

Tutors generally selected teaching materials that were relevant to adult learners' interests and needs. For example, material in the Basic Skills for Life series can tap into learners' interests successfully. The following items proved helpful: Coping with Cooking; Making Ends Meet; and A Place of Your Own. Attention was also given to study skills and skills relevant to day-today functioning, such as time-management.

Observation of teaching and interviews with tutors indicated that, within the pathfinder, the best basic skills teaching was likely to have one or more of the following characteristics:

- The material used was appropriate to the learner's interests and to his/her basic skills levels.

- The learner was, as the adult curricula stipulate, clear about the purpose of the activity and individual basic skills sessions were well structured, as underlined by the BSA (BSA, 2000a/ 2001b).

- Activities selected for use in each session were part of a well-structured individual learning plan, central to which was the concept of progression between capabilities over time, as emphasised in the adult curricula.

The best individual learning plans were explicit about the skills and knowledge being developed; included specific targets, goals and steps to be taken to achieve these; and were regularly reviewed.

\section{Facilitating take-up and attendance at basic skills sessions}

Strategies used by tutors to facilitate take-up of basic skills provision included:

- advertising basic skills work;

- providing taster sessions;

- developing a video ${ }^{40}$ illustrating what happens in basic skills tuition and featuring offenders who have attended provision;

- encouraging offenders to visit the teaching room with their case manager so that offenders know where the teaching takes place and are aware that the learning environment is pleasant and that tutors are human; and

- liaising effectively with case managers with a view to promoting basic skills tuition for suitable people in their caseload.

Some research suggests that accreditation can be an incentive to learn for those with basic skills needs (BSA, 2000a). However, the importance of recognising small steps in progress, and of not over-emphasising national tests, has recently been emphasised (Howard and Grief, 2001). In the pathfinder areas, with the exception of Dorset Probation Area where all learners were entered for Award Scheme Development and Accreditation Network's (ASDAN) 'Improving Learning', only a small minority of offenders worked towards accreditation.

Interviews with tutors and direct observations of basic skills sessions revealed that tutors developed a range of strategies to promote offenders' attendance at basic skills tuition. These strategies included:

${ }^{40}$ Positive Action Learning Support (PALS) in Nottinghamshire Probation Area have produced such a video. 
- $\quad$ ensuring that any communication sent to learners was at an appropriate literacy level;

- giving appointment cards, with the date and time of the next session with appropriate attention to the wording used and the size of lettering;

- telephoning the offender in advance of his/her basic skills session to remind him/her about the session;

- going to the learner's house to collect him/her, or asking a volunteer to do this;

- $\quad$ buying the learner an alarm clock;

- $\quad$ informing the case manager about non-attendance by email on the same day;

- $\quad$ sending letters with new appointments; and

- $\quad$ providing tea and coffee in sessions.

Some tutors were adept at tapping into learners' reasons for wanting to improve their basic skills, and at using these to motivate the learner to take up provision and to attend regularly.

The relationship between tutor and learner was emphasised by many tutors as critical to increasing confidence and motivation to learn. Tutors emphasised the value of praise and encouragement, whilst at the same time being realistic about what could be achieved and the value of acknowledging very small steps in progress to build learners' self-confidence. There was general recognition of the need to find the right balance between being supportive of individuals with a wide range of problems and emotional needs, while avoiding gravitation towards a counselling role. It was important for tutors to have access to a line manager in the probation area with whom they could discuss problematic relationships, as in one case where a tutor felt threatened by an offender she taught.

\section{Continuing professional development of tutors}

Arrangements for the supervision of, and regular contact with, basic skills tutors were in existence in the majority of the pathfinder areas. For example, in Nottinghamshire, the basic skills team met on a weekly basis, while in Sussex the team met monthly. In Thames Valley, where tutoring was undertaken by mentors, support and supervision were particularly important, and monthly meetings were held in addition to individual supervision, an induction session and regular contact by phone or email.

Recent research (Brooks et al., 2001) recommends improved opportunities for the continuing professional development (CPD) of basic skills tutors. A range of CPD opportunities is provided through the Skills for Life (DfEE, 2001) strategy. The Home Office (2001) has recommended that tutors should have access to CPD. Within the Basic Skills Pathfinder evaluation, a particularly good example of opportunities for the (CPD) of tutors was observed in Cornwall, where one day a week was dedicated to CPD of tutors. All tutors in the project areas were given the opportunity to attend training courses on the new adult curricula.

\section{Consciousness-raising of basic skills needs in the Probation Service}

A frequent observation made by tutors and project managers was that probation staff too often seemed either unaware of or unconvinced by the need to integrate basic skills provision into probation practice. Consequently, there were many examples across the pathfinder areas of strategies deployed by project managers and basic skills tutors to raise awareness among probation staff. Strategies included:

- encouraging probation officers to drop into the basic skills teaching room, as in Nottinghamshire Probation Area, so that probation officers could develop an understanding of the work that took place in basic skills sessions;

- making a video about basic skills teaching. In Nottinghamshire Probation Area, the project manager used the video of the PALS project in team meetings. In Lincolnshire Probation Area, a video about basic skills provision was used at the annual staff conference in 2000; 
- publishing a newsletter to promote basic skills work. Newsletters in the Nottinghamshire and Lincolnshire Probation Areas included success stories to increase probation officers awareness of what could be achieved; and

- regular visits by project staff to probation offices to raise awareness of basic skills issues.

\section{Links between basic skills work and other probation projects}

During the Basic Skills Pathfinder evaluation there were some initiatives to integrate basic skills work into wider aspects of probation practice. Nottinghamshire Probation Area began a communications project in which they assessed the extent to which their communications with offenders were pitched at appropriate literacy levels. Lincolnshire assessed the basic skills levels of all offenders attending the induction to the Reasoning and Rehabilitation Programme to identify those who could benefit from literacy support to help them get the most from the programme. Thames Valley and Lincolnshire Probation Areas rewrote some of their letters and leaflets for offenders, so that the information that they contained was expressed as simply and clearly as possible. ${ }^{41}$

\section{The learning}

This section, describing the experience and outcomes for those who took up basic skills provision, is shorter and less substantive than all those taking part in this pathfinder might have hoped. This reflects the low numbers who actually made it to the stage of receiving tuition and then 'stayed the course'. (The problem of attrition is discussed in detail in the next chapter of this report). But it also reflects the shortfall in data that the evaluators were able to collect. Before describing the findings, it is necessary to explain this data shortfall.

\section{Data limitations}

Individual learning records were received by the evaluation team for just 35 offenders who had accessed basic skills provision. These came from four of the pathfinder areas: Dorset, Nottinghamshire, Sussex and Thames Valley Probation Areas. Staff in the other pathfinder areas did not fill out the individual learning record because, they explained, there had been insufficient information. Where individual learning records were received, they were often incomplete, difficult to decipher, and lacking in detail. Although most of the individual learning records stated clearly what the targets for basic skills provision were, information on whether or not these targets were reached was missing from most individual learning records. Intermediate outcome information (such as information on accessing further educational provision or gaining employment) was received from Dorset, Lincolnshire, Nottinghamshire, Sussex, and Thames Valley Probation Areas.

Post-tests from those attending basic skills provision. Only 13 copies of a parallel form of the BSA's Initial Assessment tool post-test were received by the evaluation team. It was therefore not possible to carry out pre-test and post-test comparisons of scores on the BSA's Initial Assessment tool. Some reasons given by Basic Skills Pathfinder evaluation staff and basic skills tutors for the low number of post-tests completed were that the offenders:

- did not remain on basic skills provision for a sufficient length of time to complete the posttest (e.g. dropped out of basic skills provision or were breached);

- declined to complete the post-test ;

- $\quad$ became upset while completing the post-test and so the process was aborted;

- failed to attend the post-test appointment; and

- were not ready to complete the post-test at the eight month point, in the view of their tutors.

\footnotetext{
${ }^{41}$ Probation Circular 15/2002 states that a new research project is to be implemented on the relationship between offender's literacy levels and participation on general offending behaviour programmes. This follows anecdotal evidence that some offenders have difficulties with the literacy demands ofthe general offending behaviour programmes.
} 
For the purposes of the evaluation, it had been intended that post-tests would be completed at the eight-month stage of an offender's basic skills provision or at the end of the offender's basic skills provision. In practice, because very few offenders attended basic skills provision for eight months or more, the post-tests that the evaluators received were completed only for those who had been on provision for a considerable time. None were completed for those who dropped out of attending, because there had been no opportunity to complete such tests. This, of course, explains why so few post-tests were completed by pathfinder areas and thus received by the evaluation team.

Intermediate data received. In order to make use of limited progress data supplied on the individual learning records, gaps were filled where possible by gleaning information from the corresponding interviews with tutors and the learners concerned, or from observation of sessions.

Interview data. Interviews were conducted with 20 offenders (17 men and three women aged 20 to 57 years) in three pathfinder areas (Lincolnshire, Nottinghamshire and Thames Valley Probation Areas) who were on basic skills provision at the time of interview, and who had been through a complete or partial initial assessment procedure for basic skills needs for the Basic Skills Pathfinder evaluation. The interviews provided a valuable insight ${ }^{42}$ into the offenders' perspective on the content of basic skills provision, their reasons for participating, the perceived benefits of attending provision, and the impact on employment and offending. The majority of interviews were with offenders sentenced to a CRO, ranging in length from one to three years. The length of time the offenders had been accessing tuition varied from approximately two weeks to five months. Most of these offenders were attending one session per week for one to three hours. Five of them were attending in a group setting.

\section{Types of progress made: Findings from post-tuition measures}

Only small amounts of progress could be expected from so short a period of tuition for the individuals concerned and those offenders making 'good' progress were few in number. The post-test data revealed that eight individuals had increased a level on the BSA's Initial Assessment tool. Other examples of progress extracted from the various sources of data included:

- learning the alphabet for the first time;

- learning to use a dictionary or thesaurus;

- improvements in spelling, grammar and use of punctuation;

- improvements in multiplication and division;

- gaining the ability to write formal letters and to fill in forms; and

- use of computers for word processing and Internet searches.

The individuals concerned typically commented that, even in so short a period of time they had been able to learn more than they ever did in school and that the experience was 'much better than school'.

Although, it was not possible to generalise about offenders' basic skills improvements in basic skills from the data received - and given the very small number of sessions attended on average - the small number of post-tests received did indicate that considerable improvements in basic skills could be made by within a short period of time.

\section{The perspectives of those who took up tuition: findings from the interviews}

Nineteen of the 20 offenders reported that they enjoyed working with their basic skills tutor and most felt comfortable within the learning environment. The five who were working within a group situation got along with the other members of the group and felt that it provided a good support network for learning. Eleven suggested that their attitude to learning had changed because the experience and environment contrasted favourably with their memories of

${ }^{42}$ Caution is obviously required before generalising from these interviews given the small numbers involved and given that they had been selected, nonrandomly, for interviews by basic skills staff. 
school: 'These classes are completely different to school. Here you get spoken to like a person'. All of the interviewees had left school between the age of 12 to 16 years, and although six of them sat exams before they left school, only two had qualifications, both at below GCSE level C. Thirteen reported that they had been bullied by their peers, and picked on by teachers. Seventeen (85\%) interviewees stated that their desire to learn when at school had been limited, they had not liked the teachers, and their attendance had been sporadic. Others reported that although they had always wanted to learn, they had not, until now, been provided with an opportunity to do so.

Not all of the offenders interviewed had managed to attend every class, and reasons for nonattendance included: work, health issues, childcare difficulties, travel difficulties, and in one case, depression. However, $18(90 \%)$ of them expressed a wish to continue with basic skills provision after their CRO had finished - although some were apprehensive about fitting classes in around work commitments. Interestingly, three offenders were clearly aware that their basic skills would not have greatly improved by the end of their CRO, and so wished to access college provision following the end of their CRO. Two of the interviewees had already completed their CRO but had chosen to continue attending for tuition on a voluntary basis. None of the offenders interviewed reported that they did not want to continue learning in some capacity.

Most of the interviewees identified that they had made improvements in one or more of the following: reading, writing, pronunciation and spelling; using computers; handwriting; writing letters; filling out application forms; compiling CVs; filling out benefit forms; and reading newspapers. Moreover, in other areas of their lives, they reported improvements, including: increased confidence and self-efficacy; less anger and aggression; a greater will to stay off alcohol; and more participation in family life such as reading to their children. The degree of reported improvement was in line with the length of time they had been attending.

In general, the offenders interviewed felt that addressing their basic skills needs was very significant for them. Some were extremely enthusiastic about the gains they had made and the life-changing potential of classes for themselves, and for others. One reported that the basic skills sessions had resulted in 'no longer doing silly things all of a sudden'. Another suggested that many more offenders would take up basic skills provision if they were made aware of the availability of classes through advertising or greater promotion: 'I only wish I had discovered them sooner. It is the best thing l've ever done'.

Thirteen of the offenders interviewed were attending basic skills provision instead of seeing a probation officer and their attendance each week was, by agreement, counted as a contact to meet National Standards (Home Office, 2000). Most of these, though, regarded it as a way of turning required contact into a constructive and purposeful use of time. Nine (45\%) of the interviewees reported that they had chosen to attend simply in order to improve their reading and writing.

The others had additional or alternative reasons, such as improving their chances of gaining employment or better employment. In fact, 65 per cent of this small sample were employed at the time of interview. Just over half of the interviewees were working in manual or unskilled jobs. Four had semi-skilled employment such as mechanics, gardening or retail. Six were out of work because of incapacity. The seven who were unemployed felt that the classes would eventually help them in their job search, particularly with filling out application forms, letter writing and presenting themselves in job interviews. Whether in or out of employment, nearly all indicated that improved writing and reading skills would increase their confidence in taking up future employment opportunities.

Thirteen (65\%) of the interviewees reported that attending classes would make it possible for them to avoid further offending. The explanations given related to better job prospects and legitimate earning capacity as a result of improving their basic skills, and reduced anger, frustration and susceptibility to provocation, as a result of the impact on self-concept. But three of the interviewees stated that coming to the classes would have no impact on their offending, because education, reading and writing difficulties were not an aspect of their offending in the first place. Two were committed to desistance from crime but attributed this to 
being in a supportive relationship rather than improving their basic skills. Only one of the interviewees was also attending an offending behaviour programme and he reported that the basic skills classes had helped with the reading elements of the programme. Another reported that classes had helped in time-management including keeping appointments with the probation officer, and another that he had become motivated to stop drinking. Most thought that by improving their quality of life, addressing their basic skills needs would indirectly help them in their efforts to avoid re offending.

\section{Perspectives of staff on progress made}

Basic skills tutors and other project staff identified a variety a ways in which they believed individuals who attended for tuition had made improvements. Direct improvements in basic skills were mentioned, reflecting advances in numeracy and literacy. Examples were given of individuals who had made the major achievement of reading a book, or a magazine or newspaper, and who were saying that they could now tackle such activities with more confidence and with a realisation that everyday uses of literacy are within their reach. As one tutor said:

Some people when l've first seen them and ask them to write a sentence will say they haven't written anything for years and will look at the pen as if it will bite them. Then they will start to see writing as a means of expression, and not as a threat. Then they will say, 'I saw in the paper the other day...' People start to integrate reading and writing into their daily lives.'

In addition to specific improvements in literacy and numeracy, all tutors stressed other benefits including: mastery of everyday tasks; improved social and communication skills; changes in self-concept and self-efficacy; and attitudes to education and learning. Some examples follow.

Mastery of everyday tasks

The progress in basic skills classes became evident in tasks such as writing out a name and address, and making formal telephone calls. Filling in forms was frequently tackled in basics skills sessions and made a target in individual learning records. Being able to fill in an application form for housing benefit, for instance, or for a job seekers' allowance was one of the very practical ways in which offenders were seen to have benefited from sessions.

Improved social and communication skills

Tutors remarked on, for example, alterations in physical stance and in body language, increased eye-contact and verbal communication. Such transformations were summed up by one project staff member:

We had one offender who was actually very aggressive, and he would grunt through the window at the reception staff. Then he worked with a mentor [i.e. acting as a tutor] for a few months and he would actually come in with smiles.

Similar improvements were also noted in individuals who were at first withdrawn and quiet in a group setting but who began to interact with the other people present, to ask questions and express opinions.

Changes in self-confidence and self-efficacy

Tutors often referred to a growth in 'confidence' and 'self-esteem', both in individual learning records and in interviews, and such changes were frequently noted and regarded as significant and worthwhile improvements. As one tutor said:

They start taking control of their lives...It is all about taking control instead of feeling as though you are being tossed around from pillar to post.

The issue of dyslexia was raised by one tutor in relation to self-efficacy. It was emphasised that little progress would be made by a dyslexic on standard basic skills provision, and this could reinforce feelings of negativity towards learning. On the other hand, accessing relevant 
provision could help an offender realise that they were 'not thick but had a specific problem' which could be addressed and appropriately managed.

Attitudes to education and learning

Staff associated the gains in self-confidence and self-efficacy with the development of the offender's belief in him/herself as an individual who could learn, and who was not stuck with poor basic skills. Because the school experience of the people attending for tuition had not been positive, changes in perceptions of education and training were counted as important gains. Even in cases where an offender had ceased to attend, tutors hoped that the experience of basic skills tuition had been positive enough to motivate the individual to take up further educational help if the opportunity arose.

\section{Conclusion}

The Basic Skills Pathfinder evaluation areas benefited from the expertise and dedication of those responsible for basic skills tuition. Most tutors were qualified and most supervision of tutors was of a high standard. Examples of good practice included: making use of ICT and material of special interest to the learner; arrangement of transport for those who could not otherwise attend; provision for the professional development of tutors; and the development of a website for tutors. The teaching was generally done on a one-to-one basis but, by the end of the period of evaluation, more of the projects were planning group sessions in addition to one-to-one provision. There was increasing focus on building effective links with external providers.

However, a range of factors limited the potential effectiveness of basic skills provision within the pathfinder areas. The accommodation provided for teaching basic skills was often not appropriate. Progress in some cases was hampered by the limited number of hours during which offenders could access tutors and materials. There was scope for more imaginative use of teaching methods and materials. Teaching within a group setting rarely occurred and therefore its potential was under-explored. Some tutors did not have adequate access to ICT and, in a minority of cases, did not build ICT into practice. A number of implications for improving the tuition and developing basic skills courses suitable for those on community sentences arise from the findings of this evaluation and these are addressed in the final chapter.

It was not possible to draw any firm conclusions about the value of tuition and courses for those who participated in basic skills sessions because of the small numbers of offenders who attended for more than two sessions. Measures that were available, and interviews with participants and tutors, revealed that gains had been made even within a short period of time. There were examples of direct improvements (e.g. filling in application forms; learning the alphabet) and indirect improvements (e.g. improved communication skills; changed attitudes to learning opportunities). 


\section{Those who did not get there: the problem of attrition}

This chapter investigates, first, the extent of attrition at each stage of the process for addressing basic skills needs. Second, the reasons given for non-referral and non-attendance are explored together with further possible explanations for attrition and poor attendance. Third, various ways in which attrition might be reduced are considered.

\section{The extent of the problem}

The concept 'attrition' in this context refers to a gradual diminution in numbers, starting from the point of possible eligibility for basic skills provision to actually accessing and then continuing to attend a course. It will be helpful to distinguish between what might be termed service-related attrition, resulting from non-referral or omission of certain stages, and userrelated attrition, resulting from non-attendance at any of the stages, and 'dropping out' from a course having attended at least on one occasion.

The data to monitor numbers at each stage of the process were analysed to show the attrition rates at each stage, starting from the numbers of those eligible for screening, and progressing to the point of attendance for tuition or on a basic skills course. Some gaps in the data received by the evaluators restricted the comprehensiveness and precision of this analysis (see discussion 'Data sources and problems'). However, as can be seen in Figure 6.1, a clear picture has emerged of attrition at every stage of the Basic Skills Pathfinder evaluation. It can be seen that it was possible for attrition to occur between any of the following steps:

1. Preparation of court report
2. Screening
3. Referral for in-depth assessment

4. Attendance for in-depth assessment

5. Referral to course/tuition

6. Commencing course or tuition
$\rightarrow$
$\rightarrow$
2. Screening
3. Referral for initial assessment
4. Attendance at the initial assessment procedure for basic skills needs
$\begin{array}{ll}\rightarrow & \text { 5. Referral to course or tuition } \\ \rightarrow & \text { 6. Commencing course or tuition } \\ \rightarrow & \text { 7. Continuing the course or tuition }\end{array}$

\section{Data sources and problems}

In order to monitor the process and collect data on attrition and attendance, each pathfinder area was asked to record the number of:

- PSRs written;

- completed screenings;

- referrals for the further, in-depth assessment at the initial assessment procedure for basic skills needs;

- assessments carried out at the initial assessment procedure for basic skills needs;

- $\quad$ offenders who turned up for tuition; and

- $\quad$ sessions attended.

This placed a large additional workload on probation staff, resulting in omissions and inconsistencies in the way the data were collected. Monitoring systems varied and, in some cases, were not appropriately carried out. Consequently there were gaps, at all stages, in the data received by the evaluation team. It was not possible to include two of the probation areas in most of the analysis; Lincolnshire Probation Area provided data for four months only of the evaluation and Cornwall Probation Area did not send any monitoring data for the purposes of evaluation, informing the evaluation team that they did not collect these data. 
Figure 6.1: Attrition from PSR stage to initial assessment procedure for basic skills needs*

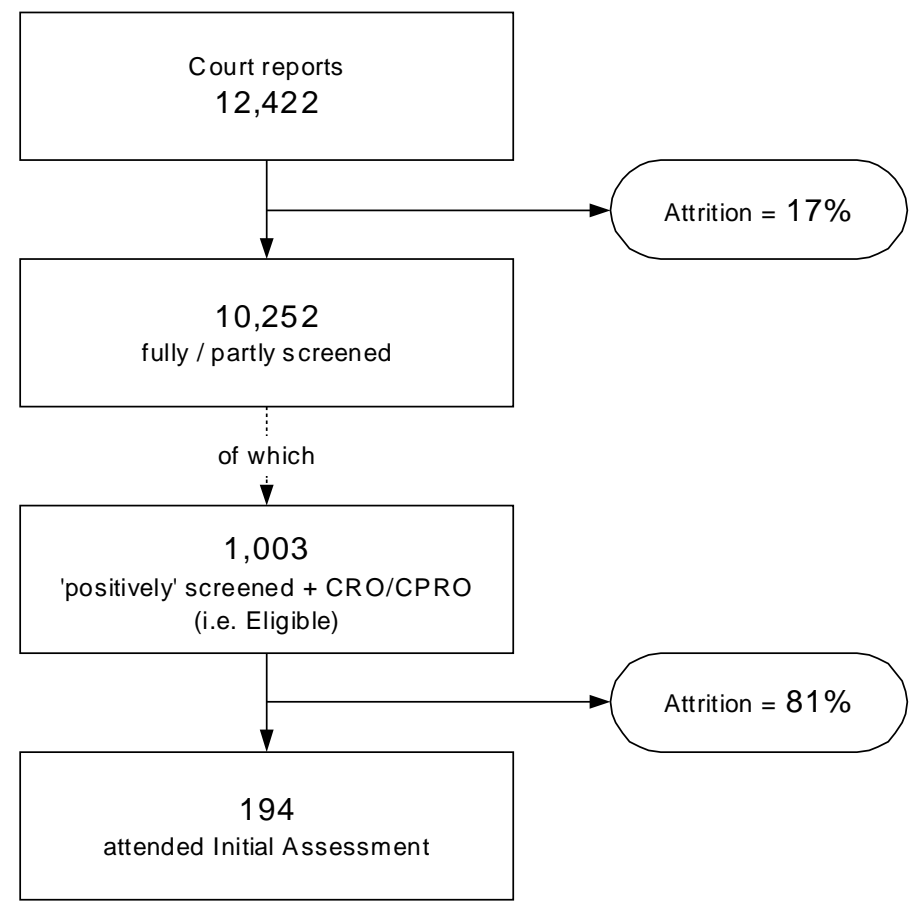

*This is based on data from seven of the pathfinder areas. The corresponding information on how many of the 'eligible' individuals commenced tuition was not available for this data set.

Figure 6.2: Attrition from screening to commencement of tuition

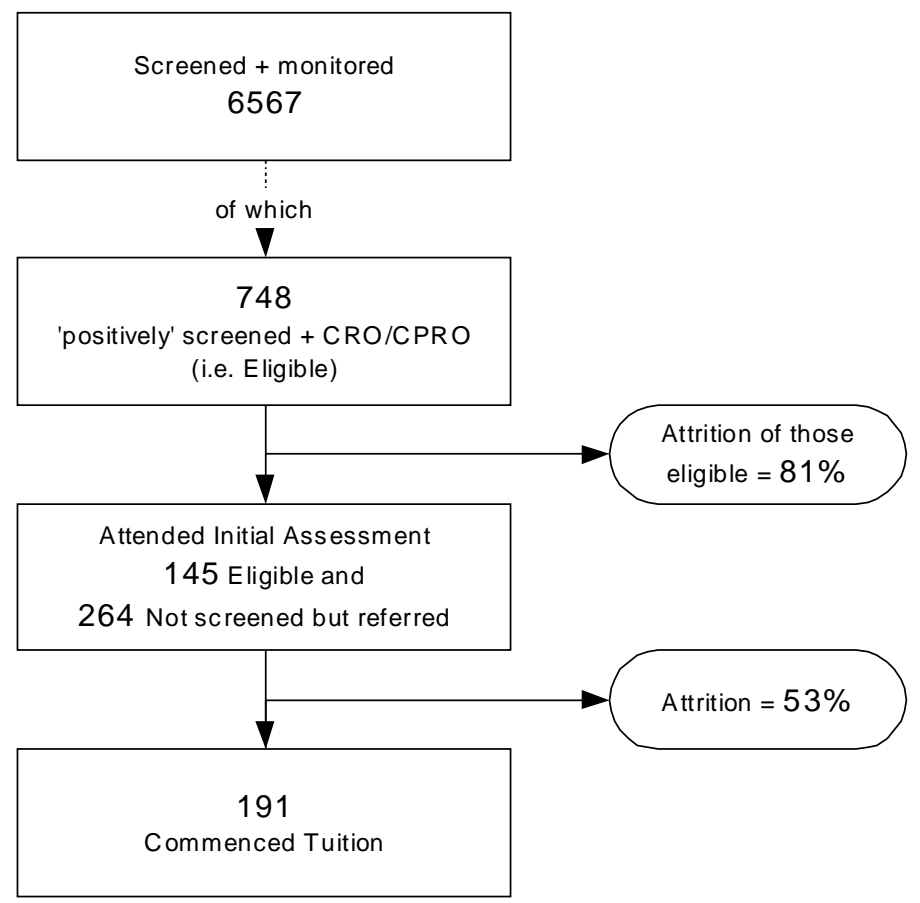

*This is based on data from five of the pathfinder areas. Insufficient data were received from two of the pathfinder projects and they are therefore left out of this analysis. In fact the evaluation team were sent 9,061 completed 'screenings' out of 10,252 cases in the database, but only 6,567 had corresponding monitoring data. 
Given the significant gaps in the monitoring data requested, a comprehensive analysis of attrition, which followed through the complete process from screening to participation in tuition, was not possible. Therefore, in order to formulate a picture of the attrition which occurred at each step, additional data sets were requested from areas, retrospectively, from the point at which offenders had been sentenced to a CRO or CPRO. It should be noted therefore that the numbers in this supplementary analysis (see Figure 6.2) are lower than those used for the statistical analysis of the scale and correlates of basic skills needs. These differences are reflected in the alternative data sets used for Figures 6.1 and 6.2 respectively. Nevertheless, both data sets tell the same story about attrition of those 'eligible' for basic skills provision.

\section{Attrition from 'report preparation' to 'screening'}

The proportion of PSR interviews that led to screening for basic skills need varied from area to area. The highest proportion of PSRs leading to screening occurred in Dorset (65\%) and Thames Valley (68\%) while the lowest proportions occurred in Nottinghamshire (40\%) and Cumbria (39\%). There was also considerable variation from month to month within areas of the proportion of PSRs leading to screening. For example, in one month Nottinghamshire screened just 15 per cent of all offenders on whom reports were written at the PSR stage but screened as many as 77 per cent in another month. Similarly, Dorset screened 39 per cent in the first month of the evaluation period but reached 93 per cent in a later month. Most of the problems experienced in achieving completion of screenings were experienced at the beginning of the evaluation.

\section{Attrition from 'screening' to 'referral for in-depth assessment'}

The level of attrition is high at every stage but most remarkably between the screening stage and the referral of offenders to the initial assessment procedure for basic skills needs. As both Figure 6.1 and 6.2 show, eight out of ten of those who were eligible for the initial assessment procedure for basic skills needs were not referred. In other words, they had been 'positively' screened as likely to have basic skills needs, and they had been sentenced to a CRO or CPRO - therefore they were clearly in the target group for the pathfinder projects.

According to the evaluation team's attrition data, if criteria for the Basic Skills Pathfinder evaluation, of $2,192,{ }^{43}$ in five pathfinder areas, who were sentenced to a CRO or CPRO, there were $748(34 \%)$ who screened 'positively' and who therefore were eligible to be referred for further screening. But of these 748 offenders 'eligible', only $145(19 \%)$ are recorded as having actually attended for in-depth assessment (see Figure 6.2). It remains possible that others were referred but the information was not relayed to the evaluators, but such omissions are unlikely to account for the 81 per cent attrition rate. As Figure 6.1 also shows, using data from all seven pathfinder areas, the same rate of attrition occurred between eligibility for indepth assessment and actually receiving that assessment at the initial assessment procedure for basic skills needs.

\section{Attrition from 'in-depth assessment' to 'attending course/ tuition'}

The nature of data received for those who actually commenced basic skills provision did not allow an estimation to be made of the attrition between the initial assessment procedure for basic skills needs and attendance for tuition of those who were 'eligible', according to the pathfinder criteria, to attend. The in-depth assessments were carried out on many offenders (discussed below) who were not included in the database of the evaluation team. As Figure 6.1 shows, 409 attended the initial assessment procedure for basic skills needs and once they made it to this stage there was an almost even chance that they would proceed to attending for tuition: 47 per cent of these individuals commenced tuition (attending at least once).

\footnotetext{
${ }^{43}$ Note that it is likely that the figure recorded is an under-estimate of the actual figure receiving a CRO or a CPRO because the evaluation team did not receive full sets of court sentence information from the pathfinder areas and other monitoring data by which to identify sentences received.
} 


\section{Reasons and explanations for attrition}

Some attrition at each stage is to be expected and is legitimate. For example, a screening test may have been carried out on a day when someone without basic skill needs was ill or had a hangover, resulting in a 'false positive'. Once the basis for this result became apparent, it would of course be inappropriate to refer such an individual for an in-depth assessment, despite the screening result. Another example of legitimate attrition would be if, somewhere during the process, an individual makes alternative arrangements to address their basic skills needs, such as getting informal help from a relative or enrolling on a basic skills course following referral by a careers centre. But other factors leading to attrition are likely to reflect a regrettable decline in numbers.

In order to gain insight into the causes of attrition at the various stages, several sources of information were used: interviews of probation staff, tutors and offenders; information on monitoring forms; and comparison of the 'experimental group' (those who attended for tuition) and a 'comparison group' (a matched group who had been 'positively' screened and sentenced to a CPO or CPRO but who had not been referred for tuition).

Pathfinder projects were asked to provide copies of PSRs (and SSRs if applicable), supervision plans and quarterly reviews for a random sample of 50 per cent of offenders who had not attended for basic skills tuition, as well as to supply such case records for all those who had attended. A content analysis of these records was carried out. ${ }^{44}$ The documents obtained for this analysis were as follows:

The experimental group

- 145 PSRs, 122 supervision plans, 67 quarterly reviews.

- 57 complete sets of information were collected.

The comparison group

- 311 PSRs, 267 supervision plans, 157 quarterly reviews

- 148 complete sets of information were collected.

It was intended that all offenders in the comparison group had been 'positively' screened and had been sentenced to a CRO or CPRO. These are people, therefore, who should have been referred for initial assessment and then, if appropriate, on to basic skills provision. In comparison, the eligibility of the experimental group for basic skills provision is open to question because of the general acknowledgement of 'exceptions to the rule' of scoring below Level 1 on the FT 20 Q screening tool. Nevertheless, an examination of court reports, supervision plans and quarterly reports for both the experimental and comparison groups was helpful in revealing why, in some cases, some gained access to basic skills provision while others did not.

\section{Why was there attrition from the PSR stage to screening?}

The evaluators were sent copies of 9,061 screenings that were fully completed, corresponding to 73 per cent of the 12,422 court reports that were prepared within the evaluation period. A further 1,191 returned the background information form but not the FT 20 Q. (Note that the number of 6,567 given in Figure 6.2 is for completed screenings plus additional monitoring data.) Therefore, around a quarter were not being screened. The main reasons, as gleaned from interviews and monitoring information, were time constraints, uncertainty about who should be screened and who could be exempted, and dissatisfaction with the quality of the screening tool.

All pathfinder areas reported that there were time constraints and competing priorities when interviewing for the PSR - the occasion designated for screening. Most obviously, time was needed to obtain the necessary information for the report, and to provide courts with the requisite information, as set out in the National Standards (Home Office, 2000).

\footnotetext{
${ }^{44}$ As elsewhere in this study, the analysis was compromised by gaps and anomalies in the information received for the evaluation, and therefore the results
} are indicative rather than conclusive. 
The FT 20 Q screening tool specifies the level and qualifications which would exempt the user from completing the remainder of the tool. For example, if the offender has GCSE English or Maths at or above Level 2 (i.e. Grade $A^{*}-C$, see Table 1.1 and Appendix A) then s/he would be exempt from completing the relevant section (literacy or numeracy) of the FT $20 \mathrm{Q}$ screening tool. In training sessions, some PSR writers commented that they did not have a detailed understanding of educational qualifications and that it was therefore difficult to know whether an offender's stated qualifications should, in effect, exempt him/her from answering the questions on the form. To assist staff with this problem, a glossary of educational qualifications was therefore prepared for PSR writers by the evaluation team. However, doubts about which educational qualifications were referred to on the form were later given as a reason for some cases where the screening had not been carried out. A further reason for non-completion of screening were various objections to the tool itself. These criticisms, together with benefits, of the FT 20 Q screening tool are discussed in Chapter 3.

The PSRs for the experimental group and for the comparison group were examined. The PSRs for both groups showed virtually no difference in the extent to which basic skills issues were mentioned, as shown in Table 6.1.

\section{Table 6.1: Reference to basic skills in court reports}

\begin{tabular}{|l|l|l|}
\hline Inclusion in court reports & Experimental group & Comparison group \\
\hline Comments about basic skills & $62 \%$ & $66 \%$ \\
\hline Basic skills identified as a problem & $56 \%$ & $51 \%$ \\
\hline Screening mentioned & $14 \%$ & $13 \%$ \\
\hline In-depth assessment recommended & $23 \%$ & $23 \%$ \\
\hline
\end{tabular}

Although report writers are required by National Standards (Home Office, 2000) to include a statement in the PSR of 'the offender's status in relation to literacy and numeracy', it became clear from this analysis that this specification is not always being met. The analysis showed in particular that very few referred specifically to the FT 20 Q screening tool, even though the pathfinder project had required them to make use of this at the PSR stage. However, about a quarter in each group, did go on to recommend in-depth assessment. It became evident, from this content analysis of court reports and from interviews, that PSR writers often based their assessment of basic skills on other information additional to or instead of the results of the FT 20 Q screening tool. Report writers based their assessment on school and employment records or relied on their previous knowledge of the individual. This helps to explain why the FT 20 Q screening tool was not completed for all PSRs written at the PSR stage, even though it had been a requirement for the pathfinder evaluation.

\section{Why was there attrition from screening to attending in-depth assessment?}

Clues from the statistical analysis

The statistical analysis of the database threw some light on the problems which contributed to attrition following 'positive' screening. Several variables distinguished those who were positively screened but did not attend for the initial assessment procedure for basic skills needs, and those who did attend the initial assessment procedure for basic skills needs.

An analysis of the attendance at in-depth assessment meetings was compared against the reports of school attendance for the same individuals. It was found that there was a correlation between receipt of in-depth assessment information and an offender's pattern of attendance at school in all seven pathfinder areas for all offenders attending the initial assessment procedure for basic skills needs. Significantly, less data from the initial assessment procedure for basic skills needs were received for those who attended school irregularly (261 sets of in-depth assessments were received for offenders who attended school regularly, while 115 were received for offenders who attended school irregularly), even though they were significantly more likely to be screened as likely to have basic skills needs. The likely motivational factors associated with irregular school attendance could provide an additional reason for non-attendance at the initial assessment procedure for basic skills 
needs. However, when this analysis was re-run for those specifically on a CRO or a CPRO and attendance at the initial assessment procedure for basic skills needs, no effects were reported. Perhaps those who are seen as suitable for 'rehabilitation' (the common element of the CRO and the CPRO) are also those who are more likely to be referred or to attend the initial assessment procedure for basic skills needs.

The statistical analysis also highlighted associations between attendance at the initial assessment procedure for basic skills needs and other factors: age; risk of reconviction; accommodation status; and drug and alcohol abuse. Younger offenders were significantly more likely to attend the initial assessment procedure for basic skills needs than older offenders. Those at 'low' risk of reconviction were significantly more likely to attend than those at 'high risk'. Offenders who were living in more temporary accommodation such as with friends were less likely to attend and offenders abusing neither drugs, nor drugs and alcohol were significantly more likely to attend the initial assessment procedure for basic skills needs than those abusing drugs, or drugs and alcohol. There was no association between alcohol only abuse and attendance at the initial assessment procedure for basic skills needs in all seven pathfinder areas. There was also no association between gender or ethnicity for all offenders attending the initial assessment procedure for basic skills needs. Also, when this analysis was re-run for those specifically on a CRO or a CPRO and attendance at the initial assessment procedure for basic skills needs, no effects were reported.

Clues from the content analysis of case records

The comparison of supervision plans and quarterly reports for the experimental and comparison groups revealed more about possible reasons for attrition between early identification of possible basic skills need and referral on to later stages in the process.

Table 6.2: Reference to basic skills in supervision plans

\begin{tabular}{|l|l|l|}
\hline Reference to basic skills & Experimental group & Comparison group \\
\hline Comments about basic skills & $71 \%$ & $34 \%$ \\
\hline Identified as a primary objective & $50 \%$ & $23 \%$ \\
\hline
\end{tabular}

Table 6.2 shows that basic skills needs were mentioned much less frequently in the plans for the comparison group than for the experimental group, and were less likely to be prioritised as a main objective. Although accessing basic skills provision was included in the objectives of the supervision plans for some of the comparison group, it was seldom one of the primary objectives of the supervision plan. Other objectives that were typically prioritised instead included, for example:

- Payment of fines to the court.

- Addressing alcohol and/ or drug use.

- Cognitive behavioural work.

- Health/depression/self harm.

- Attitudes to offending/victim awareness.

- Accommodation/employment needs.

The analysis (of PSRs as well as supervision plans and reviews) showed those in the comparison group tended to have different types of problems to those in the experimental group. This difference seems to be reflected in the differing priorities within supervision plans (see Table 6.3). Although a similar list of problems applied to both groups, a greater proportion of the comparison group had substance abuse problems, while more of the experimental group had health problems. 
Table 6.3: Problems identified in PSRs

\begin{tabular}{|l|l|l|}
\hline Problem identified in PSR & Experimental group & Comparison group \\
\hline Basic skills & $25 \%$ & $25 \%$ \\
\hline Alcohol abuse & $24 \%$ & $44 \%$ \\
\hline Drug abuse & $23 \%$ & $39 \%$ \\
\hline Alcohol plus drug abuse & $6 \%$ & $26 \%$ \\
\hline Employment issues & $33 \%$ & $40 \%$ \\
\hline Health issues & $50 \%$ & $35 \%$ \\
\hline
\end{tabular}

Offenders who were found to be at 'moderate' or 'high' risk of reconviction (according to OGRS2 and LSI-R ${ }^{45}$ completed by a PSR writer as part of the PSR interview) were not able to access basic skills provision because they would have been placed on an accredited offending behaviour programme as a priority objective of their supervision plans. As illustrated in Table 6.4, a marginally larger proportion of offenders were assessed as 'moderate' or 'high' risk in the comparison group (76\%) than in the experimental group (71\%). Quantitative analysis showed that those who were 'low' risk of reconviction were significantly more likely than those who were 'high' risk of reconviction to attend the initial assessment procedure for basic skills needs. Porporino and Robinson (1992), where evidence was presented, suggested that those 'higher' risk offenders are more likely to benefit from basic skills intervention than 'lower' risk offenders. However, supervision plans do not show that a larger proportion of offenders in the comparison group were required to attend accredited offending behaviour programmes.

Table 6.4: Risk of reconviction in the comparison group and the experimental group

\begin{tabular}{|l|l|l|c|}
\hline Group & 'Low' risk & 'Moderate' risk & 'High' risk \\
\hline Comparison group & $74(24 \%)$ & $90(29 \%)$ & $146(47 \%)$ \\
\hline Experimental group & $42(29 \%)$ & $49(34 \%)$ & $54(37 \%)$ \\
\hline
\end{tabular}

A higher proportion of offenders in the comparison group had addressing alcohol and drug abuse in the objectives of their supervision plan than in the experimental group (see Table 6.5). However, except for addressing alcohol and drug abuse, there was little evidence from supervision plans suggesting that offenders in the experimental group had fewer statutory demands and priorities in their supervision plans than those in the comparison group. There is therefore also no reason to suggest the comparison group may have had impeded access to basic skills provision because of the increased statutory demands and priorities of their supervision plans.

\section{Table 6.5: Objectives in the supervision plan}

\begin{tabular}{|l|l|c|}
\hline Objective in supervision plan & Experimental group & Comparison group \\
\hline Cognitive behavioural work & $94(65 \%)$ & $199(64 \%)$ \\
\hline Meeting National Standards & $49(34 \%)$ & $90(29 \%)$ \\
\hline Addressing alcohol abuse & $20(14 \%)$ & $78(25 \%)$ \\
\hline Addressing drug abuse & $26(18 \%)$ & $72(23 \%)$ \\
\hline Employment issues & $19(13 \%)$ & $53(17 \%)$ \\
\hline
\end{tabular}

Analysis of the quarterly reviews provided some clues/helped to explain why some 'eligible' offenders in the comparison group had not accessed basic skills provision even though such an objective had been specified in the supervision plan. The quarterly reviews showed that the objective to address basic skills problems had not been carried through because other priorities had taken over. Examples were impending non-compliance proceedings for failing to attend an offending behaviour programme or non-compliance in going for alcohol or drug abuse treatment. Understandably, these issues had taken on a higher priority. Other reasons in quarterly reviews for not achieving the basic skills objective of the supervision plan included:

\footnotetext{
${ }^{45}$ Risk of reconviction was measured by OGRS2 in six of the Basic Skills Pathfinder areas, and Sussex Probation Area used LSI-R. OGRS2 scores were categorised according to the criteria for the accredited offending behaviour programmes. The scores on LSI-R were aligned to those on OGRS2 (see Raynor et al., 2000).
} 
- lack of motivation to address basic skills needs;

- no basic skills needs following the initial assessment procedure for basic skills needs;

- employment had been found; and

- relapse into drug use.

Finally, a number of the quarterly reviews simply did not mention basic skills issues even though there had been an objective in the supervision plan to address basic skills needs. In contrast and rather obviously, when basic skills had been an objective in the supervision plan for those in the experimental group - that is those who had commenced tuition - this had generally been followed through in the quarterly review.

\section{A reversal of the trend: the problem of 'false positives' and other extras}

While the attrition of potentially eligible offenders was high, some offenders who were outside the intended target group were in fact included in the process of the initial assessment procedure for basic skills needs and referral to basic skills tuition. Thus, a number who were not 'positively' screened were, nevertheless, referred on through the next stages of the process.

Others who were screened 'positively' but who were not subsequently sentenced to a CRO or CPRO, but who received a CPO or a custodial sentence, were also referred on through the next stages of the process. At the planning stage for the pathfinder projects, it was agreed on ethical grounds that individuals should not be denied basic skills provision if, in exceptional circumstances, there seemed to be an area of basic skills provision from which they could benefit. This may have included individuals who were keen to get support or to polish their skills but who were generally up to standard in their basic skills. The resulting numbers going through at each stage partly camouflages the gaps in processing of those who were less equivocally eligible.

A number of those offenders who were referred to the initial assessment procedure for basic skills needs were assessed on the BSA's Initial Assessment tool and scored at or above Level 1 - that is, above the criterion level for referral used in the pathfinder projects. As Table 6.6 shows, 59 offenders $(21 \%)$ who attended the initial assessment procedure for basic skills needs in the five pathfinder areas for whom data monitoring information was received were assessed as being at or above Level 1 in both literacy and numeracy on the BSA's Initial Assessment tool. In many cases, these offenders would not have been considered appropriate for basic skills provision in the Basic Skills Pathfinder evaluation and so may not have been offered the opportunity to start basic skills provision. Depending on the pathfinder area, evidence from interviews suggest that some of the 78 offenders at or above Level 1 in literacy and the 127 at or above Level 1 in numeracy might also not have been offered the opportunity to start basic skills provision, even though they attended the initial assessment procedure for basic skills needs.

Table 6.6: Association between basic skills level and attendance at the initial assessment procedure for basic skills needs $\left(n=283^{*}\right)$

\begin{tabular}{|l|l|}
\hline BSA level & $\begin{array}{l}\text { Number attended initial assessment } \\
\text { procedure for basic skills needs }\end{array}$ \\
\hline Below Level 1 in literacy & $203(72 \%)$ \\
\hline Below Level 1 in numeracy & $153(54 \%)$ \\
\hline Below Level 1 in both literacy and numeracy & $133(47 \%)$ \\
\hline At or above Level 1 in literacy & $78(28 \%)$ \\
\hline At or above Level 1 in numeracy & $127(45 \%)$ \\
\hline At or above Level 1 in both literacy and numeracy & $59(21 \%)$ \\
\hline
\end{tabular}

* Of these 283 offenders for whom the BSA's Initial Assessment tool was received, not all offenders completed both the literacy and numeracy sections of the assessment, and this explains why the number of offenders scoring below Level 1 when added to those scoring at or above Level 1 does not equal 283. 


\section{Dropping-out from tuition}

The final stage at which attrition can occur is, of course, following attendance for tuition. An analysis of individual learning records and associated documents plus attendance records allowed a rough estimate to be made of the most frequent number of sessions attended by those who took up basic skills provision (that is, attended at least once). The average number of sessions attended, using information on all offenders who accessed basic skills provision, was six, and the most common number of sessions attended was two. From the available data, an analysis of 730 sessions attended by 127 offenders was conducted to ascertain the frequency of attendance.

\section{Table 6.7: Frequency of attendance}

\begin{tabular}{|l|c|}
\hline The average (or mean) number of sessions attended & 6 \\
\hline The most frequent (or modal) number of sessions attended & 2 \\
\hline The maximum number of sessions attended & 29 \\
\hline The minimum number of sessions & 1 \\
\hline
\end{tabular}

It is possible that some people continued to attend basic skills sessions after the data collection period finished, though the information received indicated that they had stopped attending. Once an individual has shown sufficient interest to attend on one occasion, it is likely that subsequent efforts will be made to re-address basic skills and therefore this analysis may show a worse short-term picture than a long-term might disclose. However, many more offenders did not even attend their first teaching appointment. Given this disappointingly high 'drop-out' rate, it is not surprising that progress records and tangible learning outcomes were scarce and scant.

\section{Understanding the reasons for dropping out}

Basic skills staff often found it very hard to keep track of offenders once they had dropped out of provision or once their provision ended. This was still the case even when they were still under community supervision. Specific outcome information on those who accessed basic skills provision was very rarely provided, presumably because the individuals had not attended for long enough, and the nature of preliminary outcome information had not been specified. Similarly, it is unlikely that the point had been reached where project staff decided that the individual had definitely dropped out. Occasionally, a clear reason was provided, including non-compliance and breach proceedings - although it is worth noting that some continued to attend basic skills sessions even though they were being breached because of other matters of non-compliance.

Attendance information was provided by six of the pathfinder areas: Cornwall, Dorset, Lincolnshire, Nottinghamshire, Sussex and Thames Valley. In some cases the attendance records may have excluded those who did not even turn up for the first appointment and some records may not have covered the whole of the evaluation period, therefore this analysis should be treated with some caution. However, enough information was obtained to allow an average attendance rate to be derived. Offenders failed to attend arranged basic skills appointments in 35 per cent of cases, taken as an average from all six projects. The percentage of offenders who failed to attend varied among pathfinder areas, as shown in Table 6.8. 
Table 6.8: Appointments missed

\begin{tabular}{|l|l|}
\hline Probation area & Sessions missed $^{\star}$ \\
\hline Cornwall & $53 \%$ \\
\hline Thames Valley & $36 \%$ \\
\hline Dorset & $34 \%$ \\
\hline Nottinghamshire & $33 \%$ \\
\hline Sussex & $29 \%$ \\
\hline Lincolnshire & $24 \%$ \\
\hline
\end{tabular}

* Some areas only provided the percentage of appointments attended or missed rather than full records for each office.

The information provided by four areas allowed some analysis to be conducted on the reasons why offenders did not keep basic skills appointments, and also why some dropped out after commencing tuition. Some reasons for failure to attend are outlined in Table 6.9. Illness accounted for one-fifth of failed appointments. Drugs and alcohol issues along with family and domestic circumstances were given as the reason for failure to attend a basic skills appointment in just under a quarter of cases. Similar reasons were provided by tutors and offenders who were interviewed.

Table 6.9: Reasons for failure to attend basic skills sessions ( $n=486)$

\begin{tabular}{|l|l|}
\hline Reason stated for non-attendance & Frequency \\
\hline No reason provided & $155(32 \%)$ \\
\hline Illness & $97(20 \%)$ \\
\hline Drug or alcohol problems & $63(13 \%)$ \\
\hline Family or domestic problems & $49(10 \%)$ \\
\hline Other reasons & $49(10 \%)$ \\
\hline Work reasons & $29(6 \%)$ \\
\hline Housing problems & $15(3 \%)$ \\
\hline Forgot & $15(3 \%)$ \\
\hline Training & $9(2 \%)$ \\
\hline Travel & $5(1 \%)$ \\
\hline
\end{tabular}

Tutors' accounts emphasised that, unsurprisingly, they found non-attendance dispiriting. From the observations, it became clear that the impact of non-attendance was particularly demoralising when tutors had travelled between probation offices for teaching sessions, carrying materials with them. Furthermore, attendance issues are likely to reduce the costeffectiveness of the current system of predominately one-to-one teaching.

\section{Should attendance for basic skills tuition be enforced?}

Once a probable basic skills need had been identified by screening, attendance for the initial assessment procedure for basic skills needs was usually enforceable during the period of the pathfinder evaluation. However, in most instances, attendance for basic skills tuition was not enforceable, and once an individual had been assessed, or had commenced attending, s/he was at liberty to withdraw at any time.

Opinion was divided among probation staff about the extent to which attendance at basic skills assessment or provision should be an enforceable part of the supervision plan. The primary objection to enforcement stated by most probation officers was that it could compromise the motivation of offenders to engage successfully with basic skills provision. In the words of one probation officer, 'You cannot force people to be educated'. A small number of probation officers were especially opposed to the enforcement of attendance at basic skills provision, arguing that it was inappropriate to 'link education with a punitive sanction' and that it was the kind of activity that had to be based on volition. In addition, many probation officers reported that the major focus of community supervision is to address offending and that basic skills work, unless directly linked to offending, should be voluntary. Few probation officers were aware of their area's policy for the inclusion and enforcement of attendance at basic skills provision in the supervision plan or, indeed, whether such a policy existed. The inclusion 
of basic skills as an objective in the supervision plan had generally been, ultimately, a matter of their own professional judgement and discretion.

Probation staff involved in the Basic Skills Pathfinder evaluation argued that if basic skills work by the offender is to be an enforceable part of a supervision plan, it should first be agreed, in principle that this was to be part of the court order. Some insisted that it should only be made part of the supervision plan if the offender's lack of basic skills was directly related to offending and risk of re offending. Some, suggested that it would only be realistic to enforce basic skills work for less 'serious' offenders because these tend to have fewer demands on their time in adhering to their CRO, while the 'serious' offenders are likely to have other enforceable elements in their court such as attending an offending behaviour programme. The prospect of basic skills work being enforceable for offenders with other statutory demands on them, was viewed as 'setting them up to fail'. In contrast, others pointed out that making attendance 'compulsory for a brief initial period' would be beneficial for potential learners who would be highly unlikely to take up the prospect of tuition voluntarily. As one project manager said:

For someone with the educational experience most offenders have had, there needs to be enforcement to get them there. Once they are there, they are hooked and they love it.

Skills for Life (DfEE, 2001) referred to the difficulties of motivating those who are disengaged from learning to take up basic skills provision. The poor referral and attendance rates during the Basic Skills Pathfinder evaluation bear out this point and underline the need for various measures (see Chapter 8) to reduce attrition. 


\section{How much does basic skills intervention cost?}

For the economic evaluation of the Basic Skills Pathfinder, a cost-benefit analysis was undertaken. This chapter provides an analysis of the resources and costs used for the set-up and on-going costs of the Basic Skills Pathfinder projects as well as the costs of each stage: screening; the initial assessment procedure for basic skills needs; tuition and other provision. A performance ranking of the projects for which data were available is presented, and conclusions are drawn about the resources needed to increase performance of future basic skills interventions.

\section{Choice of method for costing of the projects}

An economic evaluation is a performance appraisal that consists of measuring inputs and outputs of an intervention. Public sector interventions often produce outcomes that are not easy to measure in terms of value, therefore standard financial appraisals of public sector projects are not always appropriate (see Wolfe, 1973; Layard and Glaister, 1994 and Mishan, 1994). Two alternative techniques are available for economic evaluations of these projects: (1) cost-benefit analysis and (2) cost-effectiveness analysis. Both entail estimating the value of all resources employed in the implementation of the project, but they differ in the treatment of outcomes.

A cost-benefit analysis considers the positive effects of the intervention on participants together with the gains for the rest of society. A cost-effectiveness analysis considers only the benefits for the rest of society. The choice between these two alternatives depends on the characteristics of the project to be evaluated. For the economic evaluation of the Basic Skills Pathfinder a cost-benefit approach was adopted. In the absence of reconviction rates this technique allowed for a better understanding of how and whether the pathfinder projects worked since it was designed to take into consideration the immediate and intermediate effects of the intervention, such as increased employment opportunities or participation in education.

\section{Estimation of resource costs}

Irrespective of the approach chosen to treat outcomes, an economic evaluation requires the estimation of resources employed for the implementation of the programme. Accounting for the inputs to the Basic Skills Pathfinder evaluation entailed measuring the cost of all resources spent, both in developing the projects and in their provision. Costs of development spent before provision started are known as set-up or start-up costs and they normally include recruitment, specific training, new equipment and new premises costs. Costs of provision incurred on a day-to-day basis are known as on-going or running costs and they can be identified in standard financial records. In an economic evaluation there is a third category of costs to be considered that are typically not regarded as financial costs: non-financial costs, which are the costs of apparently free resources, like the use of unpaid mentors to act as tutors. Estimation of resource costs is also concerned with estimating the cost of replicating a project.

The second part of an economic evaluation involves the identification of outcome measures for use in a comparative analysis of the relative performance of each project and, ideally, to evaluate the overall performance of a project in relation to other projects. Under a cost-benefit approach, immediate and intermediate outcomes such as participation in employment or education would be good indicators of the short-term effects of the pathfinder projects. However, as has been mentioned earlier in this report, there were gaps and inconsistencies in the data collected, making the data on outcomes and progress difficult to interpret. Therefore, alternative measures of performance had to be employed. 


\section{Sources of information}

Data on the cost of resources consumed by the pathfinder projects were collected from the projects. The costing strategy followed to evaluate the Basic Skills Pathfinder was based on the Guidance Notes provided by the Home Office. ${ }^{46}$ Most of the financial information needed to complete the template could have been obtained from standard financial records. However, each service was delivering several projects at the same time, in addition to their basic skills project, and each of these projects involved some shared resources, making it difficult to distinguish the costs for one project alone. For example, in order to obtain accurate data on the costs of providing the basic skills project, staff would have had to keep track of the time they spent on the pathfinder, while the use of premises and equipment, if shared, would have had to be apportioned. One of the difficulties in the collection of financial data appeared to be the need to gather such information from diverse sources, such as project managers, financial officers and delivery staff. Therefore, in order to reduce the burden of data collection on pathfinder projects, a simplified version of the template recommended by the Home Office ${ }^{47}$ was used.

An additional complication for the economic evaluation was the scarcity of data on outcomes and progress received by the evaluation team. In order to be able to rank the pathfinder projects in terms of their activities, a performance indicator was calculated from the monitoring data submitted by the projects.

\section{The analysis of costs for the pathfinder projects}

As a result of the difficulties in recording financial data, each pathfinder used a different format to report expenses. Given these differences, the evaluators had to make some assumptions, regarding the period of analysis and staff costs per hour, in order to compare costs across projects. Each assumption was the result of some disparity in the format of the data received and they applied to on-going costs only. Set-up costs were left as they were reported since they represented a one-off expenditure in preparation for delivery.

Period of analysis

The period of input of on-going costs varied from three months to the whole of the evaluation period (12 months). Most of the data received applied to 2001, therefore the analysis was based on a typical quarter (three months) in 2001. Whenever the period of input was not a quarter, a monthly figure was calculated by dividing the total by the number of months of input.

\section{Staff costs}

The cost of staff time spent on the pathfinder projects was recorded either by hour, by month or for the whole of the evaluation period. In order to gain some indication on the costs of provision, costs per hour were calculated for those projects for which it was possible to do so. When monthly data was reported the hourly figure was calculated on the basis of 35 working hours per week. ${ }^{48}$

\section{Set-up costs}

Table 7.1 displays reported set-up costs across the pathfinder projects. Total set-up costs ranged from less than $£ 4,000$ to close to $£ 16,000$. It could be argued that totals are not suitable for comparison because a lot of data on set-up costs were missing. However, even considering training costs available for most of the pathfinder projects, the reported expenses ranged from less than $£ 500$ to $£ 8,000$. This was consistent with the disparity of implementation models used across the pathfinder areas. In general, the volume of set-up costs depends upon the initial position and experience in basic skills provision. For example, areas recruiting new specialist staff spent more than other areas on staff and areas with

\footnotetext{
${ }^{46}$ Measuring Inputs: Guidance for Evaluators, Crime Reduction Programme Guidance Note 3. RDS. Home Office, 2000 
established basic skills provision of some form required less training and awareness-raising sessions than others with less experience.

Staff set-up costs included recruitment and time spent in project development. Training set-up costs included training for administering instruments and providing basic skills. Equipment set-up costs were mainly on ICT. The 'other' category included non-classified set-up costs and, in the case of Nottinghamshire, the initial cost of WRAT bags (see Appendix C).

Probation in Partnership was a capacity building project from which the pathfinder projects in Cornwall benefited. The financial data received for Probation in Partnership included a wide variety of costs incurred during the period January 1999 to June 2000. Furthermore it was reported that the Probation in Partnership project was partly funded by the European Social Fund. Strictly speaking set-up costs should include new or additional resources needed for developing the pathfinder projects and exclude resources that were already in place when the pathfinder was awarded. From the information available it seems that Probation in Partnership pre-dates the Basic Skills Pathfinder and it was reported that: 'In addition to Cornwall Probation Service staff, a total of 146 members from a range of statutory and nonstatutory partners (including nine staff from Westcountry Training and Consultancy Services Ltd.) were involved in this capacity building project'. Therefore, it was not easy to determine how much of these training costs to apportion to the Basic Skills Pathfinder. For all these reasons the costs of Probation in Partnership have been included separately from the other activities. The figure includes the costs of Probation in Partnership apportioned at 40 per cent, which is the percentage of staff working on the pathfinder over the total of probation staff trained under the Probation in Partnership project. None of these costs have been included in the on-going category because these costs took place much earlier than the evaluation and it has not been possible to determine whether or how much of the activities undertaken by Probation in Partnership were part of the day-to-day delivery of the pathfinder project.

Table 7.1: Total set-up costs, in pounds

\begin{tabular}{|c|c|c|c|c|c|c|c|}
\hline & Cornuall & Cumbria & Dorset & Lincolnshire & $\begin{array}{l}\text { Notting- } \\
\text { Hamshire }\end{array}$ & Sussex & Thames Valley \\
\hline Staff & 3,977 & & & & & 4,248 & 2,916 \\
\hline Training & 4,950 & & 225 & 8,000 & 2,080 & 900 & 3,200 \\
\hline Travel & 1,167 & & & & & & 60 \\
\hline Equipment & & & 2441 & & & 4,358 & 9,800 \\
\hline Other & & 1,000 & & & 3,480 & & \\
\hline Total & 10,095 & 1,000 & 2,666 & 8,000 & 5,560 & 9,506 & 15,976 \\
\hline $\begin{array}{l}\text { Probation in } \\
\text { Partnership }\end{array}$ & $26,268.40$ & & & & & & \\
\hline
\end{tabular}

\section{On-going costs}

Detailed data on staff costs were requested with the aim of being able to distinguish between the costs of the different stages of the pathfinder projects. To the extent that this was possible, the cost data was disaggregated for each pathfinder. As Table 7.2 suggests, however, a lot of data were not reported and therefore caution is urged when reading the overall figures

Two additional drawbacks of the data received are worth bearing in mind. First, some staff categories are not comparable across pathfinder areas. For example, the 'multitask staff' category presented for Thames Valley refers to the three basic skills officers whose tasks were to 'do the post-sentence assessments, motivate offenders to improve their basic skills and match those who are interested with a mentor [and] ...collect some of the monitoring information needed for the pathfinder'. In the absence of data on how much time these basic skills officers spent on each of their responsibilities, it was not possible to cost each of these activities under the relevant heading. Similar problems arose with other activities that were shared by several members of staff, when information was not available on how much time each activity consumed. Management and administration responsibilities were sometimes shared by several members of staff and it was difficult to apportion costs into these categories. 
Secondly, the financial data received was a mixture of available and consumed resourcesmeaning available or consumed for the basic skills project. Available resources are those like a basic skills tutor delivering provision full-time. Consumed resources would be the number of hours that this tutor actually taught. Differences between available and consumed staff time arise, for example, through non-attendance where a session of basic skills tuition was available but not taught. In the event of non-attendance, the missed session will appear as spent when available resources were reported but not if only consumed resources were reported. Where projects reported staff categories and whether they were full-or part-time, these were available resources. Other projects reported only the amount of hours actually consumed but not the cost of resources not consumed. Cornwall, Cumbria and Dorset reported consumed resources only. Thames Valley reported available resources. Lincolnshire, Nottinghamshire and Sussex reported both. As is apparent from Table 7.2, reporting consumed resources alone resulted in smaller figures and therefore it seemed that in general not all resources available were used. Clearly attrition rates were very much related to the issue of availability and the use of resources across the pathfinder projects.

Bearing in mind the limited comparability of these data, a ranking of services in terms of staff expenses can be constructed. To evaluate the relative performance of each pathfinder project a ranking requires a reference point from which to position projects. The simplest referenced ranking consists in taking the difference between each pathfinder's costs and the average cost across the seven pathfinder projects. Under this classification the pathfinder projects would be situated above or below the mean. The way to interpret the ranking is as follows. Take the average staff expenditure across the seven projects, that is $£ 15,026$. For each pathfinder the ranking tells how many percentage points more or less than the average were spent in this pathfinder. Thames Valley spent 70 per cent more than the average, therefore their ranking indicator is 1.7. Cornwall spent a half of the average, therefore their ranking indicator is 0.53 . By construction, the raking indicator for the mean is one. On the basis of deviations from the unitary mean, Thames Valley and Nottinghamshire were ranked first and second, well above and hence more expensive than the average. Sussex was third just on the average. The other four were less expensive than the average.

The wide disparity in the format and quality of the reported financial data made it impossible to calculate average costs of each cost category across the projects. Furthermore, the data available for cost categories other than staff were insufficient for any conclusions to be drawn. The lack of financial data is, however, illustrative of the difficulties encountered in collecting it.

Table 7.2: Quarterly on-going costs, in pounds

\begin{tabular}{|c|c|c|c|c|c|c|c|}
\hline & Cornwall & Cumbria & Dorset & $\begin{array}{l}\text { Lincoln- } \\
\text { Shire }\end{array}$ & $\begin{array}{l}\text { Notting- } \\
\text { Hamshire }^{1}\end{array}$ & Sussex & $\begin{array}{l}\text { Thames } \\
\text { Valley }\end{array}$ \\
\hline Screening & $1,082.60$ & & $3,401.80$ & & & & $2,524.00$ \\
\hline $\begin{array}{l}\text { The initial } \\
\text { assessment } \\
\text { procedure for basic } \\
\text { skills needs }\end{array}$ & $1,712.40$ & & $1,690.10$ & & & $1,653.00$ & 944.60 \\
\hline Teaching & $3,673.80$ & & $1,960.80$ & $8,637.60$ & & $6,612.00$ & $3,838.40$ \\
\hline Management & $1,377.70$ & $1,948.40$ & 178.70 & 900.00 & & $1,805.30$ & $4,944.00$ \\
\hline Administration & 185.40 & 565.40 & $1,554.20$ & $1,596.00^{2}$ & & $5,089.60$ & \\
\hline Multitask & & & & & & & $13,224.00$ \\
\hline Staff & $8,031.90$ & $12,513.70^{3}$ & $8,785.50$ & $11,133.60$ & $24,082.00$ & $15,159.90$ & $25,475.00$ \\
\hline Training & & & & 750.00 & 324.00 & & \\
\hline Travel & 237.60 & & & & 505.90 & & $1,022.00$ \\
\hline Premises & & & 937.50 & & 539.50 & & $8,358.30^{4}$ \\
\hline Equipment & & & & & 516.50 & & \\
\hline Other $^{5}$ & & & 60.70 & & $1,683.00$ & $1,295.70$ & \\
\hline Evaluation & 352.20 & 71.60 & & & & & 144 \\
\hline Total & 8621.7 & $12,585.30$ & $9,783.80$ & $11,883.60$ & $27,650.90$ & $16,455.60$ & $34,999.30$ \\
\hline Ranking $^{6}$ & 0.53 & 0.83 & 0.58 & 0.74 & 1.60 & 1.01 & 1.70 \\
\hline
\end{tabular}

\footnotetext{
${ }^{1}$ Data from the Positive Action Learning Support (PALS) only.

2 Estimated at $£ 7.2$ an hour and 35 hours a week, following guidelines of the Home Office's Data Collection Tool.

${ }^{3}$ Added to this figure $£ 10,000$ reported to be the estimated cost of the subcontracted collaboration with NACRO.
} 
${ }^{4}$ Includes Premises, Utilities and the use of Equipment. Estimated following the costing strategy proposed in Hudson et al. (2001).

${ }^{5}$ Costs of teaching materials in Dorset, publicity in Nottinghamshire and overheads in Sussex.

${ }^{6}$ Deviations from the mean for staff costs only. The mean is one.

Screening and the initial assessment procedure for basic skills needs were two activities which were well defined in the pathfinder and information about the personnel involved in each and how many tests were completed was available. Comparing the actual cost of carrying out these two activities was a better means of evaluating the relative performance of the projects in terms of costs.

\section{Cost of screening}

Table 7.3 reports the effective cost of screening. The cost per screening was calculated on the basis of an average of ten minutes per screening. The number of screenings per quarter was derived from data monitoring information reported by the projects. For the two services for which data monitoring information was not available, the number of screenings completed was obtained from the database. Table 7.3 shows that a combination of the cost per screening and the number of screenings completed accounted for large differences in the total cost of screening across the projects. It also shows how total figures can be misleading. On the basis of the data reported by the projects, screening appeared to be more expensive in Dorset than in Thames Valley. However the number of screenings reportedly completed by Dorset was half that of Thames Valley, and therefore the total figure was higher for Thames Valley despite the fact that screening in Dorset was actually more expensive. This example illustrates that bigger probation areas are likely to spend more resources on comparable activities than smaller ones and it explains partly the differences in the total cost of the pathfinder projects across areas.

Table 7.3: Quarterly cost of screening, in pounds

\begin{tabular}{|l|l|l|l|l|l|l|l|}
\hline \multirow{2}{*}{$\begin{array}{l}\text { Screening } \\
\text { per quarter }\end{array}$} & Cornwall & Cumbria & Dorset & $\begin{array}{l}\text { Lincoln- } \\
\text { shire }\end{array}$ & $\begin{array}{l}\text { Notting- } \\
\text { hamshire }\end{array}$ & Sussex & $\begin{array}{l}\text { Thames } \\
\text { Valley }\end{array}$ \\
\cline { 2 - 8 } & $\begin{array}{l}\text { PSR } \\
\text { writers }\end{array}$ & $\begin{array}{l}\text { NACRO } \\
\text { tutors }\end{array}$ & $\begin{array}{l}\text { PSR } \\
\text { writers }\end{array}$ & $\begin{array}{l}\text { PSR } \\
\text { writers }\end{array}$ & $\begin{array}{l}\text { PSR } \\
\text { writers }\end{array}$ & $\begin{array}{l}\text { PSR } \\
\text { writers }\end{array}$ & $\begin{array}{l}\text { PSR } \\
\text { writers }\end{array}$ \\
\hline E/h & 14.10 & $\mathbf{8 . 6 4}{ }^{\star}$ & 18.80 & 15.00 & $\mathbf{1 7 . 4 6}$ & $\mathbf{1 7 . 4 6}$ & 14.00 \\
\hline Cost/screening & 2.30 & $\mathbf{1 . 4 4}$ & 3.10 & 2.50 & $\mathbf{2 . 9 0}$ & $\mathbf{2 . 9 0}$ & 2.30 \\
\hline Completed & 106.00 & 216.00 & 366.00 & 387.00 & 516.00 & 510.00 & 786.00 \\
\hline Total cost & 248.10 & $\mathbf{3 1 1 . 0 4}$ & $1,143.80$ & 986.30 & $\mathbf{1 , 0 6 6 . 4 0}$ & $\mathbf{1 , 0 5 4 . 0 0}$ & $1,836.60$ \\
\hline
\end{tabular}

*The bold-italic figures have been estimated. PSR writers have been assigned the wage of probation officers following the Guidelines of the Home Office's Data Collection Tool (Emmanuel Solutions Limited, 2001). In the absence of data on the wages of NACRO tutors in Cumbria, they were assigned the same wage as basic skills tutors in the Sussex Probation Area, also employed by NACRO. This occurred because NACRO tutors in Cumbria also carried out the screening process. The other wages per hour were reported by the pathfinder areas.

\section{Cost of the initial assessment procedure for basic skills needs}

Table 7.4 shows the cost of the initial assessment procedure for basic skills needs and the cost of attrition from referral to attendance at the appointments for the initial assessment procedure for basic skills needs. Data on the cost of the initial assessment procedure for basic skills needs was only available from three pathfinder areas. Where two figures are shown, it indicates that more than one category of staff was involved. The predicted cost was calculated on the assumption that all referrals to the initial assessment procedure for basic skills needs resulted in attendance at this. ${ }^{49}$ The actual cost was the cost of attended appointments. The difference expresses quarterly loss through attrition of offenders. As can be seen, the cost of attrition was higher in Dorset than in the other pathfinder areas, even if the cost per hour was not that much higher than in the other areas. According to the monitoring data, on average only ten per cent of the referrals made to the initial assessment procedure for basic skills needs resulted in attendance in Dorset, while that percentage was

\footnotetext{
${ }^{49}$ That is number of referrals multiplied by the cost of the initial assessment procedure for basic skills needs.
} 
50 per cent for the other two pathfinder projects. Thus attrition rates can generate costs and potentially make a programme uneconomic even in the absence of issues regarding the design and organisation of provision. The cost of attrition rates was also illustrative of the differences between consumed resources as reported by Dorset, and available resources as reported by Thames Valley.

Table 7.4: Quarterly cost of the initial assessment procedure for basic skills needs, in pounds

\begin{tabular}{|l|l|l|l|}
\hline $\begin{array}{l}\text { The initial assessment } \\
\text { procedure for basic } \\
\text { skills needs } \\
\text { per quarter }\end{array}$ & Dorset & Sussex & Thames Valley \\
\cline { 2 - 4 } & Basic skills tutor & $\begin{array}{l}\text { Basic skills tutor/ basic } \\
\text { skills co-ordinator }\end{array}$ & Basic skills officers \\
\hline E/h & 11.50 & $8.64 / 9.73$ & 9.80 \\
\hline Predicted cost & $1,345.50$ & 220.40 & $1,028.00$ \\
\hline Actual cost & 138.00 & 110.20 & 558.00 \\
\hline Difference & $1,207.50$ & 110.20 & 469.90 \\
\hline
\end{tabular}

\section{Cost of provision}

Table 7.5 presents the costs of provision. Where two figures are shown, it indicates that more than one category of staff was involved in provision. The tutors (volunteer mentors) in Thames Valley were assigned the minimum wage for the purposes of analysis. For the length of sessions in each pathfinder, see Appendix C. The cost per offender was calculated using the average number of sessions (less than six) attended as obtained in chapter 5 .

Table 7.5: Cost of provision

\begin{tabular}{|l|l|l|l|l|l|}
\hline Provision & Cornwall & Dorset & Lincolnshire & Sussex & Thames Valley \\
\hline & $\begin{array}{l}\text { Basic skills } \\
\text { tutors }\end{array}$ & $\begin{array}{l}\text { Basic skills } \\
\text { tutors }\end{array}$ & $\begin{array}{l}\text { Basic skills } \\
\text { tutors }\end{array}$ & $\begin{array}{l}\text { Basic skills } \\
\text { tutors/basic skills } \\
\text { co-ordinator }\end{array}$ & $\begin{array}{l}\text { Mentor co- } \\
\text { ordinator } \\
\text { /mentors }\end{array}$ \\
\hline E/h & 18.80 & 11.50 & $13.00 / 11.00$ & $8.60 / 9.70$ & $12.70 / 3.70$ \\
\hline E/session & 28.20 & 34.50 & 12.00 & 13.80 & 16.40 \\
\hline E/offender & 160.74 & & 68.40 & 78.53 & 93.48 \\
\hline
\end{tabular}

Of the five services for which data were available, only Dorset provided basic skills tuition in a group context. Of the other four pathfinder projects where provision was one-to-one, Cornwall appeared to have had the highest cost per hour, per session and per offender. Once again, the total staff costs did not reflect this feature due, in part, to differences in the take-up of provision, and to the fact that Cornwall reported only consumed resources.

Without data about the number of offenders attending group provision in Dorset, it was not possible to calculate the cost per offender. Non-attendance to basic skills appointments is crucial for the analysis of the cost of provision. If only one offender attended sessions in Dorset, the cost would have been $£ 196.65$. However, if in any session, there were two offenders, the cost per offender would have fallen to $£ 98.33$, while if the average number of offenders in the group was three, the cost per offender would have fallen to $£ 65.55$. Thus, based on data from Dorset, with an average of three or more offenders attending each session, group provision would have been cheaper than one-to-one.

\section{Performance ranking of the pathfinder projects}

The scarcity of data on outcomes and progress made it impossible to link the likewise limited data on costs to any reliable measure of outcomes. In order to obtain an idea of the relative performance of the pathfinder projects a performance indicator was calculated using data 
reported by areas through the data monitoring form (see Chapter 2). The indicator was constructed for the five pathfinder projects which supplied monitoring data. The following ratios were considered when calculating the ranking of performance:

Screenings completed to PSRs written. This ratio was favourable to smaller projects that would not have been able to complete as many screenings as larger projects in absolute terms.

Referrals to the initial assessment procedure for basic skills needs to non-referrals. This ratio was favourable to those projects where the referral system worked better.

Attendance at the initial assessment procedure for basic skills needs to non-attendance. This ratio was favourable to projects where attendance was high, irrespective of the quality of implementation of the basic skills project.

Initial assessment procedure for basic skills needs completed to attendance. This ratio was favourable to projects where an effort was made to complete the initial assessment procedure for basic skills needs when offenders attended.

In addition, average basic skills commencements were considered so as to include tuition. For each of the four ratios and commencements a ranking of pathfinder projects was calculated. It was found that some projects were above the average performance and some projects were below the average. The performance indicator was the mean of these five rankings for each pathfinder. A performance indicator constructed like this prevents an area that performs very well in just one activity (Nottinghamshire were above average only in commencements) to have a higher ranking than areas that perform just fine in three activities (Dorset was above average in the first and last ratio and on average in the second ratio). Therefore, two performance indicators were constructed. The first one was the unweighted mean of the five rankings, attaching the same weight to each ranking. The second one gave more weight to completed initial assessment procedures for basic skills needs and basic skills commencements. ${ }^{50}$ The weighted indicator could be regarded as a more desirable way to judge performance because it favours projects where provision was higher.

Table 7.6 presents the performance ranking for the five projects for which these data were available and, for comparison, it also shows the corresponding rank indicator of the costs of staff as in Table 7.3. The average across the five projects for all these indicators was one, therefore indicators higher than one represent projects that did better than the average and vice versa. In order to interpret the rankings of Table 7.6 correctly it is useful to bear in mind that staff costs above average are more expensive while performance above average indicates better performance.

Table 7.6: General ranking

\begin{tabular}{|l|l|l|l|l|l|}
\hline & Cumbria & Dorset & Nottinghamshire & Sussex & Thames Valley \\
\hline $\begin{array}{l}\text { Performance } \\
\text { indicator }\end{array}$ & 0.66 & 0.86 & 0.87 & 1.27 & 1.35 \\
\hline $\begin{array}{l}\text { Weighted } \\
\text { performance } \\
\text { indicator }\end{array}$ & 0.72 & 0.75 & 1.04 & 1.15 & 1.33 \\
\hline Staff costs rank & 0.8 & 0.6 & 1.6 & 1.0 & 1.7 \\
\hline
\end{tabular}

Before comparing the ranking of projects it is worth noting that weighting performance generates slight yet meaningful changes. All projects retained their rankings but those with higher commencements and more completed initial assessment procedures for basic skills needs improved their indicator. Nottinghamshire went from ranking below average performance under the unweighted indicator to ranking as average performance in the weighted indicator - probably due to the fact that they had the highest reported average number of basic skills commencements.

${ }^{50}$ The weights were 5 for commencements; 4 for IA completed/attendance; 3 for IA attendance/non-attendance, 2 for IA referrals/non-referrals and 1 for screenings/PSR written. 
In terms of the two proposed performance indicators, Sussex and Thames Valley appeared to be above the average, hence performed better than the other three. By comparing the proposed performance ranking with the reported staff costs ranking it can be assessed whether the projects delivered 'value for money'. Being ranked second on performance (hence relatively good performance) and third on reported staff $\operatorname{costs}^{51}$ (hence relatively inexpensive), Sussex seemed to have delivered 'good value for money'. From Tables 7.4 and 7.5, it can also be seen that the initial assessment procedure for basic skills needs and provision were also relatively inexpensive in Sussex. Thames Valley ranked first on the two performance indicators and it was also the most expensive project in terms of reported staff costs, therefore it seemed that they also delivered 'value for money'. If the ranking on staff expenses were to be taken as an approximation to expected performance, meaning that more expensive projects should be expected to deliver more, it should have been expected that Nottinghamshire was ranked second or at least above average on performance as well. Under the unweighted performance indicator, it did not seem that Nottinghamshire was delivering value for money as good as average. Weighting performance brought Nottinghamshire up to the average but not up to rank second. Conversely, Cumbria and Dorset were ranked below average spending and performance. Nevertheless, it has to be noted that a lot of data from Cumbria is missing and Dorset reported only consumed resources, which would give smaller figures if some available resources were not used.

From the data monitoring information it can be argued that the project at Sussex was on a smaller scale compared to Nottinghamshire and Thames Valley in terms of referrals to the initial assessment procedure for basic skills needs, attendance and attrition. The proposed performance indicator penalises larger areas with higher attrition. Larger areas had to spend more for the same level of provision but they also lost more with the same level of attrition. If they spent more but had higher rates of attrition they delivered less 'value for money'. By tackling attrition rates the overall economic performance of the project can be improved. Furthermore, by construction of the performance indicator larger areas could benefit more than smaller areas from tackling attrition rates. Additionally under high levels of attrition the distinction between available and consumed resources complicates the economic analysis. Resources like staff time may be in place for consumption within the basic skills project but may be displaced to other tasks within the probation area when appointments are not kept, though not necessarily tasks related to the basic skills project.

The scarcity and disparity of the data available for economic evaluation prevented further assessment of the economic performance of the pathfinder projects. However this lack of data does not necessarily mean poor organisation. Several examples presented through the analysis illustrate how shared responsibilities can complicate the costing of an intervention. Good financial data entails all the staff involved in the design and implementation of the pathfinder to inform of their activities, requiring additional management responsibilities. Nevertheless, this only needs to be done on a quarterly basis during the evaluation period, and the cost of collecting this information can be discounted from the cost of provision.

From the analysis of set-up costs, it seemed that preparing for provision of the Basic Skills Pathfinder required staff time and recruiting costs, training for administering tests, basic skills and learning difficulties and investment in some computerised equipment.

Not surprisingly, from the analysis of ongoing costs, it appeared that staff costs were the main component of resources used for the pathfinder projects. Delivery involved four types of activities: screening; the initial assessment procedure for basic skills needs; basic skills tuition; and management and administration. Shared responsibilities across members of staff made the analysis of management and administration rather difficult. Nevertheless, the first two of these activities could be analysed with the data available. On average, screening and the initial assessment procedure for basic skills needs consumed staff time to the values $£ 2.60$ and $£ 9.70$ per completed screening and the initial assessment procedure for basic skills needs, respectively. These costs do not include the administration costs of collating these instruments; though the cost of administering these instruments, if they were to be replicated in other areas, can be estimated using these figures. Regarding provision, the average cost of

\footnotetext{
${ }^{51}$ Sussexwould retain rank third on costs even if the estimated figure for screening in Table 7.3 was added to reported staff costs.
} 
an hour of teaching was $£ 11.10$. Group provision was more expensive per hour but, if reasonable attendance for group provision could be guaranteed, then group provision could be cheaper than one-to-one.

Attrition at the different stages of the pathfinder turned out to be an important variable for the economic success of the project. Each in-depth assessment appointment missed could have meant a loss for the projects of close to $£ 10$. Each 1.5 hours tuition session not attended could have meant a loss of over $£ 15$. From the analysis of the general ranking of projects for which data were available, it seemed that the size of the area in terms of the potential target group was also an issue for expenses and potential losses. Irrespective of the size, however, it looked as if tackling attrition rates at different stages would undoubtedly improve the economic performance of the pathfinder projects.

\section{Summary}

Staff costs were the main component in a cost-benefit analysis. On average, each screening and each initial assessment procedure for basic skills needs undertaken consumed staff time to the value of $£ 2.60$ and $£ 9.70$ respectively, excluding administrative costs. The average cost of one session (1.5 hours) of individualised teaching was $£ 15$. Frequent missed appointments therefore mount up to a considerable loss. Tackling the attrition rates would undoubtedly improve the economic performance of basic skills provision. Group provision was more expensive per hour; however, if attendance to group provision was guaranteed, then group provision would be cheaper than one-to-one. 


\section{Improving the process, increasing success}

This final chapter draws together the main implications from the findings of the evaluation of the Basic Skills Pathfinder. It is intended that some of these conclusions and recommendations will provide useful learning points for implementing each stage of basic skills provision, and that they will inform guidelines from the NPD for a national rollout of basic skills provision within community supervision.

It is clear from the findings of this evaluation that addressing basic skills needs presents a continuing challenge for the Probation Service, but both the extensiveness and implications of poor basic skills make this a challenge that should be taken on. The relevant work for probation staff should be integrated into case management systems to underline its importance and to ensure that more of the target population access basic skills provision. There are three clear stages which require the co-operation and participation of offenders who might have basic skills needs. In between each of these stages and alongside them, there are a range of essential professional activities to support the process. These stages and activities are shown diagrammatically in Figure 8.1. Learning points and recommendations have arisen from the pathfinder projects for each of these stages and practice issues.

\section{Stage 1: Screening}

All staff thought that offenders should have had the opportunity to be screened for basic skills needs, but there was some disagreement about when this should be undertaken and about the choice of tool. The majority of probation officers interviewed thought that, ideally, screening should be undertaken as part of the assessment during the preparation of court reports. A minority thought that time constraints when preparing reports, plus the offender's apprehension about the outcome of appearing in court, were pressures that might get in the way of screening at the PSR stage.

Although there were some objections to comprehensive, rather then selective, screening at the PSR stage, by the end of the pathfinder period the proportion of PSRs with screening had increased in most areas, indicating that it would be feasible to screen at the PSR stage. However, evidence has not been collected on whether the screening process would be more effective at the start of community supervision rather than at the PSR stage. As screening at the PSR stage is the agreed national objective, there should be some inbuilt flexibility to allow for screening also to be done at a later point in cases where there has been good reason to omit it at the time of preparing a court report.

Although there were criticisms of the FT 20 Q screening tool, it proved acceptable to most users within the pathfinder areas and was valued for the speed and ease with which it could be used. In order for the FT $20 \mathrm{Q}$ screening tool to be used in the long-term, some probation officers advised that it should be refined to make it more appropriate for use with offenders. New alternative screening tools should be reviewed by the NPD for strengths and weaknesses and for their potential appropriateness for use within community supervision. Staff welcomed an opportunity for basic skills needs to be addressed in a systematic way. If there is to be a future requirement for all probation officers to carry out the screening, there is a training implication to ensure that it is carried out in a way that minimises the number of 'false negatives' - that is, those who do have a basic skills need but are not identified as such by the screening tool. Future training could include a greater focus on strategies to motivate offenders to engage in the screening process. 
Figure 8.1: The process of addressing basic skills needs

a.

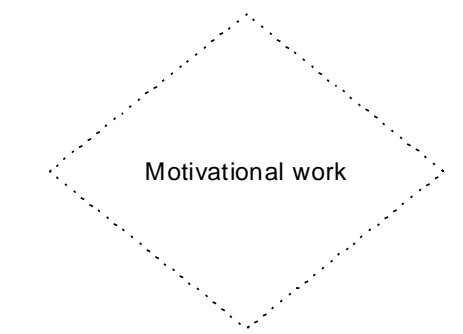

\section{SCREENING}

b.

$$
\text { Referral }
$$

Motivational work

Monitoring

2. INITIAL ASSESSMENT

C.

Referral

Motivational work

Monitoring

Support

\section{TUITION I COURSE}

d.

Motivational work

Monitoring

Support

Maintenance 


\section{Stage 2: The initial assessment procedure for basic skills needs}

The responses of those involved in the initial assessment procedure for basic skills needs suggest that it would be more appropriate, in the long-term, if this is a briefer process than was the case during the Basic Skills Pathfinder evaluation. Having to complete as many assessment tools as required during the pathfinder evaluation could be counterproductive to engaging offenders in learning. The main aim of the initial assessment procedure for basic skills needs should be to identify those offenders who could benefit from basic skills support and to motivate them to attend basic skills provision.

The BSA's Initial Assessment tool that was used in the evaluation is now out of date. The revised version of the BSA's Initial Assessment, mapped to the National Standards for literacy and numeracy (DfEE, 2001), is now available, as well as Cambridge Training and Development's (CTAD's) Target Skills. NPD should review the strengths and weaknesses of new tools with a view to recommending those which are most suitable for use with offenders sentenced to community supervision.

Further thought should be given to which psychometric instruments, if any, should be used. The feasibility of assessing speaking and listening skills should also be explored, including potential methods to assess speaking and listening, and assessment of learning styles might be useful (as reviewed by Adey et al., 1999). A shortened version of the additional background information form could also be made available to complement the information collected by OASys, the Offender Assessment System that has been developed for use in criminal justice services.

Tutors judged assessment tools, not simply for their assessment potential, but according to whether they were likely to deter or to attract potential learners. Instruments that were timeconsuming and too reminiscent of school tests were frowned upon whereas instruments that help to engage or motivate an adult with poor basic skills were favoured or recommended. Tools which worked best were those which provided a focus for developing a shared learning plan (such as the additional background information form), or which could demonstrate to the individual that that tuition sessions could be enjoyable (like the Raven's Progressive Matrices).

\section{Stage 3: Tuition}

The Basic Skills Pathfinder projects benefited from the expertise and dedication of those responsible for basic skills tuition. Tutors had at least one teaching qualification and most were keen to enhance their professional development. However, the tutors tended to experience a sense of isolation from others working in their field and also felt challenged by the demands of teaching some fairly difficult and often unmotivated people. They would be helped by induction programmes, regional meetings and availability of information about training opportunities and conferences. Opportunities for discussion should be facilitated, perhaps through a website or regional meetings for tutors involved in the provision of basic skills within the context of community supervision. Support and encouragement are needed for the development of effective working relationships between basic skills tutors and probation staff, though ultimately this depends on the interpersonal skills and networking abilities of the basic skills tutors.

\section{Effective teaching}

The Common Inspection Framework (CIF) now provides national criteria for quality in postcompulsory education and the National Research and Development Centre (NRDC) for adult basic skills is researching effective practice in the teaching of literacy, language and numeracy skills. At the outset of the pathfinder there was little research evidence on what constitutes effective basic skills teaching (DfEE, 1999; Brooks et al., 2001). Tutors should ensure that they incorporate the developments of the Skills for Life (DfEE, 2001) strategy into their planning and teaching, and should take account of different learning styles. A greater 
focus on speaking and listening should be considered. Individual learning plans should be based on the National Standards for Literacy and Numeracy (DfEE, 2001) and the relevant adult curricula.

\section{The benefits of group teaching}

Some recent developments in basic skills tuition have focused on the benefits of group teaching rather than purely individualised learning within a group context (BSA, 2001b). The training in the adult curricula to which all tutors had access, gives pointers about how to structure a whole class teaching session and about how to differentiate activities. It is important that tutors working within the context of community supervision keep abreast of new developments in teaching basic skills, and that they experiment with alternative methods, including group teaching. It is also possible that if more basic skills provision were within a group context, then more offenders could access provision for a greater number of hours each week at a reduced cost.

\section{Using information and communication technology (ICT)}

Recent reports have emphasised the potentially important role of ICT in basic skills teaching (BSA, 2000a; DfEE, 2001), but have pointed out that ICT has been under-exploited by basic skills tutors (DfEE, 1999a/2001). Fifty per cent of adults with poor skills said they would improve their basic skills if they could do so through the medium of ICT (DfEE, 2001). There are several apparent benefits:

- There is no perceived stigma related to adult learning of ICT skills.

- ICT skills are recognised as of increasing importance.

- ICT includes 'fun ways to learn' which contrast with memories of school.

Furthermore, through ICT, new approaches to the teaching of basic skills can be used, such as digital TV (DfEE, 2001; BSA, 2000a).

\section{Accommodation and other resources for tuition}

If basic skills provision is going to become an integral part of the work of the NPS, then some provision must be both visible and seen to be valued by both probation staff and offenders. Ideally, to complement provision in the community, probation offices should have a room reserved for teaching basic skills which conveys to learners that basic skills work is an aspect of community supervision of sufficient importance to warrant a designated space. Several tutors reported protracted negotiations to obtain appropriate rooms to run group sessions. It is important that those individuals in probation areas with responsibility for basic skills work recognise that group sessions are a potentially effective and cost-effective way of delivering basic skills, and that the availability of rooms of appropriate size is fundamental for group sessions to take place.

Where learning takes place in a group situation, ideally it should be possible for more than one learner to have access to a computer at the same time. Tutors who cover more than one office should be provided with a laptop for teaching sessions, unless these are already available in each office. There should be sufficient funding for the purchase of up-to-date resources, mapped to the National Standards for Literacy and Numeracy (DfEE, 2001) and the relevant adult curricula.

\section{Diversifying approaches to basic skills provision}

Recent reports and research underline that diversity of provision is important so that learners can access the form of provision which most suits them (BSA, 2000a; DfEE, 2001). In addition to development of group provision, other ways of diversifying could be explored. Diversity could encompass, for example, workshops on specific topics; drop-in centres; distance learning; family literacy programmes; intensive provision; and employment-related 'bite-sized' courses. 
Most basic skills provision within the pathfinder areas was reported as being one-to-one for an hour or an hour and a half a week. However, it has been found that intensive provision can increase the likelihood of progress (Brooks et al., 1996; Brooks et al., 2001a). 'Bite-sized' courses which tap into specific interests have been recommended to motivate adults who have become 'disengaged' from learning (BSA and Learning and Skills Council, 2001). Therefore the National Standards for Literacy and Numeracy (DfEE, 2001) and the relevant adult curricula could be the basis for developing a series of basic skills modules for use within community supervision. A potentially interesting model is provided by the PLUS programme, recently developed for the Youth Justice Board by CfBT (source: http://www.youth-justice-board.gov.uk/). Approaches to distance learning should be explored for those who live too far away to attend the tuition provided in probation offices or in central venues.

\section{External links and referring the learner to external provision}

The national strategy for basic skills being developed by NPD (Home Office, 2001) advises probation areas that their role is to 'ensure that offenders are sufficiently equipped to access basic skills provision' within the community, rather than relying on such provision to be made exclusively within community supervision. From a starting point of very poor basic skills, it is likely to be a long-term process for an individual to progress from one level up through a series of levels (BSA, 2001a). It is therefore important that individual probation areas establish effective links with external partners and provide offenders with the appropriate support and advice to take up provision in the community. Good partnership arrangements with local Learning and Skills Councils (LSCs) and with LSC funded providers will be needed in order to achieve the Service Delivery Agreement targets (Home Office, 2000).

\section{Strategic planning}

There should be consideration of what constitutes realistic progress for offenders with basic skills below Level 2. For example, it should be considered whether attendance at basic skills provision should be voluntary or whether it should be integrated within community supervision plans and made enforceable. Planning should also take account of the stage at which individuals can move on to provision outside community supervision.

\section{Monitoring and evaluation}

Getting offenders with basic skills needs through the three main stages, shown in Figure 8.1 and discussed above, requires a variety of tasks and activities to be undertaken by those who are responsible for their supervision. One of the key activities which is required to complement each stage of a basic skills project is monitoring and evaluation.

The procedures that are required for accurate and consistent monitoring were not always followed during the Basic Skills Pathfinder evaluation, indicating that this important aspect of the work may often be a casualty when staff are over-loaded. As a consequence, it has been more difficult to draw firm conclusions about which aspects of the process and of basic skills provision have been the most effective. It is important that staff recognise that data recording and monitoring, and the consistent observance of agreed procedures in every case are not simply required for time-limited external evaluations. The business of monitoring and evaluation must be seen as integral to normal practice, helping the Probation Service to build up its database for the development of evidence-based practice. Staff training should emphasise that, while tasks like data recording and form completion may sometimes seem a low priority compared to other important professional tasks, these processes will contribute to evidence-based practice, providing important information about 'what works and what does not', and ultimately informing their own practice. 


\section{An effective referral system}

The high rate of attrition at crucial stages for addressing basic skills underlined the importance of a well-planned infrastructure to facilitate each stage of the process. In particular, an effective system is needed to eliminate non-referral as one cause of attrition. While it was not possible to determine, from monitoring data, what proportion of attrition could be attributed to non-attendance and what proportion to non-referral, the content analysis of case material indicated that at least some of the attrition is the result of staff not referring individuals onto the next stage. It is therefore vital for probation officers to be provided with a simple but reliable referral process, if basic skills work is not to be overlooked amongst the array of forms to be completed and the range of other problems that offenders present.

Basic skills work was not 'high on the list of priorities' for probation staff, and referrals were often 'not thought to be necessary'. At the same time, offenders were referred who had not been screened, suggesting that an arbitrary or unofficial referral process had been in operation alongside that which had been agreed. Systems for referral need to be as quick and as simple as possible and to be clearly communicated so that everyone knows who is responsible for making the referral. Systems should also be developed for dealing with the inevitable but critical problem of non-attendance. Screening and in-depth assessment packs may encourage greater consistency in referral by staff, while contact details and other information passed to project staff may enable them to 'chase-up' on those who have been referred but who have failed to keep appointments. Following the example of the project in Thames Valley Probation Area, the appointment of a dedicated basic skills officer to ensure screening, assessment and referral take place may be the most effective approach.

Referral systems should also be flexible enough to accommodate individuals who for one reason or another were not able or willing to participate in assessment or tuition at the appropriate stage but who express an interest at a later point. An open door policy and team building between probation staff and tutors, plus the option of communication via electronic mail, will facilitate such flexibility, and make it easier to 'pick up' people with basic skills needs who have been missed at an earlier stage.

\section{Motivational work}

Probably the most critical aspect of the work to be undertaken by probation staff dealing with people who may have poor basic skills - and also by tutors and project staff involved further down the line of the process - is motivational interviewing (see Miller, 1991) or motivational casework. Following the model of change introduced by Prochaska and DiClemente (1984), aspects of motivating a person include preparation, to reduce apprehension and provide relevant and suitably inspiring information, and maintenance, to help sustain a person's motivation for a prescribed activity and to intervene when there is a loss of motivation or a crisis which throws the individual off course.

Raising the question of whether an adult might have basic skills difficulties requires tact and sensitivity. Motivational strategies and procedures are needed at every stage of the process (as illustrated in Figure 8.1), and some examples of such strategies were identified during the evaluation of the Basic Skills Pathfinder. It is necessary to motivate people to participate in being screened and assessed to see whether there is a need, and to engage in and commit to the process of learning. Relevant motivational techniques include:

- explaining the extent of reading and writing problems among adults;

- describing the three-stage process involved (screening, assessment, tuition);

- describing the nature of tuition and other provision available; and

- pointing out the links between poor basic skills, unemployment and offending.

\section{Motivation at the screening stage}

The first difficult step is to raise the possibility that a person's basic skills may benefit from improvement and then to accomplish screening to verify or eliminate the suspected problem. 
In training sessions for the Basic Skills Pathfinder evaluation, many PSR writers were concerned about how to introduce the FT 20 Q screening tool into a PSR interview and how to motivate the offender to complete the FT 20 Q screening tool. However, according to the monitoring records, very few (less than 20) refused to go through the screening process or refused to answer the FT 20 Questions. PSR writers developed ways of introducing the FT 20 Q screening tool into the PSR interview. For example, they made comments about the widespread nature of adult reading and writing problems, and described the type of help that is now available if basic skills needs are identified.

\section{Motivation at the initial assessment procedure for basic skills needs}

The interview at the initial assessment procedure for basic skills needs could play a vital role in motivating individuals to take up basic skills provision. The nature of instruments used can either be off-putting or can help to motivate and engage the individual in the process of learning. There is scope for choosing assessment tools and approaches (such as puzzles, or on line assessment procedures) that will be regarded as enjoyable or at least not boring or intimidating.

The assessment interview can also be an opportunity to provide a 'taster' of teaching and learning techniques, and the materials that will be used in sessions. If the initial assessment procedure for basic skills needs is carried out by the prospective tutor, then this meeting can be the basis for initiating a tutor-learner relationship.

As described in Chapter 6, the greatest attrition occurred between screening and initial assessment procedure for basic skills needs. Approximately 80 per cent who were 'eligible' ('positively' screened and sentenced to a CRO/CPRO) to attend the initial assessment procedure for basic skills needs did not do so. A prior step to motivating offenders is, of course, to ensure that staff are themselves motivated to tackle the issues of basic skills needs among offenders, and that they are fully aware of the nature of the process and the benefits that might be reaped. During the Basic Skills Pathfinder evaluation it became apparent that only those most directly involved were aware of what happened at the initial assessment procedure for basic skills needs. A better understanding of the assessment process may lead to more comprehensive screening at the PSR stage and enable probation staff to give out clear information about the purpose and content of the initial assessment procedure for basic skills needs.

\section{Motivating participation in learning}

The greatest 'push' is usually needed to motivate an individual through the first stages and then onto commencement of learning. Once access to tuition has been achieved, and the learner is able to see for him/herself the improvements that can be made, then the basic skills learning programme may become self-motivating. A flexible referral system will allow for later access to basic skills provision in the case of individuals who can only be persuaded to attend once a good working relationship with his/her case manager has been established.

It may be worth experimenting with taster sessions or induction days, as happened in the Dorset Probation Area, where offenders were introduced to community supervision at the beginning of their order and basic skills provision was sold to them in a motivational manner along with other aspects of community supervision. However, if at all possible, those who are attracted to basic skills work through this route should first be screened and appropriately assessed to avoid referral of people who do not meet the agreed criteria, and so that their progress can be properly monitored.

A key way in which both offenders and staff might be motivated to regard basic skills work as integral to community supervision orders is to explicitly link basic skills provision to employment-related programmes. The final word in this report, therefore points towards the development of basic skills provision which has a clear employment focus. 


\section{Conclusion}

The rationale for the Basic Skills Pathfinder evaluation and the introduction of basic skills interventions into probation practice contained two key assumptions. Firstly, that improving an offender's basic skills will increase the probability of that person gaining employment; and, secondly, that gaining employment will decrease the probability of reoffending. Such a model certainly has an intuitive appeal to it, and the second assumption seems justified in terms of the well known association between gaining a proper job and desistance from offending (though the causal order of these events is not known). The high rate of attrition in the Basic Skills Pathfinder evaluation and the small numbers of offenders who received any meaningful input means that the evaluators could not test the first assumption directly. Nonetheless, the analysis of the screening data supplied strong evidence of an association between poor basic skills and an increased risk of being unemployed amongst this large sample of offenders. Such an association, combined with the high level of need revealed by this study, argues persuasively for more attention to be paid to addressing an offender's basic skill needs during probation.

However, a number of other factors will also increase the risk of an offender being unemployed. For example, the analysis of the screening data indicated strong associations between being unemployed and an offender's gender, their patterns of substance misuse, their risk of reconviction and the region in which they lived. The wider literature on unemployment suggests that mobility, health and age might also be important factors affecting a person's employment status. Thus, the causes of offender unemployment are likely to be complex. This suggests that future developments of basic skills programmes within the Probation Service might be better conceptualised within a multi-modal framework that has, as one of its main outcomes, gaining and maintaining employment rather than the more short term goal of remedying basic skills deficiencies. Such a focus on employment outcomes is likely to provide a better fit to an offender's view of their problems and so improve motivation to attend programmes, such as basic skills, that can be seen as raising their employability. 


\section{References}

Adey, P., Fairbrother, R. and William, D. with Johnson, B. and Jones, C. (1999) Learning Styles \& Strategies: A review of research. London, Kings College School of Education.

Adult Learning and Basic Skills Unit (1994). Basic Skills in Prison: Assessing the Need. London, The Basic Skills Unit.

Agnew, R. (1992). 'Foundation for a General Strain Theory of Crime and Delinquency.' Criminology 30: 47-87.

Aronwitz, W. and DiFazio, S. (1994). The Jobless Future. Minneapolis, University of Minnesota Press.

Atkinson, J. (1992). 'Swimming Against the Tide. Literacy Difficulties and the Labour Market.' Education and Training 34 (2): 11-17.

Audit Commission (1996). Misspent Youth. Young People and Crime. London, Audit Commission.

Basic Skills Agency (1999). Basic Skills Quality Mark for Post 16 Programmes. London, BSA.

Basic Skills Agency (2000). Effective Basic Skills Provision for Adults. London, BSA.

Basic Skills Agency (2000a). Getting Better Basic Skills - what motivates adults. London, BSA.

Basic Skills Agency (2000b). Fast Track - User Guide. London, BSA.

Basic Skills Agency (2001). Basic Skills and Financial Exclusion. London, BSA.

Basic Skills Agency (2001a). Adult Basic Skills Curriculum. London, BSA.

Basic Skills Agency (2001b). Course Materials for Training on the Adult Basic Skills Curriculum. London, BSA.

Basic Skills Agency and the Learning and Skills Council (2001). Bite Size Basics. Hints and Tips for Bite Size Courses. London, BSA.

Bennett, T. (2000). Drugs and crime: The results of the second developmental stage of the NEW-ADAM programme. London, Home Office.

Berridge, D., Brodie, I., Pitts, J., Porteous, D. and Tarling, R (2001). The independent effects of permanent exclusion from school on the offending careers of young people. London, Home Office.

Brooks, G., Gorman, T.P., Harman, J., Hutchison, D. and Wilkin, A. (1996). Family Literacy Works. London, BSA.

Brooks, G., Hewitt, R., Hutchison, D., Kendall, S. and Wilkin, A. (2001). Progress in Adult Literacy: Putting the Record Straight. London, BSA.

Brooks, G., Giles, K., Harman, J., Kendall, S., Rees, F. and Whittaker, S. (2001a). Assembling the Fragments: A Review of Research on Basic Skills. London, DfES.

Bynner, J. and Parsons, S. (1999). Literacy, Leaving School and Jobs. London, BSA.

Bynner, J., McIntosh, S., Vignoles, A., Dearden, L., Reed, H. and Van Reenan, J. (2001). Improving Adult Basic Skills. Benefits to the Individual and to Society. London, DfEE. 
Bynner, J. and Parsons, S. (2002). Basic Skills and Social Exclusion. London, BSA.

Caddick, B. and Webster, A. (1998). 'Offender Literacy and the Probation Service.' The Howard Journal 37: 137-147.

Carey, S., Low, S. and Hansbro, J. (1997). Adult Literacy in Britain. London, HMSO.

Cecil, D., Drapkin, D., MacKenzie, D. and Hickman, L. (1997). 'The Effectiveness of Adult Basic Education and Life-Skills Programs In Reducing Recidivism: A Review and Assessment of the Research.' Journal of Correctional Education 51: 207 - 226.

Cloward, A., Ohlin, R. and Lloyd, E. (1960). Delinquency and opportunity: A Theory of Delinquent Gangs. New York, The Free Press.

Cohen, A. K. (1955). Delinquent Boys: The Culture of the Gang. New York, Free Press.

Davis, G., Caddick, B., Lyon, K., Doling, L., Hasler, J., Webster, A., Read, M. and Ford, K. (1997). Addressing the literacy needs of offenders under probation supervision. London, Home Office.

Devlin, A. (1996). Criminal Classes: Offenders at School. Winchester, Waterside Press.

DfEE (1999). Improving literacy and numeracy. A Fresh Start. The report of the working group chaired by Sir Claus Moser. London, Sudbury.

DfEE (1999a). Statistics of Education: Schools in England. London, HMSO.

DfEE (2001). Skills for Life. London, DfEE.

DfEE (2001a). Improving prisoners' learning skills: a new strategic partnership. London, DfEE.

DfES (2001) National Standards for Literacy and Numeracy. Nottingham, DfES.

DfES (2001a). Labour Market Quarterly Report: August 2001. Sheffield, DfES.

Edwards, H. (2000). 'Accelerated literacy learning for adults.' Literacy today June edition.

Farrington, D., Gallagher, B., Morley, L., St. Ledger, R. and West, D (1986). "Unemployment, school leaving and crime." British Journal of Criminology 26 (4): 335-356.

Felstead, A., Gallie, D. and Green, F. (2002). Work Skills in Britain 1986-2001. London, DfES and SKOPE.

Flood-Page, C. and Mackie, A. (1998) Sentencing Practice: an examination of decisions in magistrates' courts and the Crown Court in the mid-1990s. London, Home Office.

Frude, N., Honess, T. and Maguire, M. (1994), CRIME PICS II Manual. Michael and Associates, Cardiff.

Graham, J. and Bowling, B. (1995). Young People and Crime. London, Home Office.

Hinshaw, S. (1992). 'Externalizing behavioural problems and academic under-achievement in childhood and adolescence: Causal relationships and underlying mechanisms.' Psychological Bulletin 101: 443-463.

HMSO (1999). HM Prison Service Annual Report and Accounts 1998-1999. London, HMSO.

Home Office (1991). National Standards for the supervision of offenders in the community. London, Home Office. 
Home Office (1994). Probation Circular 40/1994. London, Home Office.

Home Office (1995). National Standards for the supervision of offenders in the community. London, Home Office.

Home Office (1999). The Government's Crime Reduction Strategy. London, Home Office.

Home Office (1999a). Probation Circular 17/1999. London, Home Office.

Home Office (2000). National Standards for the supervision of offenders in the community. London, Home Office.

Home Office (2000a). Probation Circular 92/2000. London, Home Office.

Home Office (2000b). Criminal Statistics - England and Wales 2000. London, Home Office.

Home Office (2000c) Cautions, Court Proceedings and Sentencing - England and Wales 2000. London, Home Office.

Home Office (2001). Consultation Paper: Improving the Basic Skills of Offenders on Community Supervision. London, Home Office.

Home Office (2001a). Prison Statistics - England and Wales 2000. London, Home Office.

Home Office (2002). Probation Circular 15/2002. London, Home Office.

Home Office (2002a). Probation Statistics - England and Wales 2000. London, Home Office.

Howard, U. and Grief, S. (2001). 'Empowering adult learners.' Briefing Learning and Skills Development Agency July 2001.

Hudson, C., McMahon, G., Hayward, G., Roberts, C. and Fernandez, R. (2001). Interim Report of the Evaluation of the Basic Skills Pathfinder Projects. Unpublished

Joshi, P. and Paci, H. (1999). 'Life in the Labour Market.' in Twenty-something in the 1990s: getting on, getting by, getting nowhere. ed. Bynner, S. London, Ashgate Publishing Ltd.

Layard, P.R.G. and Glaister S. (1994) Cost Benefit Analysis Cambridge: Cambridge University Press.

Lipsey, M. (1995). 'What do we learn from 400 research studies on the effectiveness of treatment with juvenile delinquents' in What works: reducing reoffending - guidelines from research and practice ed. J. McGuire London, John Wiley \& Sons.

MacKenzie, D. (1997). 'Criminal Justice and Crime Prevention.' in Preventing Crime: What Works, What Doesn't, What's Promising. ed. Sherman, G., Mackenzie, D., Eck, J., Reuter, P. and Bushway, S. Washington DC, National Institute of Justice.

May, C. (1999). Explaining reconviction following a community sentence: the role of social factors. London, Home Office.

Maydeu-Olivares, A., D'Zurilla, T.J. and Nezu, A.M. (1996). Social Problems-Solving Inventory-Revised (SPSI-R): technical manual. Unpublished.

McNally, J. and Murray, W. (1962). Key words to literacy: a basic word list for developing early reading and writing skills. London : Schoolmaster Publishing.

Merrington, S. (2001). Emerging ACE Data: Further Analysis of Needs and Risk. Oxford, Probation Studies Unit of the University of Oxford. 
Merton, R. (1968). Social Theory and Social Structure. Glencoe, The Free Press.

Miller, W. R. (1991). What motivates people to change? In W. R. Miller and S. Rollnick (Eds.). Motivational interviewing: Preparing people to change addictive behavior. New York: Guilford Press.

Mishan, E.J. (1994) Cost-benefit Analysis: An Informal Introduction London : Routledge.

Palfrey, C. (1974). Remedial education and the adult offender. The Howard Journal 14:78-84.

Pearson, D. and Lipton, F. (1999). The Effectiveness of Educational and Vocational Programmes: CDATE Meta-Analyses. Annual Meeting of the American Society of Criminology, Toronto.

Porporino, D. and Robinson, F. (1992). Can Educating Adult Offenders Counteract Recidivism? Ottawa, Report of the Research and Statistics Branch of the Correctional Service of Canada.

Prochaska, J. O. and DiClemente, C. C. (1984). The transtheoretical approach: Crossing the traditional boundaries of therapy. Homewood, IL: Dow Jones/Irwin.

Raven, J., Raven, J.C. and Court, J. (2000). Raven Manual. Standard Progressive Matrices. Oxford, Oxford Psychologists Press.

Raynor, P. and Vanstone, M. (1997) Straight Thinking in Probation University of Oxford Centre for Criminological Research, Oxford.

Raynor, P., Kynch, J., Roberts, C. and Merrington, S. (2000). Risk and need assessment in probation services: an evaluation. London, Home Office.

Rex, S., Gelsthorpe, L., Roberts, C. and Jordan, P. (2002). An evaluation of Community Service Pathfinder Projects. Unpublished

Rice, M. (1999). Literacy and behaviour: the prison reading survey (BL). Unpublished Ph.D. Thesis, the University of Cambridge.

Rutter, M., Gillier, H. and Hagell, A. (1998). Antisocial Behaviour by Young People. Cambridge, Cambridge University Press.

Snowling, M., Adams, J., Bowyer-Crane, C. and Tobin, V. (2000). 'Levels of literacy among juvenile offenders: The incidence of specific reading difficulties.' Criminal Behaviour and Mental Health 10 (4): 229 - 241.

Social Exclusion Unit (2001). Preventing Social Exclusion. London: Cabinet Office.

Social Exclusion Unit (2002). Reducing reoffending by ex-prisoners: Report by the Social Exclusion Unit. London, Cabinet Office.

Stewart, G. and Stewart, J. (1993). Social Circumstances of Younger Offenders Under Supervision. London, Association of Chief Officers of Probation.

Tarling, R. (1982). Unemployment and crime. London, Home Office Research and Planning Unit.

Wolfe, J. N. (1973) Cost Benefit and Cost Effectiveness: Studies and Analysis London: Allen, Unwin.

Youth Justice Board (2001). Youth Survey 2001. London, YJB. 


\section{Appendix A: The relationship of basic skills levels to other qualifications}

\begin{tabular}{|c|c|c|c|c|c|c|c|}
\hline $\begin{array}{l}\text { National } \\
\text { curriculum }\end{array}$ & $\begin{array}{l}\text { BSA } \\
\text { Levels } \\
\text { (adjusted) }\end{array}$ & $\begin{array}{l}\text { Key } \\
\text { skills } \\
\text { levels }\end{array}$ & $\begin{array}{l}\text { National } \\
\text { qualifications } \\
\text { framework }\end{array}$ & \multicolumn{2}{|c|}{ General } & $\begin{array}{l}\text { Vocationally } \\
\text { related }\end{array}$ & Occupational \\
\hline & \multirow[b]{3}{*}{$\begin{array}{l}\text { Basic } \\
\text { skills } \\
\text { Level } 2\end{array}$} & $\begin{array}{l}\text { Key } \\
\text { skills } \\
\text { level } 5\end{array}$ & $\begin{array}{l}\text { National } \\
\text { qualifications } \\
\text { framework } \\
\text { level } 5\end{array}$ & \multirow{2}{*}{\multicolumn{3}{|c|}{$\begin{array}{l}\text { Higher-level qualifications } \\
\text { BTEC Higher Nationals }\end{array}$}} & Level $5 N V Q$ \\
\hline & & $\begin{array}{l}\text { Key } \\
\text { skills } \\
\text { level } 3\end{array}$ & $\begin{array}{l}\text { National } \\
\text { qualifications } \\
\text { framework } \\
\text { level } 4\end{array}$ & & & & Level $4 N V Q$ \\
\hline & & $\begin{array}{l}\text { Key } \\
\text { skills } \\
\text { level } 2\end{array}$ & $\begin{array}{l}\text { National } \\
\text { qualifications } \\
\text { framework } \\
\text { level } 3 \\
\text { (advanced } \\
\text { level) }\end{array}$ & $\begin{array}{l}\text { A } \\
\text { Level }\end{array}$ & $\begin{array}{l}\text { Free- } \\
\text { standing } \\
\text { mathematics } \\
\text { units level } 3\end{array}$ & $\begin{array}{l}\text { Vocational A } \\
\text { level } \\
\text { (Advanced } \\
\text { GNVQ) }\end{array}$ & Level $3 N V Q$ \\
\hline $\begin{array}{l}\text { National } \\
\text { curriculum } \\
\text { level } 5\end{array}$ & \multirow[t]{2}{*}{$\begin{array}{l}\text { Basic } \\
\text { skills } \\
\text { Level } 1\end{array}$} & \multirow[t]{2}{*}{$\begin{array}{l}\text { Key } \\
\text { skills } \\
\text { Level } 1\end{array}$} & $\begin{array}{l}\text { National } \\
\text { qualifications } \\
\text { framework } \\
\text { level } 2 \\
\text { (intermediate } \\
\text { level) }\end{array}$ & $\begin{array}{l}\text { GCSE } \\
\text { grade } \\
A^{\star}-C\end{array}$ & $\begin{array}{l}\text { Free- } \\
\text { standing } \\
\text { mathematics } \\
\text { units level } 2\end{array}$ & $\begin{array}{l}\text { Intermediate } \\
\text { GNVQ }\end{array}$ & Level $2 N V Q$ \\
\hline $\begin{array}{l}\text { National } \\
\text { curriculum } \\
\text { level } 4\end{array}$ & & & $\begin{array}{l}\text { National } \\
\text { qualifications } \\
\text { framework } \\
\text { Level } 1 \\
\text { (foundation } \\
\text { level) }\end{array}$ & $\begin{array}{l}\text { GCSE } \\
\text { grade } \\
\text { D-G }\end{array}$ & $\begin{array}{l}\text { Free- } \\
\text { standing } \\
\text { mathematics } \\
\text { units Level 1 }\end{array}$ & $\begin{array}{l}\text { Foundation } \\
\text { GNVQ }\end{array}$ & Level $1 N V Q$ \\
\hline $\begin{array}{l}\text { National } \\
\text { curriculum } \\
\text { level } 3\end{array}$ & $\begin{array}{l}\text { Basic } \\
\text { skills } \\
\text { Entry } 3\end{array}$ & & Entry Level & \multirow{3}{*}{\multicolumn{3}{|c|}{ Certificate of (educational) achievement }} & \\
\hline $\begin{array}{l}\text { National } \\
\text { curriculum } \\
\text { level } 2\end{array}$ & $\begin{array}{l}\text { Basic } \\
\text { skills } \\
\text { Entry } 2\end{array}$ & & & & & & \\
\hline $\begin{array}{l}\text { National } \\
\text { curriculum } \\
\text { Level } 1\end{array}$ & $\begin{array}{l}\text { Basic } \\
\text { skills } \\
\text { Entry } 1\end{array}$ & & & & & & \\
\hline
\end{tabular}

Source: Website of the Qualifications Curriculum Authority. http://www.qca.org.uk/ 


\section{Appendix B: The Prison Service agenda for addressing basic skills needs}

In order to address basic skills needs in the Prison Service, the Prisoners Learning and Skills Unit was set up working together with HM Prison Service, the National Probation Service and other partners.

The Improving Prisoners' Learning and Skills Survey (DfEE, 2001a) states that only one in ten prisoners has a job to go to on leaving prison. This survey suggests that poor levels of education and skills 'clearly contribute to this problem. Many prisoners' literacy and numeracy skills are so poor that up to 90 per cent of all jobs may be closed to them'. In the 1998-99 Annual Report and Accounts of HM Prison Service (HMSO, 1999), the present Director General Martin Narey said with regards to education, that:

[T]he huge potential to influence people's lives in this area is starkly illustrated by the findings of the Basic Skills Agency, which estimated that between 60-70 per cent of the prison population have levels of literacy and numeracy so low that they are ineligible for 96 per cent of jobs. Our work must therefore be targeted at improving basic literacy and numeracy skills in order to make a real difference to the opportunities open to prisoners on release. Work begins this year to reduce by 15 per cent the high levels of prisoners' illiteracy and innumeracy.

The Director General secured agreement with the Prisons Board to develop a new strategy for prison education 'which supports the government's wider emphasis on improving basic and key skills' ( HMPS, 1999) and numerous strategies have since been introduced (which link with the work of the National Probation Service).

In 1999-00, prisoners gained almost 42,000 nationally recognised certificates of education, of which 32,000 were in literacy and numeracy, ${ }^{52}$ and in 2000-01, 60,000 certificates of education were achieved, with 12,500 certificates awarded at Level $2 .^{53}$ In 2000 , HM Prison Service was set targets, in the form of a Key Performance Indicator, for the percentage of prisoners leaving prison with basic skills achievement below Level 2 (Home Office, 2001a). This was the first time a Key Performance Indicator has been set for specific educational work in the Prison Services. Although the Prison Service exceeded its Key Performance Indicator in 2000-01 for the number of accredited offending behaviour programmes completed (gained 5,986 completed programmes with a Key Performance Indicator of 5,000), the basic skills Key Performance Indicator in 2000-2001 was not attained. The target set was 61.9 per cent of prisoners to be discharged with numeracy skills below Level 2, and a figure of 67.6 per cent was achieved. The number of prisoners discharged with literacy skills below Level 2 was 76.6 per cent with a target of 52.8 per cent. At the same time however, the number of hours per week spent in education increased slightly from $5.74 \mathrm{hrs}$ to $6.62 \mathrm{hrs}$ (Home Office, 2001a).

\footnotetext{
${ }_{53}$ 1999-00 Annual Report and Accounts of HM Prison Service (HMSO, 2000).

${ }_{53} 2000-01$ Annual Report of Accounts of HM Prison Service (HMSO, 2001).
} 


\section{Appendix C: Description of the projects in the Basic Skills Pathfinder evaluation}

\section{Cornwall Probation Area}

The original project in Cornwall Probation Area (Cornwall and Devon Probation Services became Devon and Cornwall Probation Area in April 2001) focused on employment intervention provided by West Country Training; all unemployed offenders supervised by Cornwall Probation Area had a condition on their order to attend a two week employment enhancement programme.

Cornwall Probation Area has a long-standing working relationship with Link into Learning. Link into Learning is a very well established dyslexia and basic skills provider across Cornwall Probation Area. In 1998, Link into Learning embarked on a capacity-building phase with Cornwall Probation Area and partner agencies. This consisted of dyslexia/basic skills awareness training for probation staff and partner agencies, simplification of text in communication systems with clients, and joint training (e.g. attendance at conferences, motivational interviewing and training sessions etc.). The aim was to increase understanding of the client group, each other's organisational cultures, and to increase the consistency of messages communicated to offenders.

Between 1998 and 2000, 200 offenders were screened for basic skills needs and dyslexia, using a dynamic, motivational screening model (Link into Learning describe screening as a detailed assessment process), delivered by tutors experienced in basic skills delivery and working with adult dyslexics. Screening assessments used were the Salford Sentence Reading Test followed up by (in some cases) the Watts Vernon reading test; an assessment of free writing; (in some cases) the Vernon Spelling Test; and version A of the numeracy assessment from the BSA's Initial Assessment tool. For dyslexia, the British Dyslexia Association's Adult Checklist, Kim's (for exploration of visual recall strategies), and the Digit Span from the Aston Index (for auditory short-term memory analysis) were used. Offenders were also screened for scotopic sensitivity and, if necessary, were referred for full assessment of scotopic sensitivity and for spectrally modified lenses. Any offender with a significant number of indicators was referred for a full specific learning difficulties/dyslexia assessment. Where analysis of results was uncertain, clients were referred to an Educational Psychologist. During the capacity building phase, systems were developed to feed back screening information to probation officers to inform management of sentences, to West Country Training to inform delivery of the ETE programme, and to partner agencies where appropriate.

During the Basic Skills Pathfinder evaluation, PSR writers administered the FT $20 \mathrm{Q}$ screening tool and the background information form at PSR stage. Due to limitations of time, the FT 20 Q screening tool was not carried out on SSRs and given local targets, this reduced the potential number of the FT 20 Q screening tools completed by 25 per cent. Two independent researchers administered the BSA's Initial Assessment tool, Raven's Progressive Matrices and the additional background information form. Probation service officers were responsible for SPSI-R (short-form) and CRIME PICS II. Link into Learning's dynamic screening process was used as well as instruments in the initial assessment procedure for basic skills needs during the Basic Skills Pathfinder evaluation.

From autumn 2000, Link into Learning was funded to provide one-to-one support for offenders in five probation offices (Camborne, Liskeard, Penzance, St. Austell and TruroFalmouth). Three Link into Learning tutors covered tuition in the offices above for a total of 15 hours per week. Offenders could attend basic skills or dyslexia provision for an hour and a 
half per week. As well as input on basic skills, tuition also focused on interlinked skills associated with successful learning, such as study skills and mind mapping. If a learner was attending dyslexia provision, s/he may follow a structured, multisensory programme (Write/Right to Read). Close liaison was maintained with other agencies.

Where appropriate, Link into Learning attempts to move offenders from one-to-one provision to one of Link into Learning's centres, where they can attend for an open-ended number of hours. Link into Learning has a large network of centres across Cornwall Probation Area (in Bodmin, Bude, Callington, Camelford, Echo, Hayle, Launceston, Liskeard, Newquay, Pathfields, Penzance, Pentreath, Pool, St. Austell, St. Columb Major, St. Mary's, St. Ives, St. Just, Saltash, Scilly Isles, Torpoint and Wadebridge), as well as outreach provision. The objective of Link into Learning is social inclusion as much as improving basic skills.

After the collection of screening data for evaluation purposes finished (July 2001), Devon and Cornwall Probation Area did not continue to use the FT 20 Q screening tool to screen for basic skills needs at PSR stage.

As part of the implementation of the national strategy for basic skills work, Devon and Cornwall Probation Area have embarked on a capacity building phase. This will involve awareness raising of basic skills work and specific learning difficulties with staff in probation, from an experienced basic skills tutor, the simplification of text, forms and communications systems, and research into the prevalence of basic skills needs and specific learning difficulties. Screening for basic skills needs is automatic for all offenders at PSR stage. Diagnostic assessment following screening will be carried out by a basic skills professional in the probation office, or another suitable venue. This should identify literacy, language and numeracy levels matched to the Basic Skills Standards, and learning issues like specific learning difficulties. This will lead to a learning plan aligned with the Adult Basic Skills Curriculum. It is the intention that a diagnostic assessment takes place as soon as is possible after sentence to ensure that it contributes to, and fully informs, the supervision plan. Basic skills provision will be in the probation office and linked to a community learning centre. The basic skills tutor will judge from working with the offender a suitable point to move him/her onto outside provision. Procedures will be put in place for referral and feedback of attendance and progress (subject to funding from the Learning and Skills Council), a mentoring scheme is also being implemented, and work has begun on the transition from one agency to another (e.g. probation and the employment service) to avoid repeated assessment and processing.

\section{Cumbria Probation Area}

Cumbria Probation Area's model for screening during the period of the evaluation was unique in that administration of the FT 20 Q screening tool and the background information form involved both members of NACRO and PSR writers. PSR writers organised the interview and partially completed the background information form (the remainder of the background information form was completed by Administration and Information Services). The FT $20 \mathrm{Q}$ screening tool was completed in an appointment which was back to back with the PSR interview. The initial assessment procedure for basic skills needs was also conducted by NACRO.

Basic skills tuition was delivered through partnership with NACRO. Four members of NACRO taught for, in total, 80 to 100 hours per week in six probation offices (Barrow-in-Furness, Carlisle, Kendall, Penrith, Whitehaven and Workington). Teaching was one-to-one and offenders could attend basic skills provision for an hour a week. There was particular focus on speaking and listening skills. Some offenders also worked towards Wordpower and Numberpower. The extent to which non-attendance at basic skills provision was breachable depended upon the centrality of basic skills needs in the supervision plan (i.e. the extent to which basic skills needs were linked to offending behaviour) and the judgement of the case manager.

After the collection of screening data for evaluation purposes finished (July 2001), Cumbria Probation Area continued to use the FT 20 Q screening tool to screen for basic skills needs, but has now moved the screening process to the start of community supervision. Currently, 
Cumbria Probation Area is maintaining basic skills provision as it was during the Basic Skills Pathfinder evaluation; is adding elements of personal development to encourage motivation etc.; amending the system of referral to include referrals from the accredited programmes team; developing a joint strategy with the Learning and Skills Council; and developing more basic skills provision.

\section{Dorset Probation Area}

In the early stage of the Basic Skills Pathfinder in Dorset Probation Area, basic skills assessment and provision were aimed at three groups of offenders: unemployed offenders were required to attend assessment and, if basic skills needs were detected, provision; offenders on a CPO were required to attend assessment, and if basic skills needs were detected, attendance at basic skills provision was voluntary; and offenders on CROs who were employed were offered voluntary assessment and provision.

During the period of the evaluation, PSR writers administered the FT 20 Q screening tool and the background information form. The basic skills tutor administered the materials for the initial assessment procedure for basic skills needs. In addition, at induction, all offenders on a CPO completed the BSA's Initial Assessment tool.

Until March 2001, there was basic skills provision in one probation office, in Poole. One basic skills tutor was employed for 30 hours a week. At the beginning of the Basic Skills Pathfinder evaluation, offenders attended a basic skills programme for half a day, four days a week, for four weeks. In Spring 2001, that changed to a potential five sessions per week that offenders could access. The course would still consist of 16 sessions in total, but there was greater flexibility over the time period the course had to be completed in. Sessions lasted for three hours, including a break. Provision was based on individualised learning in a group situation. Offenders worked towards ASDAN's 'Improving Learning'.

Attendance at basic skills provision was compulsory for offenders with basic skills below Level 1 who were on the Think First programme and for other offenders not on a CPO, if the case manager chose to make basic skills provision compulsory. Attendance was voluntary for offenders on a CPO, offenders for whom the case manager thought basic skills provision should have been voluntary, and offenders whose basic skills levels were above Level 1.

Dorset Probation Area has continued to use the FT 20 Q screening tool to screen for basic skills needs after the collection of screening data for evaluation purposes finished (September, 2001). However, Dorset has begun to undertake a full basic skills assessment with all offenders who score two or more ticks on the FT 20 Q screening tool. All offenders on a Drug Treatment and Testing Order, accredited offending behaviour programmes, and in hostels will now have a mandatory full basic skills assessment. Hostel residents on bail will be offered voluntary assessments. The requirement for offenders to undergo a mandatory basic skills assessment should be included in the PSR and supervision plan irrespective of employment status.

Basic skills tuition is now provided by Adult Education in Dorset and has been extended to Bournemouth, Weymouth (for Weymouth, Portland and Dorchester) and Wareham where offenders on CPO use the ten per cent of CPO hours work on line on basic skills. Each class must have a minimum of six offenders and offenders are able to join the classes on a 'roll on, roll off' basis.

The rural areas in Dorset Probation Area are being covered by video link to Poole Probation Centre. This facility is operational in Community Learning and Information Centres in Sherbourne, Shaftesbury, Sturminster, Newton, Blandford Forum, Bridgeport and Swanage. Each centre has a private room, and offenders are accompanied by a volunteer. This is likely to be provided by Learn Direct and offenders are monitored for progress levels which may afford them access to basic skills provision in the community. Each class must have a minimum of six offenders, although Learn Direct can work on a one-to-one basis. 
New initiatives in Dorset Probation Area have included outdoor motivation days for offenders; first aid and food hygiene courses; and an increase in the use of technology for learning.

\section{Lincolnshire Probation Area}

In the early stages of the Basic Skills Pathfinder, before the evaluation commenced, Lincolnshire Probation Area focused on developing a screening tool, with De Montfort University. The screening tool was administered at the start of community supervision.

During the Basic Skills Pathfinder evaluation, PSR writers and a small number of probation service officers administered the FT $20 \mathrm{Q}$ screening tool and the background information form.

A Basic Skills Co-ordinator was employed full time by Lincolnshire Probation Area. For much of the evaluation, the Basic Skills Co-ordinator took on project management responsibilities, after the original project manager was promoted to another post. The Basic skills co-ordinator conducted the initial assessment procedure for basic skills needs, and taught basic skills to cover if there was no other provider. Basic skills tuition was provided through partnership with the Lincolnshire Action Trust's Employment Keyskills Programme. Two basic skills tutors were contracted to work full time within community supervision. There was tuition in nine probation offices (Boston, Gainsborough, Grantham, Lincoln, Louth, Spalding, Skegness, Sleaford and Stamford). Offenders usually attended basic skills provision for an hour per week. If attendance at basic skills sessions was included in the supervision plan, basic skills sessions could count as National Standards appointments. At the same time, offenders were not breached for non-attendance at basic skills sessions, unless it was part of a wider pattern of non-compliance.

Lincolnshire Probation Area worked on simplifying the probation area's range of communications with offenders and in developing links between the co-ordinator and members of probation.

Lincolnshire Probation Area continued to use the FT 20 Q screening tool after the collection of screening data for evaluation purposes finished (September, 2001). All offenders on a CRO or who are referred to Reasoning and Rehabilitation now receive a compulsory basic skills assessment as part of their induction. Lincolnshire Probation Area is also planning to introduce dyslexia assessments, where appropriate; the Basic Skills Co-Ordinator is taking a diploma in dyslexia, in order to conduct dyslexia assessments. Lincolnshire Probation Area is also incorporating group teaching into their basic skills provision for offenders.

Lincolnshire Probation Area has compiled a thorough strategy for the implementation of basic skills work in the new case management system. This includes the use of IT to record the FT $20 \mathrm{Q}$ screening tool score and to refer offenders to the initial assessment procedure for basic skills needs, and guidelines for the inclusion of basic skills provision in supervision plans. The strategy stipulates that if basic skills work is part of the supervision plan, and basic skills appointments are agreed in the individual learning plan, then attendance at basic skills provision is enforceable.

The exit strategy also outlined area objectives for screening at PSR; referral of offenders who score below Level 1 on the FT 20 Q screening tool and where sentenced to a CRO or a CPRO to the initial assessment procedure for basic skills needs; assessment of offenders on license; guidance for unemployed offenders; feedback to case managers on progress; opportunities for offenders to gain qualifications; working towards national targets for basic skills; monitoring of basic skills needs; and providing information to the National Probation Directorate in respect of progress.

\section{Nottinghamshire Probation Area}

The Positive Action Learning Support (known as 'PALS') project provided basic skills and dyslexia tuition in Nottinghamshire Probation Area. 
Before the Basic Skills Pathfinder began, Nottinghamshire Probation Area developed its own screening indicator, which was used at the start of community supervision. For more detailed assessment of basic skills needs, Nottinghamshire Probation Area developed its own package, which was known as the WRAT bag, to be used by basic skills tutors and ETE workers. The WRAT bag consisted of the Wide Ranging Achievement Test for reading, spelling and arithmetic, 100 Key Words (Murray and McNally, 1962), Raven's Progressive Matrices and a symbol digit modalities test. If the results of these assessments showed a large difference between potential and performance, learners were given a specialist dyslexia assessment. This consisted of the Kaufman Brief Intelligence Test, laterality, visual and auditory memory and sequencing, Wepman Auditory Discrimination Test and the Rosner Test of Auditory Analysis.

During the Basic Skills Pathfinder evaluation, PSR writers administered the FT 20 Q screening tool and the background information form. The format of this changed in April 2001, when Nottinghamshire Probation Area introduced a new assessment instrument for PSR stage, the RASPER pack. This included the questions on the background information form and the FT 20 Q screening tool. The basic skills tutors and ETE workers administered the instruments in the initial assessment procedure for basic skills needs, in conjunction with 100 Key Words. If, after using Raven's, the BSA Initial Assessment and 100 Key Words, dyslexia was suspected, the offender was referred for a full dyslexia assessment, as outlined above. The tools for the initial assessment procedure for basic skills needs were put together in a package called the OUPS bag (Oxford University Pathfinder Screening).

The project manager at PALS was seconded for four and a half days per week from the Dyslexia Institute. In addition to management responsibilities, the project manager conducted dyslexia assessments and taught dyslexic offenders. There were two basic skills tutors also employed by the Dyslexia Institute, who worked in partnership with Nottinghamshire Probation Area to deliver basic skills provision, one for 35 hours a week, and one for $171 / 2$ hours a week. There were also a number of volunteers to support individual learning in a group context.

The main city probation office in Nottinghamshire Probation Area had a group room allocated for basic skills provision three days a week. Assessment and tutoring also took place in probation offices in Mansfield, Newark, Retford, Ollerton and Worksop. In Nottingham and in Mansfield, basic skills tuition consisted of individualised learning in a group context. In Newark, Retford, Ollerton and Worksop, basic skills tuition was on a one-to-one basis. Offenders could attend basic skills provision for an hour a week, except in Mansfield where they could attend for three hours, and in Nottingham where they could attend for six hours. Dyslexia provision was on a one-to-one basis, for an hour per week. Dyslexic offenders followed the Dyslexia Institute Learning Programme which was a multisensory learning programme. The dyslexia tutor also drew upon some supplementary materials, including the Units of Sound Information and Communication Technology programme, which was a structured literacy programme also used for basic skills provision.

The PALS team worked very closely with the ACCESS team of employment officers (part of Nottinghamshire Probation Area), especially when supporting learners into mainstream provision. There was a member of the ACCESS team within each probation team in Nottinghamshire Probation Area, therefore, the work of both PALS and ACCESS was integrated into the work of the probation area as a whole.

Non-attendance at basic skills provision has now become breachable for those offenders where basic skills provision has been agreed as an appropriate response to an identified need. Following two absences the PALS team reports back to the case manager who makes a judgement about the acceptability of the reasons for absence.

Nottinghamshire Probation Area has continued to use the FT 20 Q screening tool to screen at PSR stage (as part of RASPER) after the end of the collection of screening data for evaluation purposes (September, 2001), but has returned to using the WRAT bag for more detailed assessment of basic skills needs. 
Nottinghamshire Probation Area compiled an exit strategy for basic skills work which outlined the acknowledgement of the variety of individual support, and a matching of materials and work covered to the Basic Skills Curriculum; development of referral to New College Nottingham for ESOL; in-service training for basic skills tutors; development of provision for minority ethnic offenders; liaison with magistrates about the FT 20 Q screening tool and basic skills needs; Adult and Community Learning Fund funding via Nottinghamshire County Council for students who wish to continue learning after their community supervision period has finished; a work group in Worksop for drug users where they have the opportunity to makes cards, key rings etc., as well as socialising with others with similar problems; the evaluation of the literacy level of all written materials issued by Nottinghamshire Probation Area to offenders; closer liaison with employers; and the development of PALS access to the probation computer system, ICR.

\section{Sussex Probation Area}

At the beginning of the evaluation, Sussex Probation Area was two probation services: East and West Sussex Probation Services. They were amalgamated in April 2001.

Basic skills provision was delivered through partnership with NACRO in Sussex Probation Area, both pre and post amalgamation. In the early stages of the Basic Skills Pathfinder, before the evaluation, Sussex Probation Area focused on developing its own screening tool, which was administered at the start of community supervision.

During the evaluation, screening was conducted by PSR writers and the initial assessment procedure for basic skills needs was conducted by basic skills tutors and by the Basic Skills Co-Ordinator. In March 2001, a full-time administrator was appointed, to manage the collection of screening data and the referral system from screening to the initial assessment procedure for basic skills needs.

Two full-time basic skills tutors were employed by NACRO to work in probation. The tutors were supervised by the NACRO Services Sussex, Area Manager, who spent a day a week managing the Basic Skills Pathfinder evaluation. For much of the Basic Skills Pathfinder evaluation, the NACRO Services Sussex, Area Manager was the full-time Basic Skills Coordinator for Sussex Probation Area. This role included assessment of basic skills needs, some teaching and project management.

Tuition took place in four probation offices: Brighton, Crawley, Hastings and Worthing. Tuition was one-to-one and offenders could attend provision for an hour and a half per week. In addition, offenders could use the NACRO bus, in particular to develop their ICT skills. The main purpose of the NACRO bus was to cater for the educational needs of those offenders who could not access provision in a probation office. Some offenders also completed Wordpower and Numberpower at Level 1.

Sussex Probation Area has continued to use the FT 20 Q screening tool to screen at PSR stage after the collection of screening data for evaluation purposes finished (September, 2001). It has maintained the same level of service and is providing basic skills assessments, and some training in the same centres as before. Provision had been extended across the area to include CROs, CPROs, CPOs, DTTOs and offenders on licence.

\section{Thames Valley Probation Area}

At the beginning of the Basic Skills Pathfinder evaluation, Thames Valley Probation Area was two probation services: Oxfordshire and Buckinghamshire, and Berkshire Probation Services. They were amalgamated in April 2001.

Prior to becoming a Basic Skills Pathfinder, Thames Valley Probation Area delivered basic skills provision through the Breakthrough Project, which had European Social Fund funding. The Breakthrough Project used the Be Screening Toolkit which included the Adult Dyslexia 
Questionnaire. Screening, including the Adult Dyslexia Questionnaire, was conducted by probation officers at the start of community supervision. ETE workers were also trained to use these assessment tools, when offenders had not been screened by probation officers.

During the Basic Skills Pathfinder evaluation, PSR writers administered the FT 20 Q screening tool and the background information form at PSR stage. In Oxfordshire and Buckinghamshire, three basic skills officers administered the materials for the initial assessment procedure for basic skills needs. The basic skills officers were appointed in March 2001 on permanent contracts, but with specific responsibility for the initial assessment procedure for basic skills needs for the period of the Basic Skills Pathfinder evaluation. In Berkshire, the initial assessment procedure for basic skills needs was conducted by CHASE workers.

Basic skills tuition was provided by mentors, who were supervised by three Mentor Coordinators. This system of provision was established under the Breakthrough Project. Whilst numbers of mentors vary, there are usually about 150 on Thames Valley Probation Area's books, about 25 of whom are actively involved in teaching basic skills. Two Mentor Coordinators were employed for $18^{1 / 2}$ hours each a week, whilst the third Mentor Co-ordinator was full-time. The mentor co-ordinators and basic skills officers were line-managed by the services development manager, who recently became the basic skills manager for Thames Valley Probation Area.

Basic skills tuition took place in probation offices and hostels in Abingdon, Aylesbury, Banbury, Bicester, Bracknell, High Wycombe, Milton Keynes (two offices), Maidenhead, Newbury, Oxford (four offices), Slough, Reading (three offices) and Witney. Offenders could attend one-to-one basic skills provision for up to two hours per week. Attendance at basic skills assessments was compulsory, but attendance at tuition was largely voluntary and therefore not breachable, although this was not exclusively so. Thames Valley Probation Area is currently exploring possibilities of developing accreditation.

Thames Valley Probation Area has continued to use the FT 20 Q screening tool to screen at PSR stage after the collection of screening data for evaluation purposes finished (September, 2001). Also, a basic skills officer has been appointed in Berkshire with the same remit as the original basic skills officers. The basic skills exit strategy for Thames Valley Probation Area includes the development of a database for mentoring, to keep track of mentors and offenders, particularly referral, learning and progression, and outcomes; the development of basic skills provision in two probation hostels in Oxford and plans to increase provision in other hostels in Thames Valley Probation Area; group provision in Milton Keynes run by a basic skills officer and an outside basic skills tutor; and closer liaison with two Learning and Skills Councils in the area and other local learning partnerships. 


\section{Appendix D: Case studies of offenders who participated in basic skills tuition}

These case studies were compiled from the background information form, the FT $20 \mathrm{Q}$ screening tool, the data collected at the initial assessment procedure for basic skills needs, PSRs, supervision plans, quarterly reviews, offender interviews, and probation officers' and basic skills tutors' comments. Unfortunately, complete information was not available for every offender on whom a case study was written. The case studies are in part subjective accounts by offenders, probation officers, basic skills staff, and other probation staff. For this reason, caution is urged when assessing the accuracy of these case studies. The case studies are from three pathfinder areas only, and were only compiled on those offenders who were interviewed and who had, in the majority of cases, attended basic skills provision for a considerable amount of time. In order to protect the confidentiality of these individuals, the names have been changed.

\section{Case study one}

\section{Situation and background}

Ben was a 23-year-old man who resided with his partner and their 21-month-old son (with whom he had recently reunited after a temporary separation). He had never had a good relationship with his father with whom he had frequent arguments. There were no major drugs or alcohol problems reported. The only problem seemed to be accommodation, which had recently been rectified (before that he was living with a friend).

\section{Offending}

Ben's contact with the criminal justice system centred on motoring offences. He had several appearances for driving whilst disqualified and was initially banned for driving with excess alcohol. He did not see himself as a 'real criminal' and did not see that he put anyone at harm by his behaviour. Ben insisted he would not offend again and risk of reconviction was recorded as 'low' to 'medium'.

\section{School}

Ben did not enjoy school (left at 16). He came away with a negative image of education and no qualifications. He was given help by a classroom assistant at school.

\section{Employment}

Ben was happy with his job at the time of interview (in a fast food restaurant) and saw no need to change. He reported that he did not begin to attend basic skills sessions for employment reasons.

\section{Screening and PSR}

Ben scored 14 on the FT 20 Q screening tool and was reported as having major problems with basic skills. Ben's educational difficulties were diagnosed at the PSR stage where there was specific reference of his problems.

The initial assessment procedure for basic skills needs and supervision plan It was decided that Think First (an accredited offending behaviour programme) was to be the most important part of Ben's supervision plan, and it was established that once this was completed, Ben would look at his basic skills. He was administered the BSA's Initial Assessment tool and scored Entry Level in all sections except for numeracy (Level 1). Ben and his probation officer hoped that if he improved his basic skills he would be able to pass the driving theory part of his driving test; otherwise, he would not be able to gain back his driving licence. Subsequent to his completion of Think First, he was paired with a mentor and started to attend basic skills provision. (This was a good illustration of the success of the referral process later on in the offender's CRO.) 
Basic skills provision

When interviewed, Ben had been coming to classes for about a month. He thought that working with a mentor was 'all right' but he was not sure why he started mentoring to begin with. He felt that the classes were 'helping him' and he was beginning to be able to read to his son.

\section{Post test}

Ben did not complete a post test.

\section{Other improvements}

Ben reported that his confidence had improved and that he was beginning to be able to read with his son.

\section{Post CRO}

Ben reported that he might continue basic skills provision after the completion of his $\mathrm{CRO}$. He had been to college classes and he did not like them. 'Group sessions were far too much like school, and 1 to 1 is far better.'

\section{Case study two}

\section{Situation and background}

Adrian was a 25-year-old man who had had a very difficult childhood with a violent father who left the household when he was very young. His mother was anorexic and suffered from agoraphobia and she insisted that Adrian stayed at home a lot. There were also some behavioural and emotional problems while at school. Adrian frequently experienced physical abuse from his mother and brother, for example, his mother withheld food from him when he had done things that were considered 'wrong'. When he was in a Young Offenders Institution, he attempted suicide. Adrian was poorly equipped for dealing with independent living and had had great difficulty since leaving home with emotional relationships and maintaining employment. He does not abuse alcohol or drugs. At the time of interview, he had met a girlfriend who had two children from a previous relationship. She was also pregnant again. They lived in local authority accommodation.

\section{Offending}

Adrian had been previously convicted of nine offences and had served time in custody. $\mathrm{He}$ had committed acts of theft, criminal damage, handling stolen goods, driving offences, and had breached conditional discharge and CPOs and failed to surrender. Adrian had completed Think First and had not been convicted since although his risk of reconviction was recorded as 'high'.

\section{School}

Adrian reported that he had had a difficult time at school. He had attended six different schools by age 16, and some were special schools and pupil referral units. He eventually had home tuition. He gained a GCSE in Art and Design at college after leaving school. He had a violent temper at school, was the 'class clown', and was expelled. He also felt that the teachers did not like him as he used to disrupt the classes a lot.

\section{Employment}

Adrian had been doing manual jobs at the time of interview and had been lying about his qualifications in order to obtain employment. He said that he 'wants to improve his poor skills in the classes and get a better job and better money'. Adrian said that he felt angry when he could not get a job and he thought that the classes would help reduce this and intervene in the reasons why he offends.

\section{Screening and PSR}

Adrian had problems with his basic skills and was previously diagnosed as dyslexic, but was adamant that he had never been ashamed about this. He scored two on the FT $20 \mathrm{Q}$ screening tool, although most of it was not filled in and so could not be used as a measure of his basic skills. His PSR referred to literacy and numeracy difficulties and stressed dyslexia. 
The initial assessment procedure for basic skills needs and supervision plan

Adrian scored at Entry Level on all sections of the BSA's Initial Assessment tool and his Raven's score was 'below average intelligence'. He began work on literacy with a basic skills officer when he was released from a Young Offenders Institution on licence. He appeared highly motivated to work on his literacy and expressed a desire to improve on his education generally, 'to write letters to his girlfriend, to spell, and to be able to read books'. Initially he read the signs about basic skills provision in the probation office and asked his probation officer to get him involved with basic skills provision. Adrian's motivation was high.

Basic skills provision

Adrian had been coming to classes for over six months when he was interviewed. He had been writing letters and reading books in the classes and had been 'gaining confidence about his reading and writing'. He had learned to spell words, use a dictionary, write letters and to read. He thought that what he was learning in the classes was very important and he expressed a wish to get a job where reading and writing were important. He thought that this would increase his confidence, as he would know he was able to do the job properly. He also thought that '[the] classes can help him to get a better job'. He did however wish there was a little more variety in the classes, but he was happy with his progress and was feeling the extra confidence. He said he was not ready for college yet, but hoped he would be in the future.

\section{Post test}

Adrian showed a marked improvement in the BSA's Initial Assessment tool administered as a post test; reading improved from Entry Level to Level 1, and his spelling had improved to just below Level 1 from Entry Level.

\section{Other improvements}

Adrian was very motivated to improve his poor basic skills and to get a better paid job. His life seemed relatively stable at the time of interview although he had a much disrupted background. There was no explicit offence pattern, and he had decided he had had enough of offending. According to his probation officer, Adrian had improved quite visibly, and he was happy with the sessions. His confidence and esteem had improved, and Adrian commented about this frequently himself in the interview.

\section{Post CRO}

Adrian said that he wished to continue the classes following the end of his community supervision order and even 'hoped the court will extend his order so he can stay in classes longer'. This will not be necessary though, as his basic skills officer (who was teaching him at the time) said she was willing to continue working with him after his order was completed until he was ready to move into college provision.

\section{Adrian's basic skills officer}

Adrian's basic skills officer reported that:

[A]lthough his attendance was poor to begin with, we were able to establish that this was due to personal problems rather than motivational issues. Following his break-up from his tumultuous relationship, he began to attend regularly and saw basic skills provision as an opportunity to do something more constructive with his days.

In addition:

Adrian had made very good progress with his basic skills, was enjoying the classes, and had started to take homework with him. Adrian also started using the classes as a 'sounding board' to express his feelings.

His basic skills officer concluded that 'Adrian's confidence had improved greatly and he is feeling very pleased with himself'. 


\section{Case study three}

\section{Situation and background}

Brian was a 40-year-old man who was very emotionally fragile and had a precarious mental state, having been diagnosed with persistent personality disorder which resulted in psychotic behaviour from time to time. He spent his youth in local authority care because of the extreme sexual abuse he suffered at the hands of various men with whom his mother had had relationships. He was also the victim of abuse in residential care and he used to dread having to go and see his parents at weekends. His mother died when he was 11. Brian left care without preparation for the outside world and suffered a fall in 1993 which inflicted serious head injuries and caused short-term memory problems. He also had a history of self harm. At the time of interview, Brian was living with his family in local authority accommodation. Brian had never been given any help with his past problems, apart from once when he saw a counsellor who also abused him. His brother and sister were in psychiatric hospitals because of the abuse they endured in their childhoods and Brian was regretful of this.

\section{Offending}

This offence (affray) occurred one night because the victim questioned his sexuality. He committed the act as 'silly things tip me over the edge'. He went around to the victim's house as he was intoxicated, carrying with him an imitation firearm. He was eventually tackled by armed police officers who could have shot at him. He had few convictions but his temper had got him into trouble in the past when he had been binge drinking. Brian was classified as 'low' risk of reconviction.

\section{Employment}

Brian had not held permanent employment for 15 years due to his mental state and was registered disabled. He said that he would love to be able to work and that sometimes he helped his friend out in her hair salon.

\section{School}

Brian left school without any formal qualifications, although he attended most of the time in the last two years and took exams. He attended seven schools, none for any length of time. He said that he had had a 'terrible experience at school, I was bullied the whole time, other children knew I was in a children's home and therefore outcast me... I had no motivation the whole time.'

\section{Screening and PSR}

The PSR writer carried out an assessment which revealed he had significant learning disabilities. Brian scored 19 on the FT 20 Q screening tool. This was not taken further in the PSR, with the focus being on his mental health and alcohol issues.

The initial assessment procedure for basic skills needs and supervision plan

Basic skills needs were taken up in his supervision plan where Brian was described as highly motivated. It was suggested that he receive help and assistance with his literacy and numeracy so that he would be able to read better and become more numerate. Brian commented that he took up basic skills provision because he stated in his initial interview with his probation officer that his problems were with reading, writing and alcohol. He was referred to the initial assessment procedure for basic skills needs and spoke to the basic skills tutor about basic skills work. Brian scored at Level 1 on all sections of the BSA's Initial Assessment tool apart from the section on punctuation, on which he scored at Entry Level. Brian scored 'below intellectually average' on Raven's.

\section{Basic skills provision}

It was intended that the basic skills classes would help Brian read and write with confidence by completing a range of appropriate exercises using spelling, punctuation and grammar packs.

\section{Post test}

In the BSA's Initial Assessment tool administered as a post test, Brian's improved to above Level 1 in reading, just below Level 1 in spelling and punctuation, and at Level 1 in numeracy. 


\section{Other improvements}

When interviewed, Brian had been coming to classes for nine months for an hour and a half each week. He did spelling, phonetics, punctuation, abbreviation, full stops, maths and DIY. He thought that what he learned in the classes was very important. He reported that working with the tutor had been 'brilliant' although he had been worried at the beginning as he thought it may be just like school and 'starting at the bottom of the ladder again'. His wife used to have to come with him to support him, but just before the time of interview, he had begun to come by himself. He said that the classes were helping him greatly 'in every way... I used to drink seven days a week, and now I have given up for two months now.' He used to be in trouble all the time because he was drinking and getting into fights, but at the time of interview, he reported that he had stopped going out and so did not place himself in a position to get into trouble. Brian talked a lot about his family and his 17-year-old son who helped him with his reading and writing at weekends. He said:

It was a shame more people do not know about the classes... what was needed was more publicity... what I needed was a kick up the backside and I got the push... two weeks into the classes I was going to give up, then I thought to myself, you cannot give up after two weeks just because it is not working out, so I stuck it for another month and later I was glad I did. I used to be scruffy but now I am all cleaned up, everything has changed, my attitude at home, I am just much happier now.

Brian had begun to read to his grandchildren which he could never do before, and it was evident that he was very proud of this. All of Brian's quarterly reviews recorded his progress and commented on his basic skills work, first saying that he was partly achieving his supervision plan objective by attending provision, then largely achieving the objective by remaining committed to provision, and then completely achieving his objective and 'despite everything he remains committed to basic skills' (Brian was accused of the rape of a friend during his $\mathrm{CRO}$, which caused him to relapse into binge drinking).

\section{Post CRO}

Brian had been asked by his basic skills tutor to stay on as a basic skills volunteer when his CRO finished.

Brian's tutor

Brian's basic skills tutor reported that he had produced an:

[E]xcellent piece of writing, which was excellent in composition but horrifying in content - the story of his life. He also writes poetry. He used to come in scruffy and smelling of alcohol - and he has now stopped drinking and comes in clean and tidy. $\mathrm{He}$ also used to take his wife with him everywhere, and now he comes in alone. He was astounded by how much he improved, with his BSA's Initial Assessment tool score. Brian also said that if it wasn't for basic skills provision, he would not be here now.

\section{Case study four}

\section{Situation and background}

Andrew was a 24-year-old man with a vulnerable disposition. At the time of interview, he lived with his partner and they had just taken up relationship counselling. Their children had been placed on the Child Protection Register as they were at risk of physical violence. He had undertaken work on anger management.

\section{Offending}

The offence for which Andrew was before the court was driving whilst disqualified, committed three days after his custodial licence expired. He had many previous convictions and a custodial sentence imposed for three burglaries, possession of CS gas and driving without licence or insurance. It was noted in Andrew's PSR that he acted on impulse, and that his past offences (of which there were many) had been dealt with by attendance orders, conditional discharges, CROs, CPOs, CPROs and custodial sentences. He had breached many of his community sentences and it had been suggested that he could become easily 
overwhelmed. At the time of interview, he had been sentenced to a CRO. Andrew's risk of reconviction status was not stated.

\section{School}

Andrew left school at 15 with no qualifications. He said school had been 'alright' and he had liked it. He had been interested in what he learnt at school, especially maths, English and science.

\section{Employment}

Andrew had mainly held manual employment since leaving school, and at the time of interview was unemployed and claiming benefits. He expressed a wish to be a mechanic but he had not been able to read the manuals in the past.

\section{Screening and PSR}

Andrew scored 16 on the FT 20 Q screening tool.

The initial assessment procedure for basic skills needs and supervision plan

Andrew did not complete the BSA's Initial Assessment tool for the Basic Skills Pathfinder evaluation because he had been receiving basic skills help on a previous probation order before he went to jail. This may have provided the impetus to take up basic skills provision again.

\section{Basic skills provision}

Andrew was interviewed when he had been coming to classes for about ten weeks (on this $\mathrm{CRO}$ ). He had decided to start coming to basic skills provision originally because he had 'appalling spelling and writing'. In the classes, he did reading, writing and spelling. He found working with the tutor 'really fun and enjoyable'. He felt the classes were helping him with his writing a lot, and he thought what he learnt in the classes was important. He also found that the basic skills provision in community supervision was much better than school classes.

\section{Post test}

Andrew did not complete a post test.

\section{Other improvements}

Andrew said that he wanted to be a mechanic but that he had not been able to read the requisite manuals before. He had enrolled on a college course commencing September 2002 on mechanics and was trying hard to get a job in this field. He said that he wished to continue basic skills classes in community supervision when he started at college.

\section{Post CRO}

Andrew wished to continue with basic skills provision within community supervision after his $\mathrm{CRO}$ ended and to combine his work with a college course in mechanics.

\section{Andrew's tutor}

Andrew's tutor said that 'Andrew has had many set backs but has managed to attend regularly. Andrew said that his improvements have helped him read with his children and in Internet chat rooms. He has also grown in confidence and esteem.'

\section{Case study five}

\section{Situation and background}

Alex was a 20-year-old man who had experienced major problems with alcohol and drugs, although (at the PSR stage) he reported that his problems were under control. During Alex's interview, he expressed a wish to find alternative accommodation because the conditions in which he was residing were very cramped. In addition, Alex reported that many of the people he shared his accommodation with were drug users and he did not feel this was conducive to his rehabilitation. 


\section{Offending}

Alex's offence was criminal damage which he attributed to being drunk at the time. This reflected a pattern of offending, and although it was believed that he only responded to situational factors in offending when he was drunk, he was considered at 'high' risk of reconviction. He was currently on a 12-month CPRO.

\section{School}

Alex had not enjoyed his school experience describing it as 'crap'. He felt that he had been 'picked on' by teachers and that he could not learn there because he hated it so much. Alex left school when he was 16 and had no qualifications.

\section{Employment}

Alex was very proactive in seeking employment and hoped that improving his basic skills would help him with this.

\section{Screening and PSR}

Alex scored 20 on the FT 20 Q screening tool and significant basic skills problems were recorded in his PSR.

The initial assessment procedure for basic skills needs and supervision plan

Alex was unable to complete the BSA's Initial Assessment tool and so completed a local assessment instead. He scored 'below intellectually average' on Raven's. Basic skills work was included as an objective in his supervision plan, along with addressing alcohol and drug use. His quarterly reviews reported that he was continuing to attend basic skills provision and was making progress in basic skills.

\section{Basic skills provision}

Alex was interviewed when he had been coming to basic skills provision for about a year. He did not initially decide to access basic skills provision for his own benefit, but rather because it was part of his supervision plan. He said that he had not wanted to come to basic skills provision at the start, but knew that he would be breached if he failed to attend. Since then, he had enrolled in a college course which he combined with basic skills provision within community supervision. Alex expressed dissatisfaction and frustration with the pace of his progress in basic skills and felt that because he was attending both basic skills provision in college and in community supervision, his improvements should have been more rapid. $\mathrm{He}$ reported that although his confidence was growing, it was only doing so very slowly. Nonetheless, Alex intended to persevere and would continue in college when his CPRO was complete even if he did not attend basic skills provision in community supervision any longer.

\section{Post test}

Alex did not complete a post test.

\section{Other improvements}

Alex reported that his self-confidence had improved and continued to do so, albeit slowly. He said that he enjoyed coming to basic skills sessions in both community supervision and in college, and spent about five hours per week practising what he had learnt at home. In addition, he reported that he had not offended since he began basic skills provision.

\section{Post CRO}

Alex would continue with basic skills tuition but probably in college.

Alex's tutor

Alex's basic skills tutor reported that when he began basic skills provision he was not coping well:

His appearance was poor, he was drinking quite heavily and was unable to feed himself properly. Since then, there has been good progress, he now takes pride in his appearance and he is always washed and generally shaven. He takes pride in telling me how he shops and what he has been able to cook for himself. He has represented 
the UK in Sweden, as part of a group of local people from five EU countries with similar problems. He has attended weight training sessions organised by probation. He has a long way to go, but he has also made good progress in getting himself sorted.

\section{Case study six}

\section{Situation and background}

Adam was a 26-year-old man who had experienced an incredibly troubled childhood and was in care for most of his life because of parental abuse. He reported that he owed his temper and unruly behaviour to the instability of his life and the lack of care that he experienced in foster homes. These experiences had had an impact on his self-efficacy and he had a long history of depression and self-harm. At the time of interview, Adam was leading a chaotic life and had just broken up with his long-term girlfriend who left him for a heroin addict. He felt very resentful about this, and reported that it had caused him to self-harm again, a situation he thought was improving. Adam had been separated from his children from a previous marriage and had been accused of assaulting his former partner, their mother. This situation also led to a decline of his mental health. He had a good relationship with his current property owner and was seeking psychiatric help.

\section{Offending}

Adam's offence (assaulting a police constable) took place when he was very inebriated, and his recollection of this was minimal, although he accepts the victim and witness accounts as accurate. His attack resulted from a dispute with his ex-girlfriend which upset him greatly, and led him to be verbally abusive to bystanders, hence the police intervention, which he felt was unwarranted and excessive. Adam's risk of reconviction status was not stated.

\section{School}

In his interview, Adam reported that 'I was a bit of a hooligan at school' and he was both suspended and expelled from school. He was not interested in school before that and believed that he had suffered from learning disabilities while at school.

\section{Employment}

Adam was not able to work because of his psychiatric problems.

\section{Screening and PSR}

Adam did not complete the FT 20 Q screening tool during the PSR interview although basic skills work was mentioned in his PSR as being a problem. In addition, the PSR stated that he wished to enrol in classes to improve his basic skills.

The initial assessment procedure for basic skills needs and supervision plan Adam scored below Level 1 in all sections of the BSA's Initial Assessment tool. He also scored 'below intellectually average' on Raven's. Basic skills work was included in the objectives of Adam's supervision plan and reported as continuing work in his quarterly review.

\section{Basic skills provision}

At the time of his interview, Adam had been coming to basic skills classes for six months. He began to come initially because he felt that doing something was better than only seeing his probation officer. He said that he could not attend basic skills provision when he was feeling particularly depressed.

\section{Post test}

Adam completed a parallel version of the BSA's Initial Assessment tool administered as a post test, and scored Level 1 in literacy, below Level 1 in spelling, at Level 1 in punctuation, and at Entry Level in numeracy. This showed that Adam's improvements were in punctuation, and although his numeracy level declined, it was worth noting that he did not work on numeracy in the basic skills classes. 
Other improvements

Although Adam had had some psychiatric issues since he began basic skills provision, he did feel that he had improved overall and attributed this to the support he received from his basic skills tutor with whom he preferred to speak about his problems. He also reported that he had not offended since he began basic skills provision and felt that this was because of his improvement in confidence and esteem. At the time of interview, Adam had just submitted a short story (with the help of his basic skills tutor) to a competition of which he was very proud. He was excited to see how that turned out.

\section{Post CRO}

Adam said that he wanted to continue with basic skills provision following the completion of his order, and had also applied for college courses.

Adam's tutor

Adam's basic skills tutor commented that:

Adam had a record of self-harm which, when things get him down, may still occur. However, this behaviour [has] lessened since I have known him. He generally remains positive about his daughters, even though they are likely to be adopted, and we spend a lot of time discussing what may be appropriate presents for them when he receives an access order. He has submitted a story to the prison/probation literary competition and enjoys writing short stories. He has started using the Internet and said he likes going on it now he's not ashamed of his spelling. 


\section{Appendix E: Reliability of the BSA Fast Track 20 Questions screening tool}

The FT 20 Q screening tool is undoubtedly a crude instrument but it does have some degree of validity, as assessed both by the work of the BSA and from an analysis of data derived from this evaluation.

There are three possible outcomes from the use of the FT 20 Q screening tool as a screening instrument:

- A correct evaluation of an offender's basic skills needs.

- A false negative, when an offender's basic skills needs are not detected by the instrument.

- A false positive, when the instrument indicates an offender as having a basic skills need when, in fact, s/he does not.

The accuracy of the tool is obviously important to eliminate false positives and false negatives. One way to test its reliability is to compare its results against another tool to assess basic skills. The BSA found a high correlation (77\%) between the FT 20 Q screening tool scores and scores on the BSA's Initial Assessment tool for the general population of adults on whom the FT 20 Q screening tool was piloted (BSA, 2000b). As part of the evaluation of the Basic Skills Pathfinder this association was further tested, analysing the data collected and a significant association between the two tools was found.

Reliability of the FT 20 Q was estimated, based on individuals for whom scores on the FT 20 Q screening tool and the BSA's Initial Assessment tool were received. An examination of the data from the sample of offenders who scored below Level 1 on the FT 20 Q and who were then assessed using the BSA's Initial Assessment tool shows that there were relatively few false positives (9\%). Given that the definition of Level 1 in basic skills has changed with the introduction of the Adult Basic Skills Curriculum (see Appendix A), so that the level of attainment required for someone to be judged at or above Level 1 has now increased, this is likely to reduce further the proportion of false positives. Consequently, there is a degree of confidence in the estimates of the prevalence of basic skills needs amongst those offenders screened at PSR stage using the FT 20 Q screening tool.

Data on the proportion of false negatives in the screening sample was not systematically collected. However, a strong association between the FT 20 Q screening tool and the BSA's Initial Assessment tool was found for both the complete sample ${ }^{54}$ and for offenders sentenced to a CRO or a CPRO. In the sample of offenders who were sentenced to a CRO or a CPRO, offenders who scored below Level 1 on the FT 20 Q screening tool were significantly more likely to score below Level 1 on the literacy sections of the BSA's Initial Assessment tool than offenders who scored at or above Level 1 on the FT 20 Q screening tool ${ }^{55}$ (see Figure E.1).

\footnotetext{
${ }^{54}$ Chi-square $=104.81, \mathrm{df}=1, \mathrm{p}<0.001$; odds ratio $=28$ for the literacy section and Chi-square $=48.26, \mathrm{df}=1, \mathrm{p}<0.001$; odds ratio $=4.5$ for the numeracy section.

${ }_{55}$ Chi-square $=23.591, \mathrm{df}=1, \mathrm{p}<0.001$, odds ratio $=9$.
} 
Figure E.1: The FT 20 Q screening tool and literacy on the BSA's Initial Assessment tool $(n=112)$

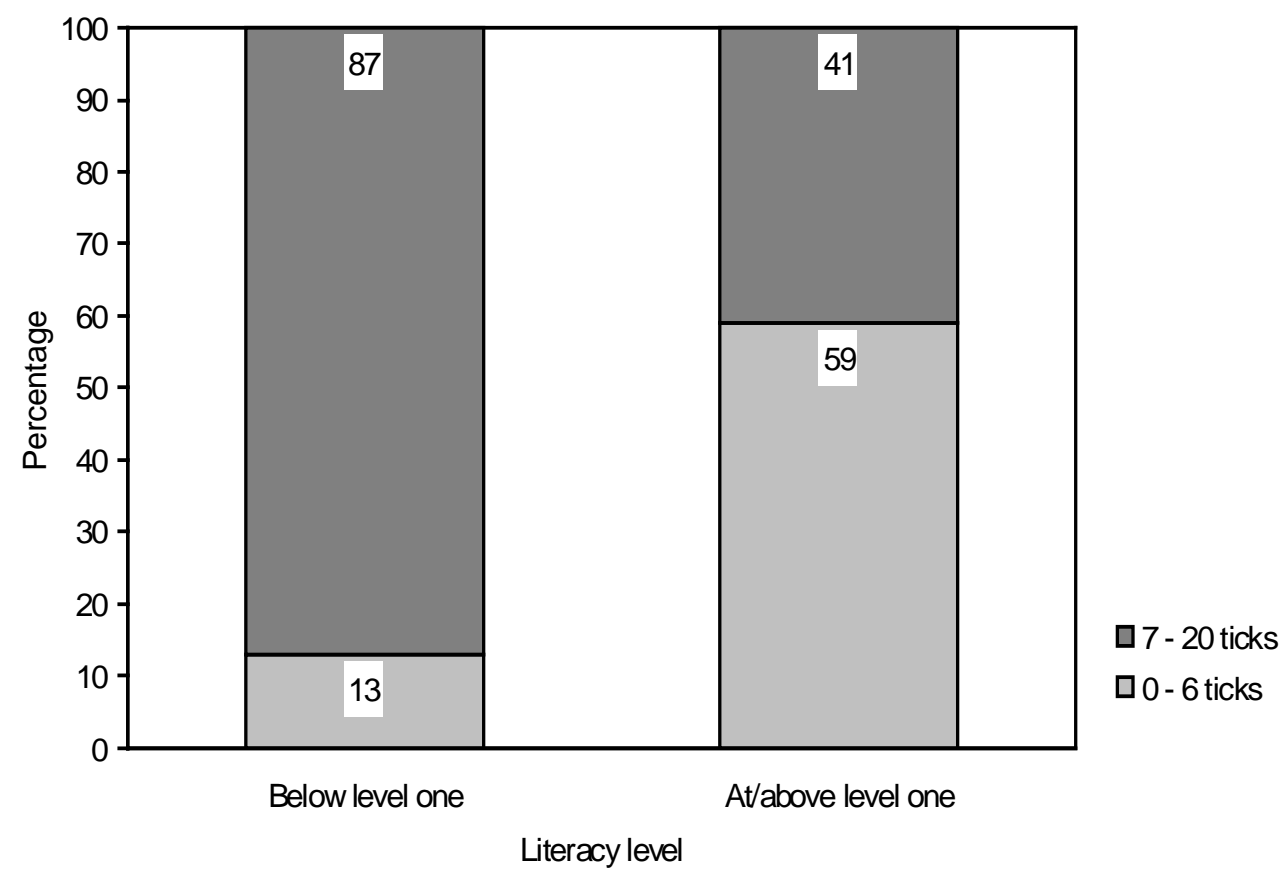

Figure E.2: The FT 20 Q screening tool and numeracy on the BSA's Initial Assessment tool $(n=211)$

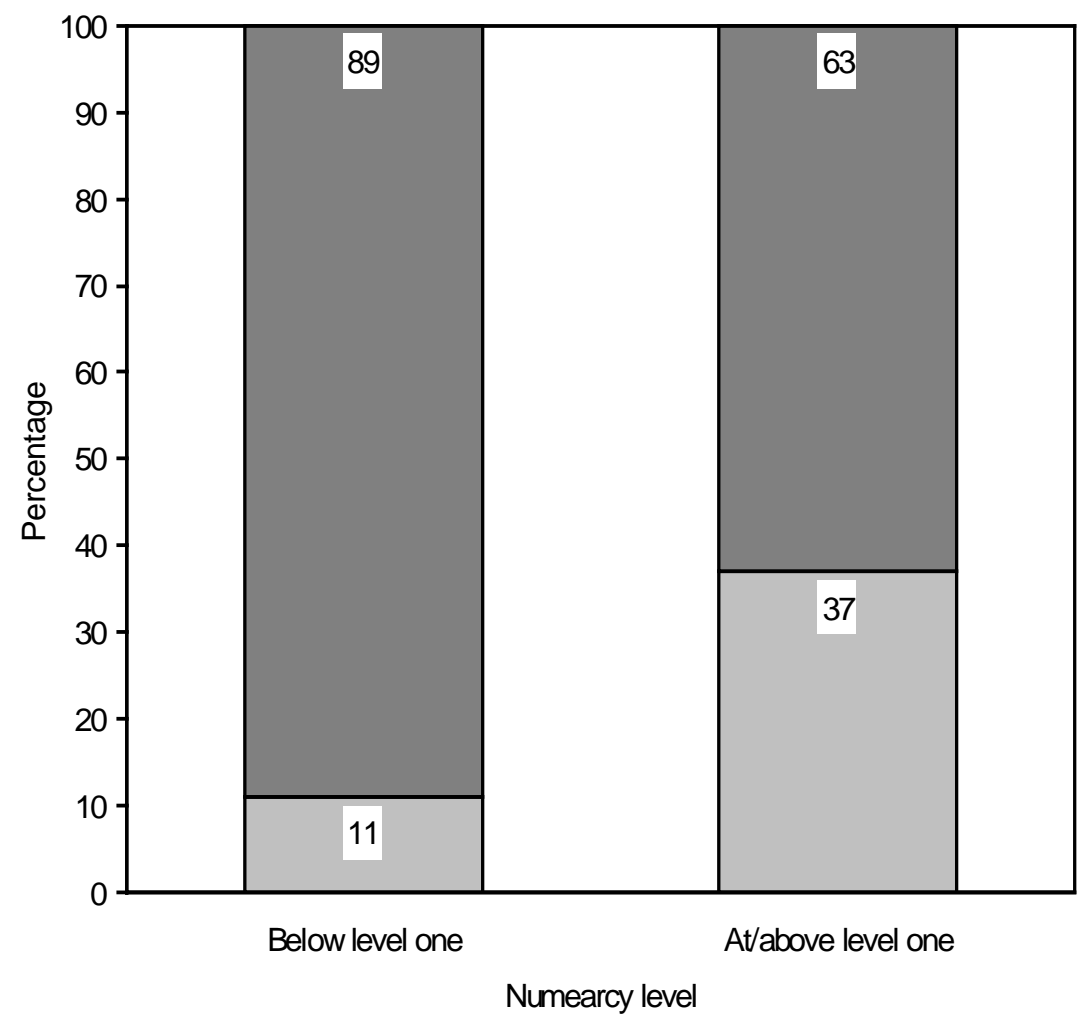

प7- 20 ticks

व 0 - 6 ticks 
The offenders in the sample who were sentenced to a CRO or a CPRO and who scored below Level 1 on the FT 20 Q screening tool were also more likely to score below Level 1 on the numeracy section of the BSA's Initial Assessment tool than offenders who scored at or above Level 1 on the FT 20 Q screening tool. ${ }^{56}$ However for this sample, and also for the overall sample, the association between the FT 20 Q screening tool and the BSA's Initial Assessment tool was not significant when numeracy scores on the BSA's Initial Assessment tool were dichotomised by 'at or above Entry' and 'below Entry Level'57 (see Figure E.2). Thus, the evidence indicates that although the FT 20 Q screening tool was designed to identify numeracy needs below Entry Level, it largely did not do so for this sample.

The evidence from the Basic Skills Pathfinder evaluation suggests then that although the FT $20 \mathrm{Q}$ screening tool is statistically significant in indicating both an offender's literacy and numeracy below or at or above Level 1, it is not so for indicating an offender's numeracy below or at or above Entry (i.e. functional numeracy), although it was originally designed to do so. This may have policy implications for the type of screening tool used in the future to assess numeracy in community supervision.

Nonetheless, examining the data from the sample of offenders who scored below Level 1 on the FT 20 Q screening tool, and who were then assessed using the BSA's Initial Assessment tool, shows that there were relatively few false positives $\left(35,9 \%{ }^{58}\right)$. Given that the definition of Level 1 in basic skills has changed with the introduction of the Adult Basic Skills Curriculum (see Appendix A), so that the level of attainment required for someone to be judged at or above Level 1 has now increased, this is likely to reduce further the proportion of false positives. Consequently, there is a degree of confidence in the estimates of the prevalence of basic skills needs amongst those offenders screened at PSR stage using the FT 20 Q screening tool.

\section{Raven's Progressive Matrices}

The data from the initial assessment procedure for basic skills needs also indicate that there was a strong association between the scores on the BSA's Initial Assessment tool and Raven's Progressive Matrices. Offenders who scored below Level 1 on the literacy sections of the BSA's Initial Assessment tool were significantly more likely to be classified as 'below intellectually average' on the basis of their scores on Raven's Progressive Matrices than offenders who scored at or above Level 1 on the literacy sections of the BSA's Initial Assessment tool. ${ }^{59}$ In addition, offenders who scored below Level 1 on the numeracy section of the BSA's Initial Assessment tool were also significantly more likely to be classified as 'below intellectually average' on the basis of their scores on Raven's Progressive Matrices than offenders who scored at or above Level 1 on the numeracy section of the BSA's Initial Assessment tool ${ }^{60}$ (see Figures E.3 and E.4).

\footnotetext{
${ }^{56}$ Chi-square $=19.983, \mathrm{df}=1, \mathrm{p}<0.001$; odds ratio $=5$.

${ }^{57}$ Chi-square $=0.062, \mathrm{df}=1, \mathrm{p}<1$.

${ }^{58}$ The estimation is based on those offenders for whom scores on the FT 20 Q screening tool and the BSA's Initial Assessment tool were received.

${ }^{59}$ Chi-square $=53.97, \mathrm{df}=1, \mathrm{p}<0.001$, odds ratio $=29$.

${ }^{60}$ Chi-square $=27.49, d f=1, p<0.001$, odds ratio $=6$.
} 
Figure E.3: Literacy on the BSA's Initial Assessment tool and Raven's Progressive Matrices ( $n=164)$

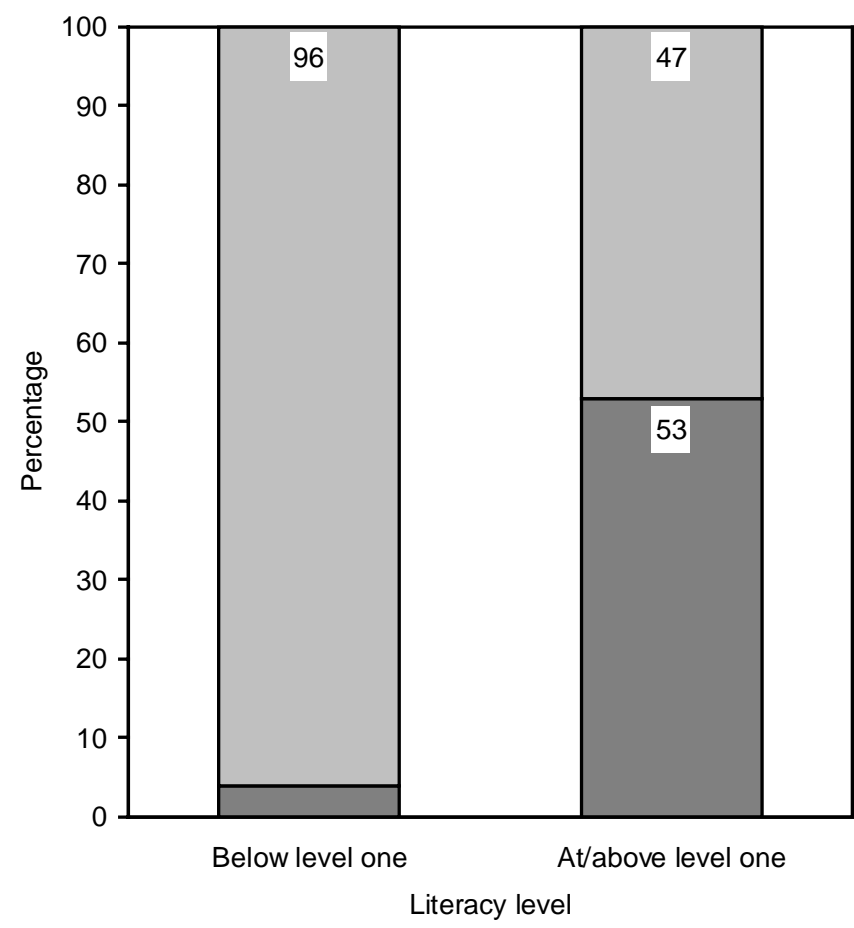

$\square$ 'Below intellectually average'

$\square$ 'Intellectually average/above'

Figure E.4: Numeracy on the BSA's Initial Assessment tool and Raven's Progressive Matrices $(n=312)$

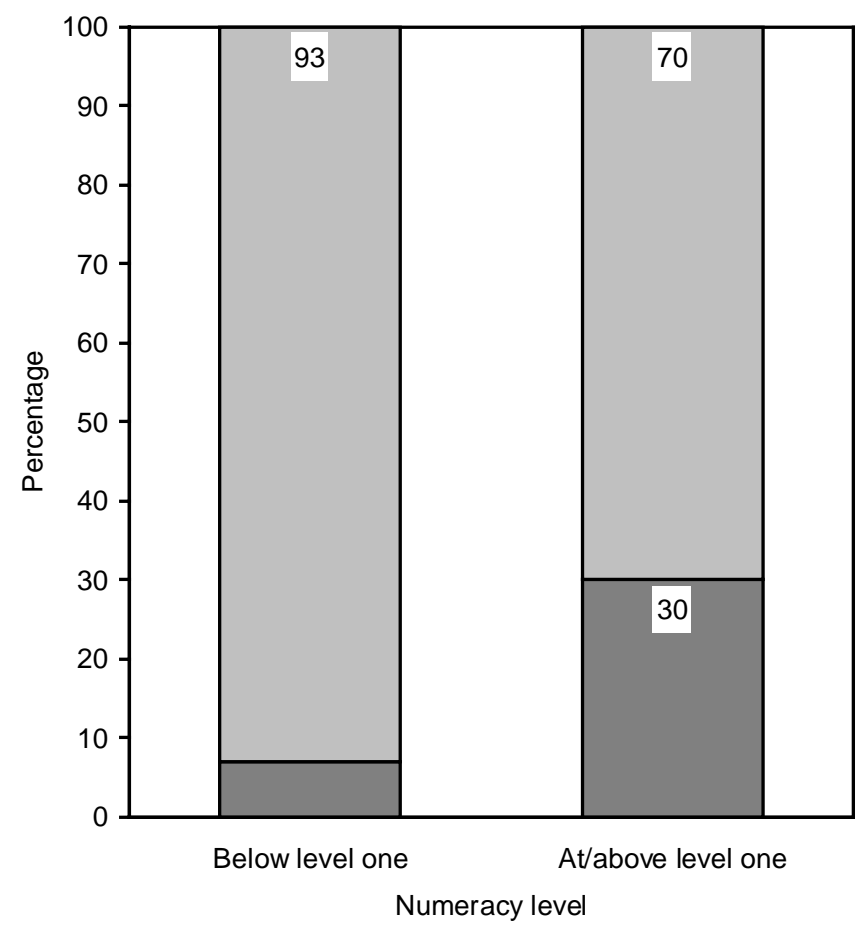

$\square$ 'Below intellectually average'

口 'Intellectually average/above' 
An analysis of the whole sample for which there were Raven's data reveals no significant associations between the Raven's classification of eductive ability ${ }^{61}$ and risk of reconviction or patterns of school attendance. ${ }^{62}$ However, an offender with a low Raven's score was more likely to score below Level 1 on the FT 20 Q screening tool compared to an offender classified as 'intellectually average and above' and was also significantly more likely to have no qualifications. ${ }^{63}$ Interestingly, there was no association between an individual's Raven's score and his/her employment status. ${ }^{64}$

${ }^{61}$ The full classification was dichotomised to 'intellectually average above' and 'below intellectually average' to cope with the small number ofcases in some categories.

Chi-square $=9.5$, d.f. $=8, p=0.3 ;$ Chi-square $=2$, d.f. $=4, p=0.73$ respectively.

${ }^{3}$ Chi-square $=8.1$, d.f. $=1, p=0.04 ;$ Chi-square $=9.2$, d.f. $=3, p=0.03$ (adjusted residual 2.5 ) respectively.

${ }^{64}$ Chi-square $=1.62$, d.f. $=1, p=0.204$. 


\section{Appendix F: Analysis of the total screening sample}

A total of 10,252 fully or partially completed screenings with offenders were returned by the Basic Skills Pathfinder areas. The 1,167 cases for which no information on sentence type was received are indicative of the large amount of missing data in the data base.

A comparison of the screening sample with previous studies and other information on offenders was carried out to find out how representative this particular sample was to the offending population more general. The characteristics of the screening sample can be summarised as follows:

- $\quad$ Eighty-five per cent were male

- $\quad$ Nineteen per cent were below 21 years of age, 40 per cent were below 25

- Ninety-two per cent were classified as white and the remainder as black Other (2\%), black Caribbean (1.5\%), black African, Indian, Pakistani and Bangladeshi (all $<1 \%$ ) or other $(2.5 \%)$

- Sixty-six per cent were single, divorced or separated (10\% had dependant(s)), 31 per cent were married or had a partner (16\% had dependant(s)); the remainder were 'not known'

- Forty per cent lived in rented accommodation, nine per cent owned their own home, 39 per cent lived with friends, family or others, and the remainder lived in Bed and Breakfast accommodation, lodgings, a unit or a hostel

- Thirty-eight per cent were in a 'low' risk of reconviction category, 40 per cent were in a 'medium' risk category and 22 per cent were in a 'high' risk category ${ }^{65}$

- Twenty-four per cent were sentenced for the principal offender of violence against the person, 22 per cent for theft, 22 per cent for a motoring offence, seven per cent for burglary, seven per cent for a drugs offence, five per cent for a sexual offence, and the remainder committed fraud and forgery, criminal damage or 'other' offences

- Twenty-eight per cent were sentenced to a CRO, seven per cent were sentenced to a CPRO, 26 per cent were sentenced to a CPO, 27 per cent were sentenced to custody and the remainder received a fine, or were sentenced to a Drug Treatment and Testing Order, discharge or suspended sentence.

The data on gender and age of offenders were generally consistent with past data collected at the PSR stage on offenders sentenced for all offences by all courts. ${ }^{66}$ The figure for minority ethnic cases was generally lower than that found in other large-scale quantitative studies (Merrington, 2001; Flood-Page and Mackie, 1998). However, this could be due to the areas selected for the Basic Skills Pathfinder evaluation. In three Basic Skills Pathfinder areas, Cornwall, Cumbria and Lincolnshire Probation Areas, there were less than one per cent of cases in the non-white category of race/ethnic classification. ${ }^{67}$ In Sussex Probation Area, just over three per cent of cases were in the non-white category, in Dorset Probation Area eight per cent, and in Nottinghamshire Probation Area ten per cent. It was only in Thames Valley Probation Area (16\%) that there was any significant minority ethnic presence in the data collected. ${ }^{68}$

Of offenders within the screening sample for the Basic Skills Pathfinder evaluation, 78 per cent were sentenced in the Magistrates Court, 21 per cent in the Crown Court, and one per cent in an 'other' court. The proportion of offenders being sentenced for different types of offence in the Basic Skills Pathfinder evaluation screening sample was different from what might be expected in a random sample of those found guilty and sentenced by the courts. In 2000 , the proportion of offenders found guilty or cautioned for an indictable offence was 41 per cent for theft and handling, 18 per cent for drugs offences, 14 per cent for violent offences

\footnotetext{
${ }^{65}$ Risk of reconviction was measured by OGRS2 in six of the basic skills pathfinder areas, and Sussex Probation Area used LSI-R. OGRS2 scores were categorised according to the criteria for the accredited offending behaviour programmes. The scores on LSI-R were aligned to those on OGRS 2. (see

Raynor et al., 2000)
66 See Flood-Page and Mackie (1998) (in particular Appendix A) and Merrington (2001) for two studies using large quantitative samples with similar See Flood-Page and Mackie (1998) (in particular Appendix A) and Merrington (2001) for two studies using
demographic characteristics. Also see Criminal Statistics - England and Wales 2000 (Home Office, 2000b).

There was just one person in Cornwall who was not white, in Cumbria Probation Area, one Indian and four 'other,' and in Lincolnshire, ten people who were not white.

${ }^{68}$ Caution is urged when interpreting these figures, as there was a significant amount of missing information which was not provided from basic skills pathfinder areas.
} 
(including sexual offences and robbery), seven per cent for burglary, five per cent for fraud and forgery, three per cent for criminal damage, and 12 per cent for other offences ${ }^{69}$ (Home Office, 2000c). The data collected at the screening stage of the Basic Skills Pathfinder evaluation indicate that there was a higher proportion of violent offenders, much less theft, drugs, and fraud and forgery, and a larger proportion of motoring offences compared to the proportions cited by the Home Office ${ }^{70}$ (Home Office, 2000c).

The percentage of those in the Basic Skills Pathfinder evaluation screening sample who were sentenced to custody (28\%) or community supervision (35\%) was higher than would be expected of a random sample of all sentencing decisions. In 2000, only 31 per cent of all those sentenced for an indictable offence in a Magistrates Court were sentenced to community supervision, compared to 14 per cent who received custody and 31 per cent who were fined. The relative figures for the Crown Court were 26 per cent sentenced to community supervision and 64 per cent sentenced to custody (Home Office, 2000c).

It is possible that those offenders for whom a PSR is completed (see Chapter 2) are more likely to be sentenced for a more serious offence than those for whom a PSR is not completed, or are more likely to have previous convictions. PSRs are only used when a court requires guidance as to a suitable sentence for the offender, and it is unlikely that in less serious offences (usually summary offences) a court would require a PSR if it intends to impose a fine or a discharge. Thus, the discrepancy in offence type and sentence for the Basic Skills Pathfinder evaluation screening sample compared to Criminal Statistics England and Wales 2000 (Home Office, 2000b) could possibly be attributed to the sampling method used for the Basic Skills Pathfinder evaluation, i.e. collecting data on offenders for whom a PSR was written.

\section{Gender}

Table F.1 shows the gender of the cases in the screening database broken down by pathfinder area and sentence. The proportion of women in the screening sample supplied by each pathfinder area was consistent, ranging from 13 per cent of the total sample in Thames Valley Probation Area to 18 per cent of the total in Cumbria Probation Area. These differences were not statistically significant. ${ }^{71}$ There were no significant differences between the pathfinder areas in terms of the proportion of women being sentenced to either a CRO or a CPRO. Approximately 20 per cent of those sentenced to a CRO are normally women (Home Office, 2000a), and the proportion of women who were sentenced to a CRO or a CPRO in the Basic Skills Pathfinder evaluation was broadly comparable to this proportion. This varied from 15 per cent of CRO or CPROs in Dorset Probation Area to 19 per cent in Cornwall Probation Area. Women constituted 15 per cent of the total sample at the initial assessment procedure for basic skills needs. ${ }^{72}$

\footnotetext{
${ }^{69}$ Caution is advised when comparing the data from the basic skills pathfinder with official statistics, as different criteria was used for categorisation in official statistics, i.e. offenders who were found guilty or cautioned, whereas the offenders in the basic skills pathfinder sample were those on whom PSRs were written and were sentenced by the courts

${ }^{70}$ It is possible that not all cases for which basic skills pathfinder areas provided data would have been indictable offence cases, but given the requirement that a PSR was written, evidence suggests that most would have been.

${ }_{71}^{71}$ Chi-square $=3.7$, d.f. $=6, p=0.7$.

${ }^{72}$ However, evidence suggests that pathfinder areas referred offenders other than those sentenced to a CRO or a CPRO to the initial assessment procedure for basic skills needs.
} 
Table F.1: Gender description by pathfinder area and sentence type

\begin{tabular}{|c|c|c|c|c|}
\hline \multirow{2}{*}{ Pathfinder area } & \multirow{2}{*}{ Sentence } & \multicolumn{2}{|l|}{ Gender } & \multirow[b]{2}{*}{ Total } \\
\hline & & Male & Female & \\
\hline \multirow[t]{5}{*}{ Cornwall } & Custody & $57(93 \%)$ & $4(7 \%)$ & 61 \\
\hline & CRO or CPRO & $51(81 \%)$ & $12(19 \%)$ & 63 \\
\hline & $\mathrm{CPO}$ & $39(78 \%)$ & $11(22 \%)$ & 50 \\
\hline & Other & 49 (83\%) & $10(17 \%)$ & 59 \\
\hline & Total & $196(84 \%)$ & $37(16 \%)$ & 233 \\
\hline \multirow[t]{5}{*}{ Cumbria } & Custody & $138(83 \%)$ & $28(17 \%)$ & 166 \\
\hline & CRO or CPRO & $246(82 \%)$ & $56(19 \%)$ & 302 \\
\hline & $\mathrm{CPO}$ & $164(83 \%)$ & $34(17 \%)$ & 198 \\
\hline & Other & $24(80 \%)$ & $6(20 \%)$ & 30 \\
\hline & Total & $572(82 \%)$ & $124(18 \%)$ & 696 \\
\hline \multirow[t]{5}{*}{ Dorset } & Custody & $329(92 \%)$ & $29(8 \%)$ & 358 \\
\hline & CRO or CPRO & $223(85 \%)$ & $38(15 \%)$ & 261 \\
\hline & $\mathrm{CPO}$ & $256(82 \%)$ & $57(18 \%)$ & 313 \\
\hline & Other & $178(77 \%)$ & $54(23 \%)$ & 232 \\
\hline & Total & $986(85 \%)$ & $178(15 \%)$ & 1,164 \\
\hline \multirow[t]{5}{*}{ Lincolnshire } & Custody & $178(93 \%)$ & $13(7 \%)$ & 191 \\
\hline & CRO or CPRO & $477(84 \%)$ & $94(17 \%)$ & 571 \\
\hline & $\mathrm{CPO}$ & $227(86 \%)$ & $37(14 \%)$ & 264 \\
\hline & Other & $36(82 \%)$ & $8(18 \%)$ & 44 \\
\hline & Total & $918(86 \%)$ & $152(14 \%)$ & 1,070 \\
\hline \multirow[t]{5}{*}{ Nottinghamshire } & Custody & $831(92 \%)$ & $73(8 \%)$ & 904 \\
\hline & CRO or CPRO & $780(82 \%)$ & $172(18 \%)$ & 952 \\
\hline & $\mathrm{CPO}$ & $503(89 \%)$ & $63(11 \%)$ & 566 \\
\hline & Other & $235(78 \%)$ & $66(22 \%)$ & 301 \\
\hline & Total & $2,349(86 \%)$ & $374(24 \%)$ & 2,723 \\
\hline \multirow[t]{5}{*}{ Sussex } & Custody & $340(92 \%)$ & $29(8 \%)$ & 369 \\
\hline & CRO or CPRO & $360(81 \%)$ & $83(19 \%)$ & 443 \\
\hline & $\mathrm{CPO}$ & $321(85 \%)$ & $58(15 \%)$ & 379 \\
\hline & Other & $187(84 \%)$ & $37(17 \%)$ & 224 \\
\hline & Total & $1,208(86 \%)$ & $207(15 \%)$ & 1,415 \\
\hline \multirow[t]{5}{*}{ Thames Valley } & Custody & $425(94 \%)$ & $27(6 \%)$ & 452 \\
\hline & CRO or CPRO & $443(84 \%)$ & $85(16 \%)$ & 528 \\
\hline & $\mathrm{CPO}$ & $459(87 \%)$ & $70(13 \%)$ & 529 \\
\hline & Other & $180(78 \%)$ & $50(22 \%)$ & 230 \\
\hline & Total & $1,507(87 \%)$ & $232(13 \%)$ & 1,739 \\
\hline
\end{tabular}

Table F. 2 shows the gender composition of those who were sentenced to a CRO or a CPRO and who scored below Level 1 on the FT 20 Q screening tool. The vast majority of the cases $(83 \%)$ were male, and significantly more males (36\%) than females (31\%) scored below Level 1 on the FT 20 Q screening tool.

Table F.2: The FT 20 Q screening tool scores of men and women sentenced to a CRO or CPRO

\begin{tabular}{|l|l|l|l|}
\hline \multirow{2}{*}{ Gender } & The FT 20 Q screening tool scores & Total \\
\cline { 2 - 4 } & $0-6$ ticks & $7-20$ ticks & $477(17 \%)$ \\
\hline Female & $328(69 \%)^{\star}$ & $149(31 \%)$ & $2,314(83 \%)$ \\
\hline Male & $1,463(63 \%)$ & $851(36 \%)$ & 2,791 \\
\hline Total & $1,791(64 \%)$ & $1,000(36 \%)$ & \\
\hline
\end{tabular}

*The percentage values in parentheses are the percentage of cases within each gender.

\section{Age distribution}

Table F. 3 shows the age distribution of male and female offenders who were sentenced to a CRO or a CPRO. This age distribution was representative of the age distribution normally found among those sentenced to community supervision. In broad terms, approximately 20 per cent of males and females sentenced to community supervision are aged 18 to 20 , approximately 40 per cent of both males and females are aged 21 to 30 and approximately 45 per cent of both are aged 31 years and above. ${ }^{73}$ There were no significant differences in the

\footnotetext{
${ }^{73}$ Home Office, 2002a.
} 
age distribution of either male or female offenders ${ }^{74}$ in the different pathfinder areas. However, there were significant differences between the age distribution of male and female offenders who were sentenced to a CRO or a CPRO. On average, female offenders tended to be older than male offenders who were sentenced to a CRO or a CPRO. From Table F.3., it can be seen that 66 per cent of male offenders were under the age of 30 years. By contrast, only 58 per cent of female offenders were under the age of 30 years. Women aged between 31 and 50 years of age were significantly more likely to be sentenced to a CRO or a CPRO than men of the same age. ${ }^{75}$

Table F.3: The age distribution of male and female offenders who were sentenced to a CRO or a CPRO aggregated across all pathfinder areas

\begin{tabular}{|l|l|l|l|l|l|l|}
\hline Gender & $18-20^{\star}$ & $21-25$ & $26-30$ & $31-40$ & $41-50$ & $51+$ \\
\hline $\begin{array}{l}\text { Male } \\
(\mathrm{n}=2,500)\end{array}$ & $490(20 \%)^{\star \star}$ & $671(27 \%)$ & $488(19 \%)$ & $567(23 \%)$ & $196(8 \%)$ & $88(4 \%)$ \\
\hline $\begin{array}{l}\text { Female } \\
(\mathrm{n}=520)\end{array}$ & $85(16 \%)$ & $126(24 \%)$ & $93(18 \%)$ & $147(28 \%)$ & $58(11 \%)$ & $11(2 \%)$ \\
\hline
\end{tabular}

* Ages are shown in years.

${ }^{\star *}$ The percentage values in parentheses are the percentage of cases within each gender.

\section{Ethnicity}

Table F.4 shows the number and percentage of cases from different ethnic groups. Clearly, the vast majority of offenders (92\%) in the total sample were white. The next largest group, Black Other, comprised only two per cent of the cases in the screening sample. Disaggregating the sample by ethnic group and pathfinder area revealed that Thames Valley Probation Area had the highest proportion (285 out of 1,788 cases, 16\%) of offenders from a minority ethnic group, followed by Nottinghamshire Probation Area with ten per cent (273 out of 2,799 cases) and Dorset Probation Area with eight per cent (92 out of 1,136).

\section{Table F.4: The ethnic composition of the total sample}

\begin{tabular}{|l|l|}
\hline Ethnic group & Frequency \\
\hline White & $8,220(92 \%)$ \\
\hline Black Caribbean & $121(1.4 \%)$ \\
\hline Black African & $74(<1 \%)$ \\
\hline Black other & $171(2 \%)$ \\
\hline Indian & $41(<1 \%)$ \\
\hline Pakistani & $85(<1 \%)$ \\
\hline Bangladeshi & $5(<1 \%)$ \\
\hline Chinese & $2(<1 \%)$ \\
\hline Other & $213(2.4 \%)$ \\
\hline Missing data & 1,320 \\
\hline Total & 10,252 \\
\hline
\end{tabular}

*The percentage values in parentheses are the percentage of all cases, excluding 'missing'.

Of the 2,860 cases who were sentenced to a CRO or a CPRO, 2,683 (94\%) were white. It is worth noting that white offenders were significantly ${ }^{76}$ more likely to be sentenced to a CRO or a CPRO than offenders were from other ethnic groups, whilst Black Caribbean, Black Other and Pakistani offenders ${ }^{77}$ were significantly less likely to be given a CRO or a CPRO compared to other offenders. There was, however, no significant association ${ }^{78}$ between ethnic group and risk of reconviction, though there was some evidence that Indian offenders may have been more likely to be in the lowest risk group compared with other offenders.

\footnotetext{
${ }^{74}$ Chi-square $=41.2$, d.f. $=30, p=0.84 ;$ Chi-square $=40.48$, d.f. $=30, p=0.96$ respectively

Adjusted residual for females aged $31-40$ years is 2.7 , and for those aged $41-50$ years is 2.5 .

${ }^{76}$ Adjusted residual for fem

Adjusted residuals $=-2.2,-2.7$ and -2.2 respectively

${ }^{78}$ Chi-square $=1.7$, d.f. $=2, p=0.42$
} 


\section{Accommodation status}

Table F.5 shows the accommodation status of offenders in the screening sample broken down by their sentence type. The largest proportions of offenders were either living in rented accommodation or with family, friends or others. The same pattern applied for those who were sentenced to a CRO or a CPRO. An offender was significantly more likely to be sentenced to a CRO or a CPRO if s/he was either a tenant or lived in a hostel, and significantly less likely to be sentenced to the same sentence if $s /$ he was an owner occupier. ${ }^{79}$ Offenders who lived with family, friends or others were significantly more likely to be sentenced to a custodial sentence than other offenders were, whilst owner occupiers were significantly more likely to be sentenced to a CPO than other offenders were. ${ }^{80}$

Table F.5: Accommodation status and sentence type of offenders

\begin{tabular}{|l|l|l|l|l|l|l|l|}
\hline $\begin{array}{l}\text { Sentence } \\
\text { type }\end{array}$ & $\begin{array}{l}\text { Owner } \\
\text { occupied }\end{array}$ & Tenant & $\begin{array}{l}\text { B\&B/ } \\
\text { lodgings/ } \\
\text { hotel }\end{array}$ & $\begin{array}{l}\text { Unit/ } \\
\text { hostel }\end{array}$ & $\begin{array}{l}\text { Family/ } \\
\text { friends/ } \\
\text { others }\end{array}$ & Other & Total \\
\hline Custody & $171(7 \%)^{\star}$ & $841(37 \%)$ & $36(2 \%)$ & $40(2 \%)$ & $944(41 \%)$ & $270(12 \%)$ & 2,302 \\
\hline CRO/ CPRO & $221(8 \%)$ & $1,189(42 \%)$ & $51(2 \%)$ & $73(3 \%)$ & $\begin{array}{l}1,112 \\
(40 \%)\end{array}$ & $173(6 \%)$ & 2,819 \\
\hline CPO & $279(13 \%)$ & $891(42 \%)$ & $45(2 \%)$ & $12(0.6 \%)$ & $812(39 \%)$ & $64(3 \%)$ & 2,103 \\
\hline Other & $89(9 \%)$ & $430(43 \%)$ & $28(3 \%)$ & $19(2 \%)$ & $352(35 \%)$ & $92(9 \%)$ & 1,010 \\
\hline Total & $760(9 \%)$ & $3,351(41 \%)$ & $160(2 \%)$ & $144(2 \%)$ & $\begin{array}{l}3,220 \\
(39 \%)\end{array}$ & $599(7 \%)$ & 8,234 \\
\hline
\end{tabular}

*The percentage values in parentheses are the percentage of cases within each sentence type.

There was a significant association between the type of accommodation an offender lived in and the pathfinder area in which they were supervised. ${ }^{81}$ Underlying this is a complex pattern that is difficult to explain, but is likely to be related to the local housing and labour market. For example, in Cornwall and Dorset Probation Areas, offenders were less likely to be owner occupiers than in other areas, whilst offenders in Cumbria and Nottinghamshire Probation Areas were more likely to be owner occupiers. ${ }^{82}$ By contrast, offenders in Dorset Probation Area and particularly in Sussex Probation Area were more likely to be living in Bed and Breakfasts, Lodgings or Hotels, whilst those in Nottinghamshire Probation Area were much less likely to be living in this sort of accommodation. ${ }^{83}$ Finally, in Thames Valley Probation Area, offenders were less likely to be tenants compared with other areas but more likely to be living with family, friends or others. ${ }^{84}$

As Table F. 6 shows, such patterns persisted for the 2,819 offenders who were sentenced to a CRO or a CPRO and for whom data were received on both the type of accommodation reported at the PSR stage and the pathfinder area in which they were supervised. Once again, the majority of offenders who were sentenced to a CRO or a CPRO were either living as tenants or with family, friends and others. Those in Nottinghamshire Probation Area were more likely to be owner occupiers while those in Dorset and Sussex Probation Areas were significantly less likely to own their homes. ${ }^{85}$ Those in the Thames Valley Probation Area were significantly less likely to be tenants, whilst those in Sussex Probation Area were more likely to be living in Bed and Breakfasts, Lodgings and Hotels. ${ }^{86}$

\footnotetext{
${ }^{79}$ Adjusted residuals of $2.0,4.2$ and -3.1 respectively.

${ }^{80}$ Adjusted residuals of 2.2 and 7.4 respectively

${ }^{81}$ Chi-square $=210.1$, d.f. $=30, p<0.001$.

Adjusted residuals $-2.2,-3.5,4.4$ and 2.7 respectively.

${ }^{3}$ Adjusted residuals $2.9,7.2$ and -7.5 respectively.

Adjusted residuals -4.1 and 3.6 respectively.

Adjusted residuals $2.5,-2.2$ and -2.1 respectively.

${ }^{86}$ Adjusted residuals -3.2 and 6.6 respectively.
} 
Table F.6: The type of accommodation being used by offenders who were sentenced to a CRO or a CPRO, broken down by pathfinder area

\begin{tabular}{|l|l|l|l|l|l|l|l|}
\hline Pathfinder area & $\begin{array}{l}\text { Owner } \\
\text { occupied }\end{array}$ & Tenant & $\begin{array}{l}\text { B\&B, } \\
\text { lodging or } \\
\text { hotel }\end{array}$ & $\begin{array}{l}\text { Unit or } \\
\text { hostel }\end{array}$ & $\begin{array}{l}\text { Family, } \\
\text { friends or } \\
\text { others }\end{array}$ & Other & Total \\
\hline Cornwall & $3(6 \%)$ & $26(47 \%)$ & $2(4 \%)$ & $3(6 \%)$ & $20(36 \%)$ & $1(2 \%)$ & 55 \\
\hline Cumbria & $\begin{array}{l}25 \\
(10.3 \%)\end{array}$ & $117(48 \%)$ & $1(0.5 \%)$ & $6(2.5 \%)$ & $\begin{array}{l}79 \\
(32.5 \%)\end{array}$ & $15(6.2 \%)$ & 243 \\
\hline Dorset & $11(4 \%)$ & $109(43 \%)$ & $7(3 \%)$ & $6(2 \%)$ & $96(38 \%)$ & $23(9 \%)$ & 252 \\
\hline Lincolnshire & $34(7 \%)$ & $228(44 \%)$ & $12(2 \%)$ & $10(2 \%)$ & $203(39 \%)$ & $36(7 \%)$ & 523 \\
\hline Nottinghamshire & $84(10 \%)$ & $361(42 \%)$ & $1(0.1 \%)$ & $23(3 \%)$ & $349(41 \%)$ & $42(5 \%)$ & 860 \\
\hline Sussex & $20(5 \%)$ & $170(44 \%)$ & $23(6 \%)$ & $6(2 \%)$ & $148(38 \%)$ & $20(5 \%)$ & 387 \\
\hline Thames Valley & $44(9 \%)$ & $178(36 \%)$ & $5(1 \%)$ & $19(4 \%)$ & $217(44 \%)$ & $36(7 \%)$ & 499 \\
\hline Total & $221(8 \%)$ & $\begin{array}{l}1,189 \\
(42 \%)\end{array}$ & $51(2 \%)$ & $73(3 \%)$ & $\begin{array}{l}1,112 \\
(40 \%)\end{array}$ & $173(6 \%)$ & 2,819 \\
\hline
\end{tabular}

${ }^{*}$ The percentage value shown in parentheses is the percentage of cases within each pathfinder area.

\section{Domestic circumstances}

Another potential indicator of the stability of someone's lifestyle is their domestic circumstances, i.e. whether they live with a partner or have dependants. In the overall sample, 8,162 cases provided information on marital status and dependants. Of these, 5,393 (66\%) were single, divorced or separated, of which $873(5 \%)$ had dependants. 2,541 (31\%) cases were either married or lived with a partner. Of these, 1,290 (51\%) had dependants. There was a significant association ${ }^{87}$ between marital status and sentence type. For example, those offenders living with a partner and with dependants were significantly less likely to be sentenced to a CRO or a CPRO than other offenders were, and those who were living with a partner were significantly more likely to be sentenced to a CPO than other offenders were. ${ }^{88}$

\section{Alcohol and drug abuse}

At the PSR stage, the PSR writer was asked to make a judgement about whether or not they thought an offender was abusing alcohol and/or drugs. Table F.7 shows the frequency of these judgements broken down by sentence type. It is clear from the 7,792 cases for which the data were provided, that those who were sentenced to either custody (59\% of cases) or a CRO or a CPRO (66\% of cases) were significantly more likely to be judged by the PSR writer as abusing alcohol and/or drugs. ${ }^{89}$ This judgement was reversed for those subsequently sentenced to a CPO (only $35 \%$ of cases were judged to be abusing alcohol and/or drugs).

Table F.7: PSR writer's judgement about substance abuse by an offender, broken down by sentence type

\begin{tabular}{|l|l|l|l|l|l|}
\hline Sentence type & $\begin{array}{l}\text { Abuse neither } \\
\text { alcohol/drugs }\end{array}$ & $\begin{array}{l}\text { Abuse only } \\
\text { alcohol }\end{array}$ & $\begin{array}{l}\text { Abuse only } \\
\text { drugs }\end{array}$ & $\begin{array}{l}\text { Abuse both } \\
\text { alcohol/drugs }\end{array}$ & Total \\
\hline Custody & $901(41 \%)$ & $369(17 \%)$ & $569(26 \%)$ & $340(16 \%)$ & 2,179 \\
\hline CRO/CPRO & $900(34 \%)$ & $608(23 \%)$ & $760(28 \%)$ & $407(15 \%)$ & 2,675 \\
\hline CPO & $1,274(65 \%)$ & $303(15 \%)$ & $251(13 \%)$ & $135(7 \%)$ & 1,963 \\
\hline Other & $465(48 \%)$ & $136(14 \%)$ & $253(26 \%)$ & $121(12.4 \%)$ & 975 \\
\hline Total & $3,540(45 \%)$ & $1,416(18 \%)$ & $1,833(24 \%)$ & $1,003(13 \%)$ & 7,792 \\
\hline
\end{tabular}

*The percentage values in parentheses are the percentage of cases within each sentence type.

\footnotetext{
${ }^{87}$ Chi-square $=42$, d.f. $=18, p<0.001$

Adjusted residuals $=-2.6$ and 3.7 respectively.

${ }^{9}$ Chi-square $=515.8$, d. $=9, p<0.001$.
} 


\section{Schooling and qualifications}

Table F.8 shows the qualifications gained by offenders in the screening sample categorised by sentence type, and Table F.9 shows their pattern of school attendance. The large number of offenders who held no qualifications and who attended school irregularly was comparable to that found in other research conducted with similar sample groups of offenders. There was a significant association between the levels of qualifications held and sentence type, with those being sentenced to either custody, or to a CRO or a CPRO being significantly less well qualified than offenders sentenced to a CPO. ${ }^{90}$ The scale of the problem posed by the lack of qualifications amongst offenders was gauged by comparing the results presented in Table F. 8 with the percentage of employed adults with differing levels of qualification derived from the nationally representative 2001 Skills Survey (Felstead et al., 2002). Of those employed in the 2001 Skills Survey, 11 per cent held no qualifications at the time of the survey, 14 per cent had Level 1 qualifications, 21 per cent Level 2 qualification, and 54 per cent had Level 3 qualifications and above. While these qualifications were not always judged by those interviewed during the survey as being necessary to do a job, they were considered necessary to get the job they currently held. This suggests that offenders may be at a severe disadvantage in the current labour market.

Table F.8: The highest level of qualification obtained by offenders, broken down by sentence type

\begin{tabular}{|l|l|l|l|l|l|}
\hline Sentence type & $\begin{array}{l}\text { No } \\
\text { qualifications }\end{array}$ & $\begin{array}{l}\text { Level 1 } \\
\text { qualifications }\end{array}$ & $\begin{array}{l}\text { Level 2 } \\
\text { qualifications }\end{array}$ & $\begin{array}{l}\text { Level 3+ } \\
\text { qualifications }\end{array}$ & Total \\
\hline Custody & $1,257(57 \%)$ & $484(22 \%)$ & $339(15 \%)$ & $131(6 \%)$ & 2,211 \\
\hline CRO/CPRO & $1,517(56 \%)$ & $656(24 \%)$ & $417(15 \%)$ & $145(5 \%)$ & 2,735 \\
\hline CPO & $944(46 \%)$ & $513(25 \%)$ & $468(23 \%)$ & $148(7 \%)$ & 2,073 \\
\hline Other & $522(52 \%)$ & $226(23 \%)$ & $177(18 \%)$ & $77(8 \%)$ & 1,002 \\
\hline Total & $4,240(53 \%)$ & $1,879(23 \%)$ & $1,401(18 \%)$ & $501(6 \%)$ & 8,021 \\
\hline
\end{tabular}

*The percentage values in parentheses are the percentage of cases within each sentence. See Appendix A for the levels in the National Qualifications Framework.

Table F.9: Offenders' school attendance, broken down by sentence type

\begin{tabular}{|l|l|l|l|}
\hline Sentence type & Regular attendance & Irregular attendance & Total \\
\hline Custody & $955(49 \%)$ & $991(51 \%)$ & 1,946 \\
\hline CRO/CPRO & $1,274(52.5 \%)$ & $1,153(47.5 \%)$ & 2,427 \\
\hline CPO & $1,216(67 \%)$ & $593(33 \%)$ & 1,809 \\
\hline Other & $479(56 \%)$ & $370(44 \%)$ & 849 \\
\hline Total & $3,924(56 \%)$ & $3,107(44 \%)$ & 7,031 \\
\hline
\end{tabular}

*The percentage values in parentheses are the percentage of cases within each sentence type.

There was also a significant association between an offender's pathfinder area and the level of qualifications s/he held. ${ }^{91}$ For example, offenders in Cumbria and Nottinghamshire Probation Areas $^{92}$ were significantly more likely to have no qualifications compared with offenders in other areas, whilst those in Dorset, Sussex and Thames Valley Probation Areas were significantly less likely to have no qualifications compared with offenders in other areas. ${ }^{93}$ A possible reason for this might have been that the pattern of school attendance varied between the pathfinder areas, but there was no significant association between pathfinder areas and school attendance for those sentenced to a CRO or a CPRO. ${ }^{94}$

\footnotetext{
${ }^{90}$ Chi-square $=90.5$, d.f. $=9, p<0.001$. For example, adjusted residuals for those being sentenced to either custody or a CRO or a CPRO and having no qualifications are 4.4 and 3.4 respectively.

${ }_{92}$ Adjusted residuals 6 and 3.4 respectively.

${ }^{93}$ Adjusted residuals $-3.2,-2.1$ and -4.1 respectively.

${ }^{94}$ Chi-square $=11.4$, d.f. $=6, p=0.075$.
} 


\section{Risk of reconviction}

Six of the Basic Skills Pathfinder areas provided OGRS2 scores and the seventh, Sussex Probation Area, supplied LSI-R scores for offenders as part of the screening data. These data were used to classify offenders as being at 'low', 'medium' and 'high' risk of reconviction. Table F.10 shows the proportion of offenders falling into each of these risk categories broken down by pathfinder area. These figures are broadly comparable to what would be expected of this population (see Raynor et al., 2000). Cumbria, Lincolnshire and Nottinghamshire Probation Areas ${ }^{95}$ all had a significantly greater proportion of offenders falling into the 'high' risk category compared to other pathfinder areas, whilst Dorset and Sussex Probation Areas had a significantly greater proportion of offenders in the 'low' risk category. ${ }^{96}$

\section{Table F.10: Risk of reconviction, broken down by pathfinder area}

\begin{tabular}{|l|l|l|l|l|}
\hline Pathfinder area & 'Low' risk & 'Medium' risk & 'High' risk & Total \\
\hline Cornwall & $90(39 \%)$ & $105(46 \%)$ & $36(16 \%)$ & 231 \\
\hline Cumbria & $200(33 \%)$ & $231(39 \%)$ & $168(28 \%)$ & 599 \\
\hline Dorset & $538(44 \%)$ & $482(39 \%)$ & $218(18 \%)$ & 1,238 \\
\hline Lincolnshire & $318(29 \%)$ & $423(38 \%)$ & $371(33 \%)$ & 1,112 \\
\hline Nottinghamshire & $796(34 \%)$ & $998(42 \%)$ & $562(24 \%)$ & 2,356 \\
\hline Sussex & $585(57 \%)$ & $367(36 \%)$ & $83(8 \%)$ & 1,035 \\
\hline Thames Valley & $567(38 \%)$ & $585(39 \%)$ & $349(23 \%)$ & 1,501 \\
\hline Total & $3,094(38 \%)$ & $3,191(40 \%)$ & $1,787(22 \%)$ & 8,072 \\
\hline
\end{tabular}

*The percentage values in parentheses are the percentage of cases within each pathfinder area.

A similar pattern emerged for offenders sentenced to a CRO or a CPRO except that Nottinghamshire Probation Area no longer had a significantly greater proportion of offenders in this sentence group who fell into the 'high' risk category. Dorset Probation Area had a significantly greater proportion of these offenders who fell into the 'medium' risk category rather than the 'low' risk category, as did Thames Valley Probation Area. The proportions in each category of risk differed in Sussex Probation Area and this is possibly because Sussex Probation Area uses LSI-R to measure risk of reconviction.

\footnotetext{
${ }^{95}$ Adjusted residuals 3.6, 9.7 and 2.4 respectively.

${ }^{96}$ Adjusted residuals 4 and 12.9 respectively.
} 


\section{Appendix G: Logistic regression of variables associated with basic skills needs}

Table G.1 summarises the results of a logistic regression referred to in Chapter 4 . The response variable is employment status at the time of the PSR $(1=$ unemployed, $0=$ employed). The parameter . is the probability of being unemployed. All of the explanatory variables are categorical. The reference category for each variable is as follows:

- Highest qualification achieved - Level 3 and above

- School attendance - regular attendance

- Gender - male

- FT 20 Q score -0 to 6 ticks, i.e. no probable basic skills need

- Age group - 51 years and over

- Alcohol and drug abuse - abuses neither drugs nor alcohol

- Risk of reconviction - 'low' risk.

Table G.1: Results of a logistic regression for the probability of being unemployed for the complete screening sample $\left(n=4283,{ }^{*} p<=0.05\right.$; $\left.{ }^{* *} p<=0.01\right)$

\begin{tabular}{|l|l|l|l|l|}
\hline Variable & Level & Estimate & Std. error & Exp (B) \\
\hline $\begin{array}{l}\text { Highest qualification } \\
\text { achieved }\end{array}$ & No qualifications & $0.44^{\star \star}$ & 0.152 & 1.56 \\
\hline & Level 1 & 0.25 & 0.154 & 1.28 \\
\hline & Level 2 & 0.09 & 0.158 & 1.10 \\
\hline School attendance & Irregular & $0.33^{\star \star}$ & 0.076 & 1.40 \\
\hline FT 20 Q score & $7+$ ticks & $0.28^{\star \star}$ & 0.080 & 1.34 \\
\hline Gender & Female & $0.74^{\star \star}$ & 0.110 & 2.10 \\
\hline Age group (years) & $18-20$ & $-0.59^{\star \star}$ & 0.223 & 0.55 \\
\hline & $21-25$ & $-0.59^{\star \star}$ & 0.219 & 0.55 \\
\hline & $26-30$ & -0.26 & 0.222 & 0.78 \\
\hline & $31-40$ & $-0.49^{\star}$ & 0.216 & 0.62 \\
\hline $\begin{array}{l}\text { Alcohol and drug } \\
\text { abuse }\end{array}$ & $41-50$ & -0.42 & 0.236 & 0.66 \\
\hline & Abuses alcohol & 0.11 & 0.092 & 1.12 \\
\hline & Abuses drugs & $1.09^{\star \star}$ & 0.091 & 2.98 \\
\hline Risk of reconviction & Abuses alcohol and & $0.74^{\star \star}$ & 0.110 & 2.09 \\
\hline & Medium & $0.73^{\star \star}$ & 0.081 & 2.08 \\
\hline Constant & High & $1.15^{\star \star}$ & 0.105 & 3.17 \\
\hline
\end{tabular}

Table G.2 shows the results for the logistic regression referred to in Chapter 3 . The response variable is employment status at the time of the PSR $(1=$ unemployed, $0=$ employed $)$. The parameter $\pi$ is the probability of being unemployed. All of the explanatory variables are categorical. The reference category for each variable is as above. Note that three of the explanatory variables that made a significant contribution to the model in Table G.1 do not make a significant contribution when modelling the probability of employment for the CRO or CPRO sample: highest qualification achieved, school attendance and age. 
Table G.2: Results of a logistic regression for the probability of being unemployed for those offenders sentenced to either a CRO or a CPRO $\left(n=1,492,{ }^{*} p<=0.05\right.$; ** $\left.p<=0.01\right)$

\begin{tabular}{|l|l|l|l|l|}
\hline Variable & Level & Estimate & Std. error & Exp (B) \\
\hline FT 20 Q score & $7+$ ticks & $0.29^{\star}$ & 0.118 & 1.34 \\
\hline Gender & Female & $1.04^{\star \star}$ & 0.183 & 2.84 \\
\hline \multirow{2}{*}{$\begin{array}{l}\text { Alcohol and drug } \\
\text { bbuse }\end{array}$} & Abuses alcohol & 0.13 & 0.143 & 1.14 \\
\cline { 2 - 5 } & Abuses drugs & $1.40^{\star \star}$ & 0.155 & 4.07 \\
\cline { 2 - 5 } & $\begin{array}{l}\text { Abuses alcohol } \\
\text { and drugs }\end{array}$ & $0.79^{\star \star}$ & 0.173 & 2.21 \\
\hline \multirow{2}{*}{$\begin{array}{l}\text { Risk of } \\
\text { reconviction }\end{array}$} & Medium & $0.61^{\star \star}$ & 0.136 & 1.85 \\
\hline Constant & High & $1.25^{\star \star}$ & 0.175 & 3.50 \\
\hline
\end{tabular}

Table G.3 shows the results of the logistic regression referred to in Chapter 3 . The response variable is the score on the FT 20 Q dichotomised into 0 to 6 ticks (no probable basic skills need $=0$ ) and below Level 1 (a probable basic skills need=1) at the time of the PSR. The parameter $\pi$ is the probability of having a probable basic skills need. All of the explanatory variables are categorical. The reference category for each variable is as above. Table G.4 shows the results of the equivalent analysis just using those who were sentenced to either a CRO or a CPRO. Note that in the model for those sentenced to either a CRO or a CPRO, risk of reoffending makes no significant contribution to the model, whilst alcohol and drug abuse do. Understandably, there is a large association between the response variable and highest qualification obtained and the pattern of school attendance in both models.

Table G.3: Results of a logistic regression for the probability of having a probable basic skills need for the whole screening sample $\left(n=5873\right.$, * $p<=0.05$; $\left.{ }^{* *} p<=0.01\right)$

\begin{tabular}{|l|l|l|l|l|}
\hline Variable & Level & Estimate & Std. error & Exp (B) \\
\hline \multirow{2}{*}{$\begin{array}{l}\text { Highest } \\
\text { qualification } \\
\text { achieved }\end{array}$} & No qualifications & $2.64^{\star \star}$ & .253 & 14.04 \\
\cline { 2 - 5 } & Level 1 & $1.68^{\star \star}$ & 0.257 & 5.37 \\
\cline { 2 - 5 } $\begin{array}{l}\text { School } \\
\text { attendance }\end{array}$ & Level 2 & 0.35 & 0.274 & 1.42 \\
\hline \multirow{4}{*}{ Age group (years) } & Irregular & $0.63^{\star \star}$ & 0.068 & 1.87 \\
& & & 0.198 & 1.99 \\
& & $0.69^{\star \star}$ & & \\
\cline { 2 - 5 } & $21-25$ & & & 1.41 \\
\cline { 2 - 5 } & $26-30$ & 0.34 & 0.194 & 1.10 \\
\cline { 2 - 5 } & $31-40$ & 0.09 & 0.198 & 1.14 \\
\cline { 2 - 5 } & $41-50$ & 0.13 & 0.208 & 1.26 \\
\hline \multirow{4}{*}{$\begin{array}{l}\text { Risk of } \\
\text { reconviction }\end{array}$} & Medium & $0.23^{\star \star}$ & 0.076 & 1.25 \\
\hline Constant & High & $0.219^{\star}$ & 0.091 & \\
\hline
\end{tabular}


Table G.4: Results of a logistic regression for the probability of having a probable basic skills need for those sentenced to either a CRO or a CPRO $(n=2,028$, * $p<=0.05$; ${ }^{* *} p<=0.01$ )

\begin{tabular}{|c|c|c|c|c|}
\hline Variable & Level & Estimate & Std. error & $\operatorname{Exp}(B)$ \\
\hline \multirow{3}{*}{$\begin{array}{l}\text { Highest } \\
\text { qualification } \\
\text { achieved }\end{array}$} & No qualifications & $2.08^{\star \star}$ & 0.327 & 7.97 \\
\hline & Level 1 & $1.19^{\star \star}$ & 0.335 & 3.27 \\
\hline & Level 2 & -0.27 & 0.378 & 0.76 \\
\hline $\begin{array}{l}\text { School } \\
\text { attendance }\end{array}$ & Irregular & $0.57^{\star \star}$ & 0.109 & 1.77 \\
\hline \multirow[t]{5}{*}{ Age group (years) } & $18-20$ & $1.19 * \star$ & 0.343 & 3.30 \\
\hline & $21-25$ & $0.91^{\text {** }}$ & 0.335 & 2.49 \\
\hline & $26-30$ & 0.57 & 0.342 & 1.76 \\
\hline & $31-40$ & 0.58 & 0.336 & 1.78 \\
\hline & $41-50$ & 0.48 & 0.360 & 1.6 \\
\hline \multirow{3}{*}{$\begin{array}{l}\text { Alcohol and drug } \\
\text { abuse }\end{array}$} & Abuses alcohol & -0.25 & 0.140 & 0.78 \\
\hline & Abuses drugs & $-0.30^{\star}$ & 0.132 & 0.74 \\
\hline & $\begin{array}{l}\text { Abuses alcohol } \\
\text { and drugs }\end{array}$ & -0.15 & 0.159 & 0.86 \\
\hline Constant & & -2.95 & & \\
\hline
\end{tabular}


Produced by the Research Development and Statistics Directorate, Home Office This document is available only in Adobe Portable Document Format (PDF) through the RDS website

Home Office

Research, Development and Statistics Directorate

Communication Development Unit

Room 264

50 Queen Anne's Gate

London SW1H 9AT

Tel: 02072732084 (answerphone outside of office hours)

Fax: 02072220211

Email: publications.rds@homeoffice.gsi.gov.uk

ISBN 1844732444

C Crown copyright 2004 